\title{
Marble decay: towards a measure of marble degradation based on ultrasonic wave velocities and thermal expansion data
}

\author{
Siegfried Siegesmund ${ }^{1} \cdot$ Johanna Menningen $^{1} \cdot$ Victoria Shushakova $^{1}$
}

Received: 20 January 2021 / Accepted: 15 April 2021 / Published online: 23 May 2021

(c) The Author(s) 2021

\begin{abstract}
Marble as ornamental and dimensional stones as well as in their natural environments show complex weathering phenomena. Physical, chemical, and biological weathering of marble are well documented. The impact of climate change on monuments and historic buildings in terms of modeling and predicting future scenarios requires new approaches to forecast the ongoing decay in the near and far future. Ultrasonic wave velocities are a powerful and sensitive tool for the damage assessment of marble. For a maximum porosity of up to $1 \%$, ultrasonic wave velocities ( $P$-wave velocities) are ranging between $1 \mathrm{~km} / \mathrm{s}$ and over $6 \mathrm{~km} / \mathrm{s}$. Water saturation has an important influence on the magnitude and directional dependence of ultrasonic wave velocities together with the mineralogical composition and the rock fabrics. Ongoing experimental alteration approaches were used to document the state of deterioration using Vp-systematics. In addition, thermal expansion and the residual strain values after applying thermal impacts were used to introduce a new quantitative measure based on experimental length changes and volume changes. To quantify such volume changes, a so-called decay index was proposed. Marbles are sensitive to weathering and have different volume changes under exposure depending on fabric parameters. The volume extension index of marble, based on thermal expansion measurements under dry and water-saturated conditions, is proposed as a decay index for quantifying sample stability and for defining the directions of maximum and minimal dilatation. Such decay index was implemented to different marble types and it was turned out that marbles with the larger decay indexes are more prone to weathering than with smaller ones. The effect of changing climate and, in consequence, different weathering actions can help to calculate or forecast risk numbers based on the Vp data in combination with the proposed decay index especially for marbles.
\end{abstract}

Keywords Marble decay · Ultrasonic wave velocities $\cdot$ Thermal expansion $\cdot$ Risk assessment $\cdot$ Climate change and deterioration

\section{Introduction}

Marbles have been considered to be among the most important building materials since ancient times. Regarded as special stones, they are captivating because of their pureness,

This article is part of a Topical Collection in Environmental Earth Sciences on "Building Stones and Geomaterials through History and Environments - from Quarry to Heritage. Insights of the Conditioning Factors", guest edited by Siegfried Siegesmund, Luís Manuel Oliveira Sousa, and Rubén Alfonso López-Doncel.

Siegfried Siegesmund

ssieges@gwdg.de

1 GZG-Structural Geology and Geodynamics, University of Göttingen, Goldschmidtstr 3, D-37077 Göttingen, Germany formability, and translucence. However, degradation of sculptures, architectural heritage, and façade stones fabricated from marbles can be problematic. There are several approaches to determine weathering rates. One approach could be to carry out experiments in the laboratory or to study natural weathering processes over a very long period. Within the framework of the international program MULTIACCESS (Model for multi-pollutant impact and assessment of threshold levels for cultural heritage) coordinated by the Swedish Corrosion Institute in Stockholm, damage functions have been developed for various materials as well as for the Portland limestone (Brimblecombe 2003) The relationship between the released air pollutants, meteorological influencing variables, and the resulting material losses was determined. The worldwide storage tests resulted in the so-called "multi pollutant situations", which yielded damage functions 
calculated on the basis of statistical methods. Besides $\mathrm{SO}_{2}$ and $\mathrm{pH}$ values of precipitation, emissions of $\mathrm{NO}_{2}$ and $\mathrm{PM}_{10}$ were also considered in the equations. Moreover, papers predicting carbonate stone surface recession for chemical dissolution, induced by changes in precipitation amount and atmospheric $\mathrm{CO}_{2}$ concentration, have been well known since a very long time. In particular, all these works stressed the increasing importance that climate parameters will have in addition to air pollution, in the decay.

The deterioration of building stones depends in the future mainly on the climate. Many experimental studies have shown that temperature changes, both increases and decreases, induce significant deterioration. Even when the temperature changes are not particularly large, repeated heating and cooling of stone will eventually lead to deterioration over time (e.g., Kessler 1919; Battaglia et al. 1993; Winkler 1994; Siegesmund et al. 2000; Zeisig et al. 2002). This deterioration is most spectacular for marbles, but is also observed for other rocks, like granite, Nagelfluh, and limestone (e.g., Siegesmund and Dürrast 2011). The paper of Bonazza et al. 2009 deals with the prediction of thermal stresses on stone in Europe over the next century. The thermoclastism risk on marbles for the twenty-first century is discussed using a revised damage function. The authors figured out that the susceptibility of marbles derives from the anisotropy in thermal response of calcite, which expands in the vertical c-axis and contracts in the horizontal one. Research carried out so far indicates that marbles are less resistant towards thermoclastism compared to other rock types like, e.g., granites, limestones or sandstones, etc. According to Timoshenko and Goodier (1970), the maximum horizontal thermoelastic stress can be calculated by combining the Young's modulus, the Poisson's ratio, the thermal expansion, and the temperature. Based on this equation, Scheffzük et al. 2004 calculated a thermoelastic stress of around $42 \mathrm{MPa}$ for a marble. Considering a strong crystallographic preferred orientation of the calcite crystals, a thermoelastic stress can reach up to between $201 \mathrm{MPa}$ for a temperature difference of 100K. Additionally, Scheffzük et al. 2007 had calculated a residual stress magnitude of 77.5 $\mathrm{MPa}$, i.e., the so-called locked-in stress. Already, Winkler 1994 mentioned that prestressed crystalline marble tends to expand more during the first cycle of heating the locked-in stresses are released. Considering the processes on marble deterioration, it is for sure that the thermal expansion is only important for 1-3 thermal cycles afterwards any residual stresses, i.e., progressive increase in length change occur when water is present (see Koch and Siegesmund 2004 or Siegesmund et al. 2008)

Thermal degradation in the form of microcracking results in a volumetric expansion of a stone sample. Accordingly, microcracking of a stone sample upon heating or cooling will result in a permanent volumetric expansion of a stone sample when it returns to its ambient temperature. This relative volume change as measured by thermal dilation is thus a measure or index of stone degradation. Thus, the overall objective of this approach is to develop a volumetric extension index (a deterioration index) for the characterization of the degradation potential of widely used types of marbles and to elucidate the influence of fabric parameters on this deterioration index. The index will reflect the relative volume change on the basis of the knowledge of thermal dilatation.

To get an insight into their weathering state, a nondestructive analysis of them is desired. Ultrasonic wave velocity systematics and US tomography are possible tools to receive the desired insight, while a sound interpretation depends on the knowledge regarding the specific material. Systematic analyses were performed on six marble types, which were often used as a heritage stone (Table1, Fig. 1): the Spanish Blanco Macael, the Italian Carrara Gioia and Lasa, the Polish Großkunzendorf and Prieborner, and the

Table 1 Marble varieties, provenience and selected microfabric characteristics

\begin{tabular}{|c|c|c|c|c|}
\hline & Location & Composition & Average grain size & Grain boundary configuration \\
\hline Thassos [Th] & Greece & Dolomitic & $1.75 \mathrm{~mm}$ & Equigranular-interlobate \\
\hline Lasa [LA] & Italy & Calcitic & $1 \mathrm{~mm}$ & Inequigranular-interlobate \\
\hline Volakas [G] & Greece & Dolomitic & $75-100 \mu \mathrm{m}$ & Inequigranular-polygonal \\
\hline Sölk [SK] & Austria & Calcitic & $1.25 \mathrm{~mm}$ & Inequigranular-interlobate \\
\hline Wachau [W] & Austria & Calcitic & $1-1.5 \mathrm{~mm}$ & Seriate-interlobate \\
\hline Arabescato Altissimo Carrara [AA] & Italy & Calcitic & $200-300 \mu \mathrm{m}$ & Equigranular straight \\
\hline Blanco Carrara [BC, Gioia] & Italy & Calcitic & $150 \mu \mathrm{m}$ & Equigranular straight \\
\hline High-Temperature Carrara (HT) & Italy & Calcitic & $200-800 \mu \mathrm{m}$ & Inequigranular-polygonal \\
\hline Wunsiedel & Germany & Calcitic & $434 \mu \mathrm{m}$ & Seriate-interlobate \\
\hline Priborn & Poland & Calcitic & $242 \mu \mathrm{m}$ & Equigranular-polygonal \\
\hline Großkunzendorf & Poland & Calcitic & $545 \mu \mathrm{m}$ & Seriate-interlobate \\
\hline Bianco Macael & Spain & Calcitic & $495 \mu \mathrm{m}$ & Equigranular-polygonal \\
\hline
\end{tabular}


Fig. 1 Marble microfabric: a Arabescato Altissimo (AA) marble; b Bianco Carrara (BC) marble; c Sölk (SK) marble; d Lasa (LA) marble; e High-Temperature Carrara (HT) marble; f Greek Volakas (G) marble; $\mathbf{g}$ Wachau (W) marble; $\mathbf{h}$ Thassos (Th) marble. The microfabric is shown as a cropped selection $(305 \times 285$ pixels $)$ from microstructures obtained by EBSD in $\mathrm{XZ}$ plane of marble samples
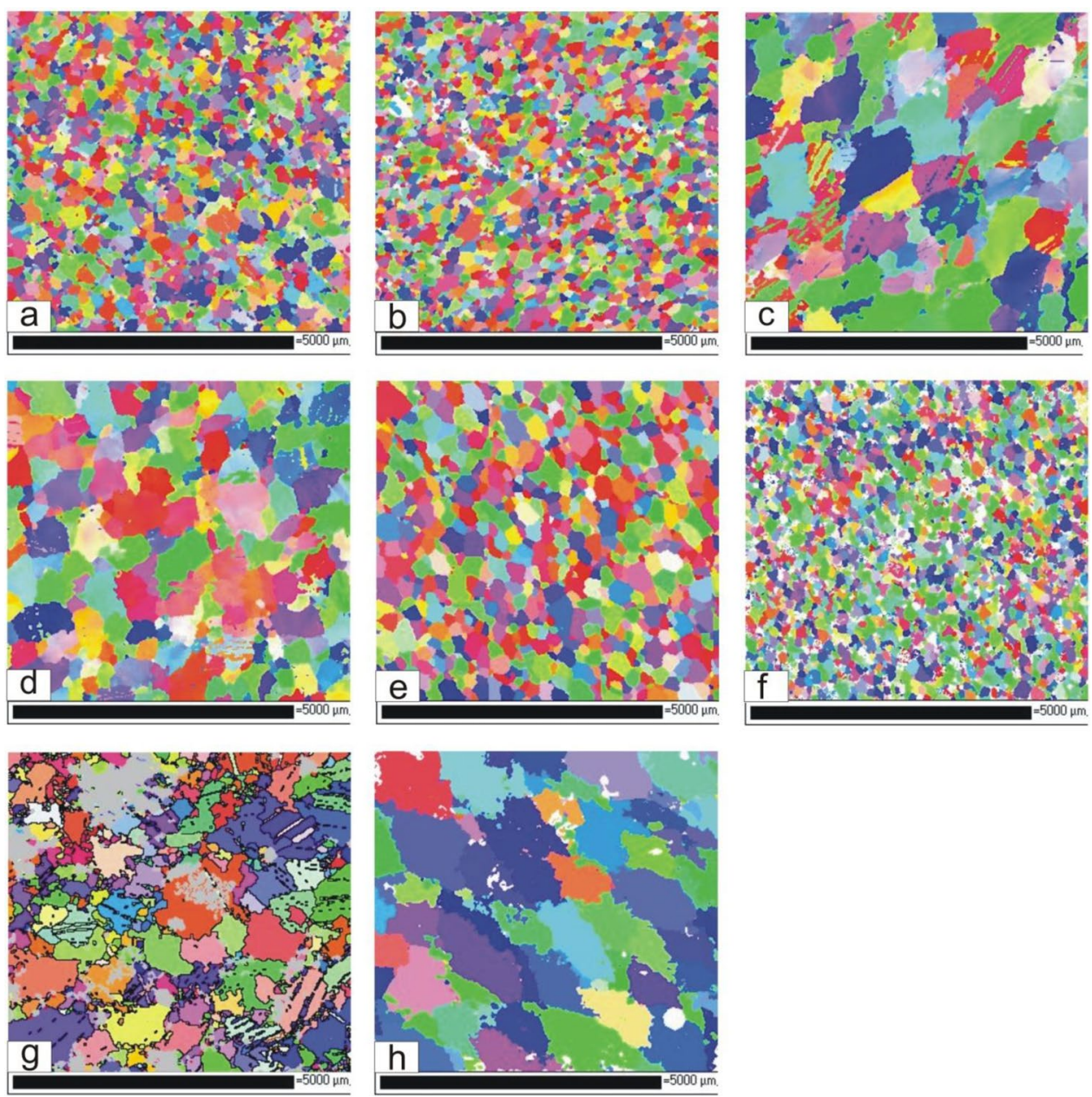

less common German Wunsiedel marble which is primarily used regionally. To relate their weathering state to an ultrasonic velocity, a successive artificial weathering has been performed, analyzing all important rock physical changes within the alteration (Menningen 2020). In addition, the thermal expansion systematics were also performed on several Carrara varieties, Sölk, Wachau, Thassos, and Volakas marbles (Table1, Fig.1).

\section{Rock materials, macroscopic description, and decay phenomena}

The investigated marbles originated from 15 different locations. They are well known and widespread used as building stones (Blanco Macael, Rosa Estremoz, Carrara (several varieties), Großkunzendorf, Prieborn, Wunsiedel, Lasa, Thassos, Volakas, Sölk, Wachau) in the past and also in our days. Mineralogically all samples belong to calcitic and dolomitic marbles with quartz, biotite, muscovite, phlogopite, and ore minerals as accessories. The most important characteristics of the fabric elements are summarized in Table 1.
The average grain size which was calculated from microscopical observations or from the digitized images of the grain boundaries varies from fine-grained to medium-grain size $50 \mu \mathrm{m}$ up to $3 \mathrm{~mm}$. All samples are also characterized by a large variation considering the shape fabric examples are given in Figs. 1, 2, 3, 4, 5, 6, and 7. The grain boundary orientation given for the XY-, XZ-, and YZ-planes may differ from a more or less random distribution to a distinct planar or linear shape fabric. An example for a random distribution is the Arabella marble, while most of the other marbles (e.g., Sölk, Thassos and Carrara) exhibit a shape preferred orientation (Fig. 1). A more detailed discussion on the fabric is given for Blanco Macael, Carrara, Lasa, Großkunzendorf, Prieborn, and Wunsiedel marbles, because they are more or less representative for the whole collection and exhibit fabric characteristics which are important for the understanding of the observed petrophysical properties and degradation phenomena. The shape of the grain aggregates can generally be classified between equigranular-polygonal, inequigranular-polygonal, or seriate-interlobate in the sense of Moore (1970). Since a dolomitic composition is discussed as a main factor for the durability of marbles, dolomitic and 


\begin{tabular}{|c|c|}
\hline $\begin{array}{c}\text { Grainfabric } \\
\text {-equigranular polygonal }\end{array}$ & $\begin{array}{c}\text { Preferred grain shape orientation } \\
\text { - in ZY-plane elongation in } \\
\text { Y-direction }\end{array}$ \\
\hline $\begin{array}{c}\text { Medium grain size } \\
-495 \mu \mathrm{m}\end{array}$ & $\begin{array}{c}\text { Texture } \\
\text { - c-axis fibre type } \\
\text { medium intensity }\end{array}$ \\
\hline $\begin{array}{c}\text { Grain boundary geometry } \\
\text {-straight to lobate }\end{array}$ & \begin{tabular}{c} 
\\
\hline
\end{tabular}
\end{tabular}

Grain fabric
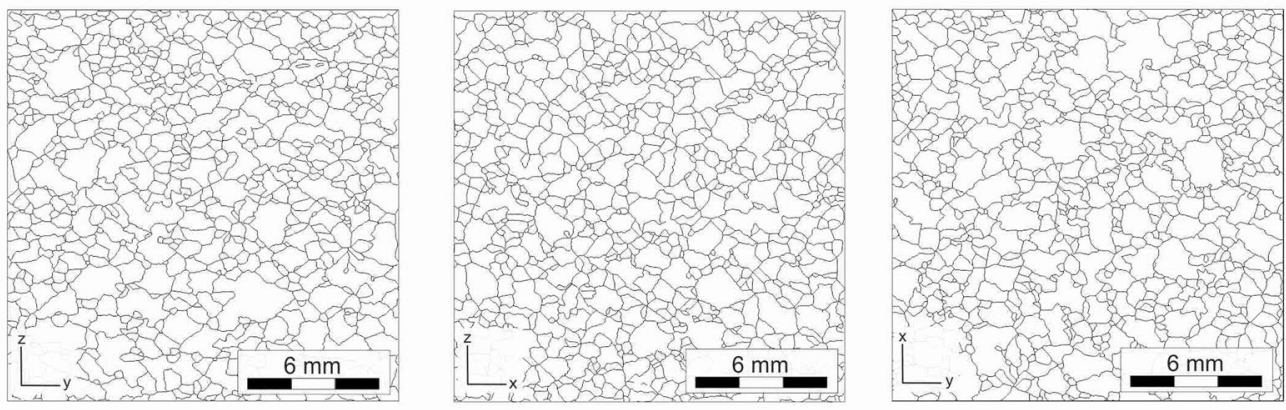

Grain area distribution
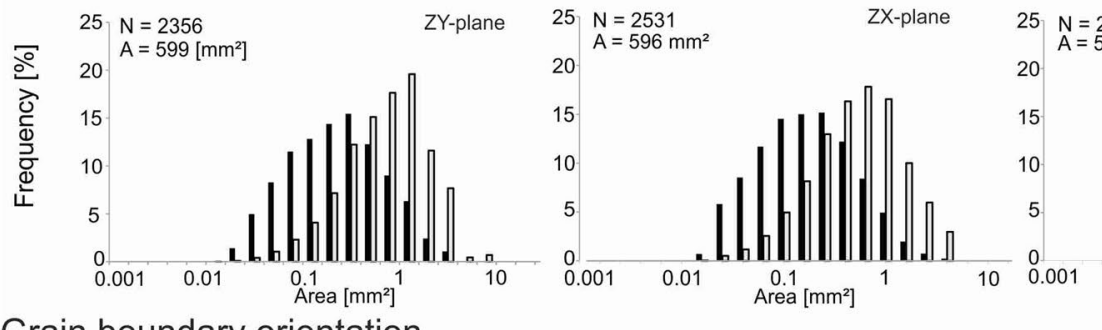

$$
\begin{aligned}
& \mathrm{N}=2040 \\
& A=599 \mathrm{~mm}^{2}
\end{aligned}
$$

$\mathrm{XY}$-plane

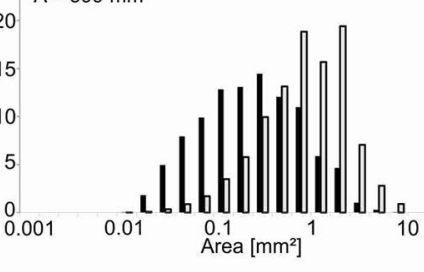

Grain boundary orientation
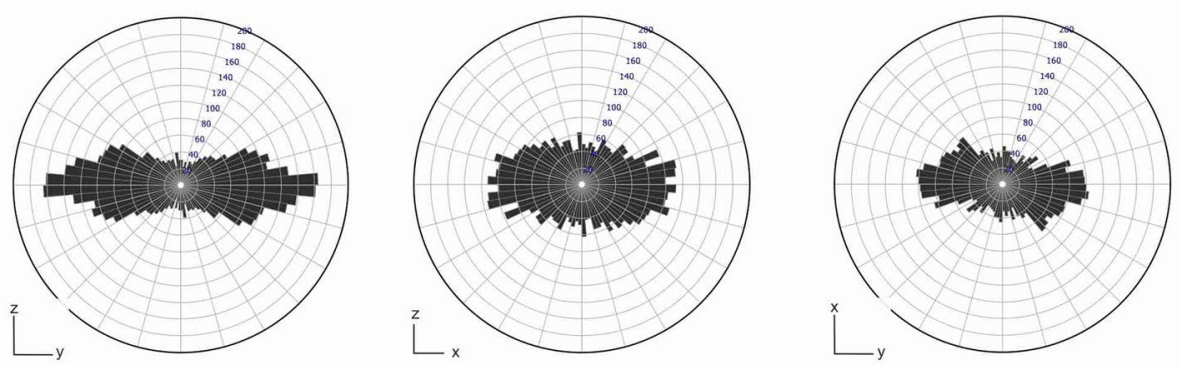

Texture:
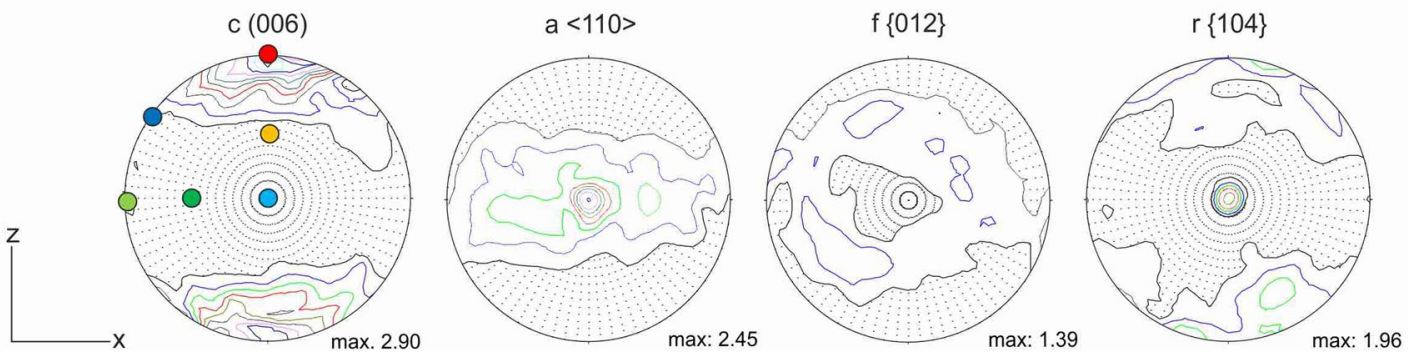

Fig. 2 Main fabric characteristics of the Blanco Macael. Characteristic line drawing of a microscope image, grain size [relative frequency of specific area class has been calculated with respect to the total area (grey bars; $A$ total area) and total number of grains (black bars; $N$ total number of grains)], shape preferred orientation and texture 
Fig. 3 Main fabric characteristics of the Carrara Gioia. Characteristic line drawing of a microscope image, grain size [relative frequency of specific area class has been calculated with respect to the total area (grey bars; $A$ total area) and total number of grains (black bars; $N$ total number of grains)], shape preferred orientation and texture

\begin{tabular}{|c|c|}
\hline $\begin{array}{c}\text { Grain fabric } \\
\text {-equigranular polygonal }\end{array}$ & $\begin{array}{c}\text { Preferred grain shape orientation } \\
- \text { in ZX-plane elongation in } \\
\text { X-direction }\end{array}$ \\
\hline $\begin{array}{c}\text { Medium grain size } \\
284 \mu \mathrm{m}\end{array}$ & $\begin{array}{c}\text { Texture } \\
- \text { c-axis fibre type with medium } \\
\text { intensity }\end{array}$ \\
\hline $\begin{array}{c}\text { Grain boundary geometry } \\
\text { straight to interlobate }\end{array}$ & \\
\hline
\end{tabular}
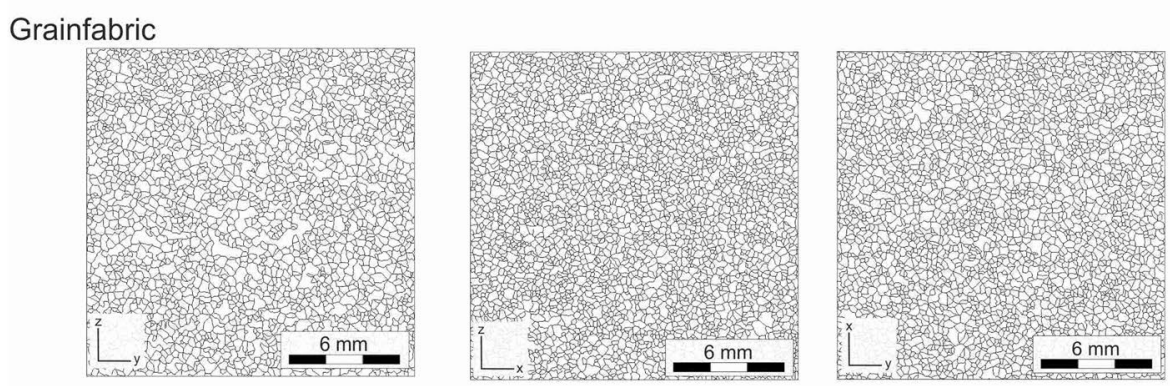

Grain area distribution
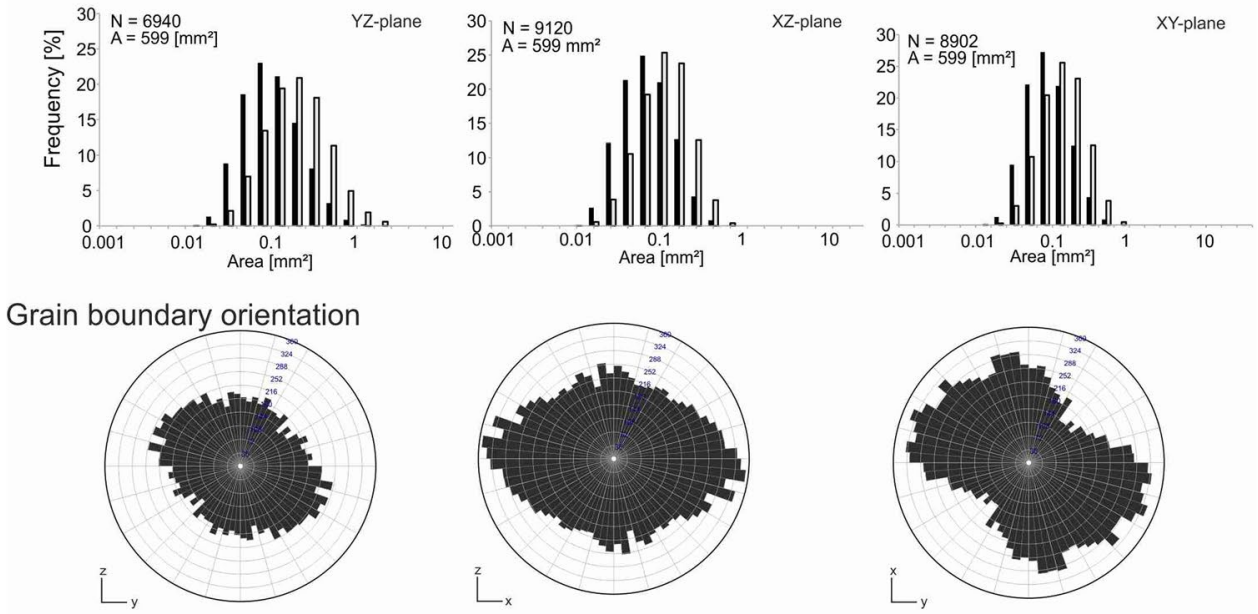

Texture:
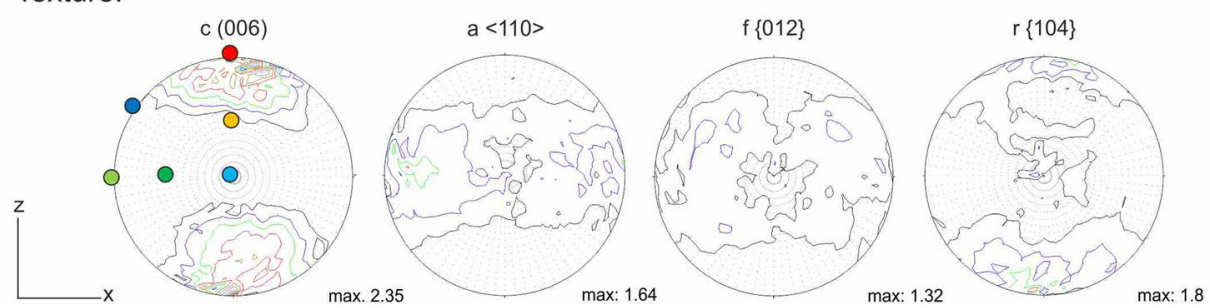

calcitic marbles were introduced. Carrara (calcite) and Thassos (dolomite) are fine-grained marbles with more or less straight grain boundaries, a so-called foam structure. In contrast, Thassos and Sölk are coarser grained, while the grain boundaries can be recognized as equigranular-interlobate and inequigranular-interlobate. The much higher irregularity of the lobate grain boundaries is clearly documented in Thassos and Sölk exhibiting two sets of conjugate planar fabrics with an opening angle of around $50^{\circ}$ which are slightly asymmetrically disposed to the foliation. These fabrics can easily be observed in the thin sections and in the corresponding grain boundary surfaces (Fig.1). In summary, the grain boundary geometry or the grain interlocking for all marbles ranges between equigranular-polygonal (Rosa Estremoz) up to seriate-interlobate (Großkunzendorf) with a slight tendency to be inequigranular-amoeboid (Wachau). This implies that the metamorphic and deformation history over geologically long time spans controlling the development of rock fabrics was quite different for all selected samples. Recrystallization processes, for instance, may control the grain size and the configuration of grain boundaries. Evidence for grain boundary migration recrystallization is the presence of highly irregular grain boundaries. The driving force is the difference in the dislocation density resulting 
Fig. 4 Main fabric characteristics of the Lasa marble. Characteristic line drawing of a microscope image, grain size [relative frequency of specific area class has been calculated with respect to the total area (grey bars; $A$ total area) and total number of grains (black bars; $N$ total number of grains)], shape preferred orientation and texture

\begin{tabular}{|c|c|}
\hline $\begin{array}{c}\text { Grain fabric } \\
\text {-equigranular polygonal }\end{array}$ & $\begin{array}{c}\text { Preferred grain shape orientation } \\
\text { - ZY-plane elongation in } \\
\text { Z-direction }\end{array}$ \\
\hline $\begin{array}{c}\text { Medium grain size } \\
-419 \mu \mathrm{m}\end{array}$ & $\begin{array}{c}\text { Texture } \\
\text { - a-axis fibre type with medium } \\
\text { intensity }\end{array}$ \\
\hline $\begin{array}{c}\text { Grain boundary geometry } \\
\text {-straight to interlobate }\end{array}$ & \\
\hline
\end{tabular}

\section{Grain fabric}
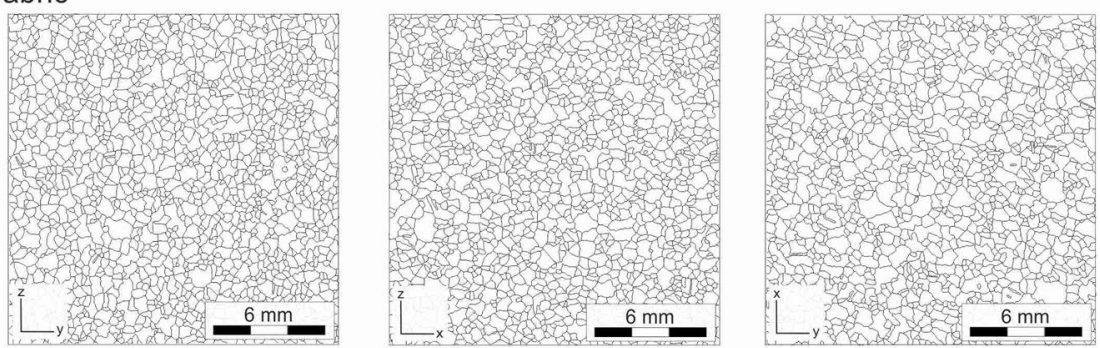

Grain area distribution
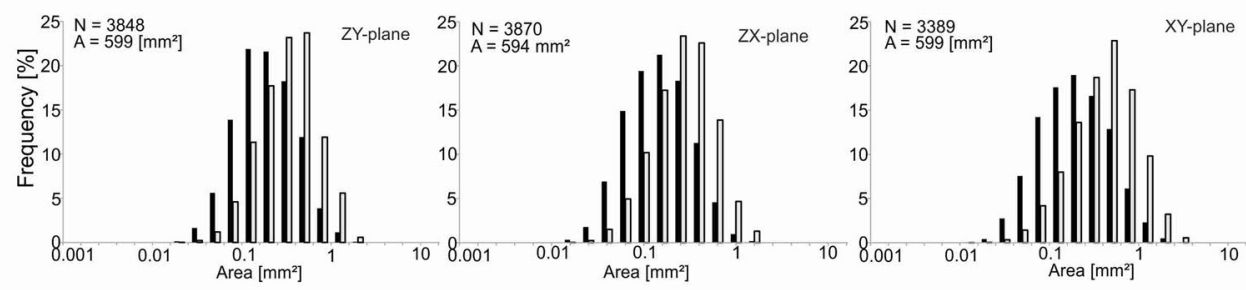

Grain boundary orientation
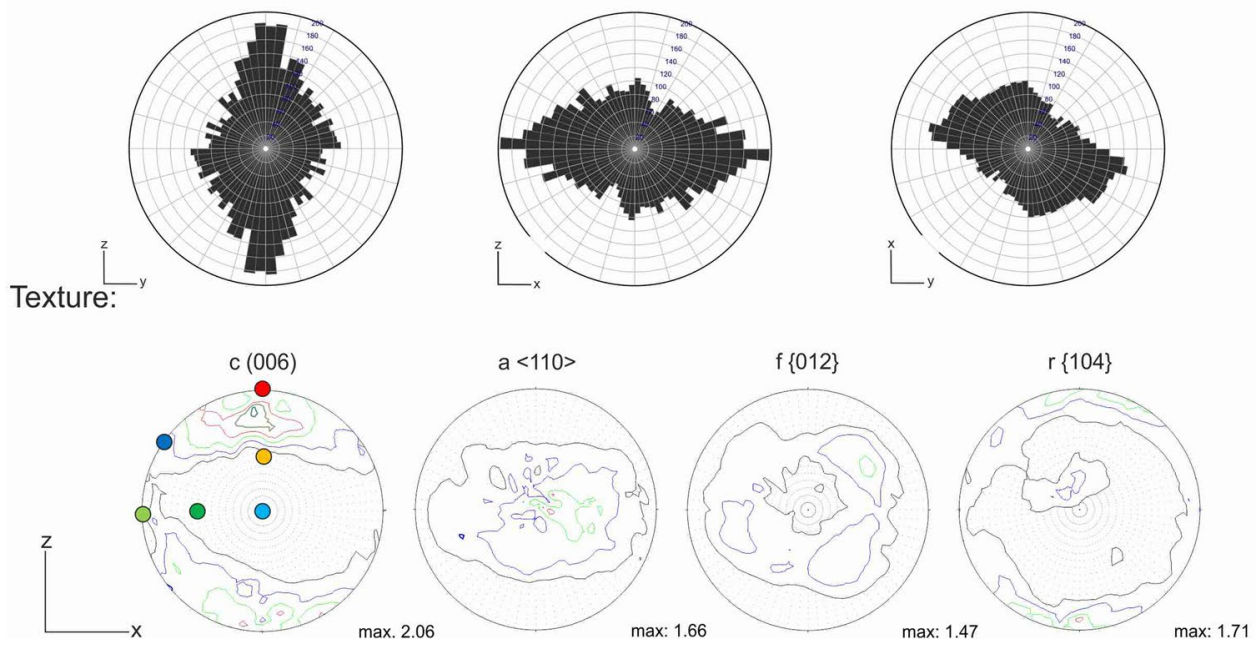

to a bulging of the grain boundaries into crystals with the higher dislocation density (Gottstein and Mecking 1985). In other cases, subgrain recrystallization may lead to an equilibrium fabric of polygonal crystals with interfacial angles of approximately $120^{\circ}$ (see Carrara), a so-called foam structure. From the mechanical point of view, it seems to be clear that a decrease in grain boundary energy is correlated with the decrease in strength of a polycrystalline material. Beside a lot of other processes (for a review, see Skrotzki 1995), the deformation may be responsible for the development of a lattice preferred orientation (here referred as texture) which has also a significant control on the physical properties and their directional dependence (e.g., Siegesmund and Dahms 1995). All samples were analyzed with respect to their textures. Leiss and Ullemeyer (1999) discussed the fundamental texture types of calcite and dolomite which are found in nature. In summary, they can be described by a rotating single crystal with the c-axis or a-axis as the rotation axis, respectively. These c-axis and a-axis fiber types can overlap forming intermediate texture types. The recalculated c-axis and a-axes pole figures of Blanco Macael, Rosa Estremoz, Carrara, Großkunzendorf, Prieborn, Wunsiedel and Lasa, are illustrated in Figs. 2, 3, 4, 5, 6, and 7. Usually, a single maximum which is in most cases elongated to an 
Fig. 5 Main fabric characteristics of the Großkunzendorf marble. Characteristic line drawing of a microscope image, grain size [relative frequency of specific area class has been calculated with respect to the total area (grey bars; $A$ total area) and total number of grains (black bars; $N$ total number of grains)], shape preferred orientation and texture

\begin{tabular}{|c|c|}
\hline $\begin{array}{l}\text { Grain fabric } \\
\quad \text {-seriate-interlobate }\end{array}$ & $\begin{array}{l}\text { Preferred grain shape orientation } \\
\text { - in ZX-and XY-plane elongation in } \\
\text { X-direction, foliation parallel }\end{array}$ \\
\hline $\begin{array}{c}\text { Medium grain size } \\
-545 \mu \mathrm{m}\end{array}$ & \multirow{2}{*}{$\begin{array}{l}\text { Texture } \\
\text { - c-axis fibre type with low } \\
\text { intensity }\end{array}$} \\
\hline $\begin{array}{c}\text { Grain boundary geometry } \\
\text {-curved to interlocking }\end{array}$ & \\
\hline
\end{tabular}

\section{Grain fabric}
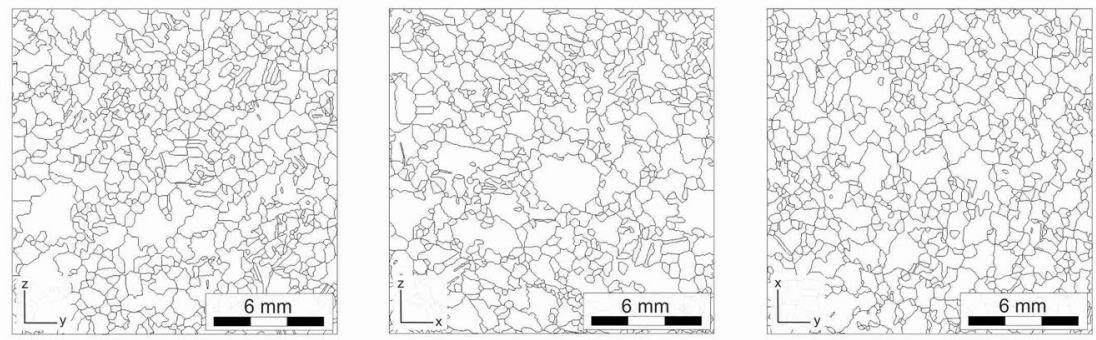

Grain area distribution
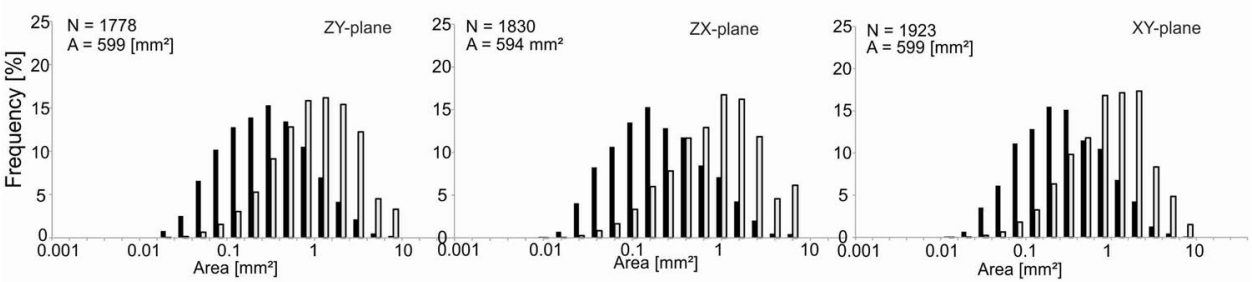

Grain boundary orientation
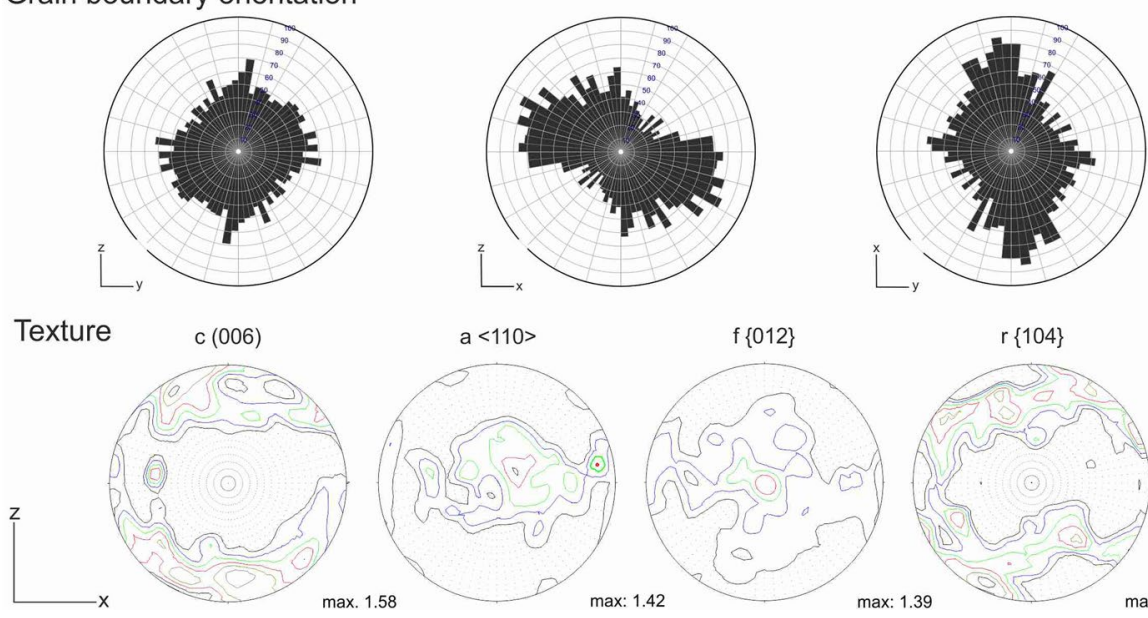

$r\{104\}$

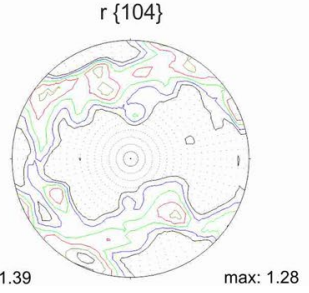

oval-shaped pattern can be observed. According to the crystallography of calcite, the (110) poles are arranged on a great circle around the (001) pole density maximum. The maximum intensity is highly variable and at maximum with 5.9 m.r.d. (multiples of random distribution) of (001) indicates a strong texture and, consequently, a pronounced anisotropy of the physical properties must be expected. To characterize the textures of all 18 samples, the tensor shape T calculated from the pole figure tensor is applied to describe the different c-axis concentrations (Jelinek 1981). T calculated from the pole figure tensor characterizes the texture differences very well. It covers the range from $T=-0.859$ (Wachau) to $T=0.881$ (Rosa Estremoz) indicating a well-pronounced cluster-like and a moderate girdle-like shape of the intensity distribution as the extreme cases. Extremely planar c-axes distributions (i.e., complete girdles) are not observed. The maximum intensity obtained from a simplified texture reproduction with $L=2$ ranges from 1.4 to 5.9. It more or less concurs with the shape parameter $\mathrm{T}$.

\section{Petrophysical properties}

The alteration of marble leads to a significant porosity increase and change of the pore space properties. Generally, the porosity has a direct and indirect effect on most physical rock properties and is the most important rock 
Fig. 6 Main fabric characteristics of the Prieborn marble. Characteristic line drawing of a microscope image, grain size [relative frequency of specific area class has been calculated with respect to the total area (grey bars; $A$ total area) and total number of grains (black bars; $N$ total number of grains)], shape preferred orientation and texture

\begin{tabular}{|c|c|}
\hline $\begin{array}{c}\text { Grain fabric } \\
\text {-equigranular polygonal }\end{array}$ & $\begin{array}{c}\text { Preferred grain boundary orientation } \\
\text { - in XY- and YZ-plane elongation } \\
\text { perpendicular to the foliation }\end{array}$ \\
\cline { 1 - 1 } $\begin{array}{c}\text { Medium grain size } \\
-242 \mu \mathrm{m}\end{array}$ & $\begin{array}{c}\text { Texture } \\
\text { - c-axis fibre type with a } \\
\text { strong intensity }\end{array}$ \\
\hline $\begin{array}{c}\text { Grain boundary geometry } \\
\text {-straight to lobate }\end{array}$ & \\
\hline
\end{tabular}

\section{Grain fabric}
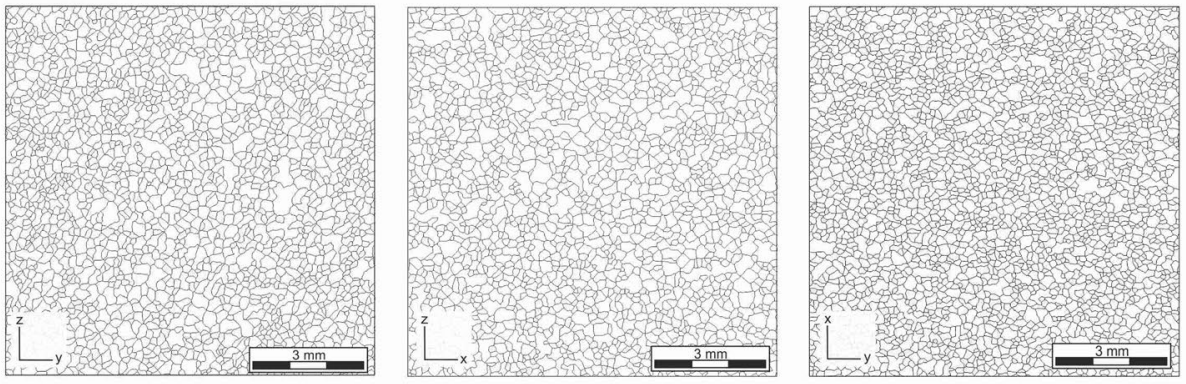

Grain area distribution
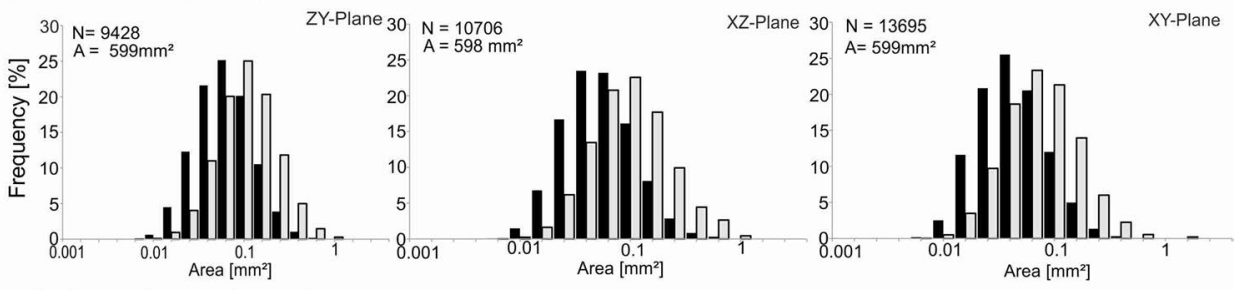

Grain boundary orientation

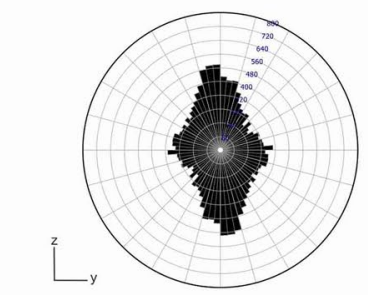

Texture:
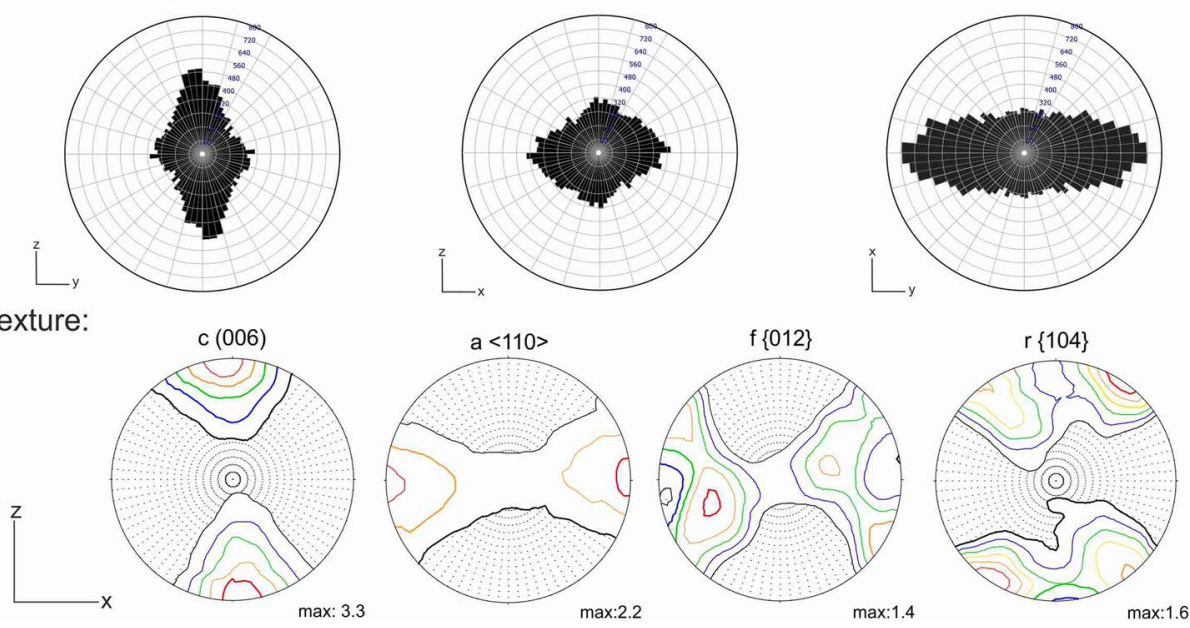

increase of this porosity which is still very low and ranging between 0.4 and $0.7 \%$ up to $2.33 \%$ reported for a Carrara marble by Rüdrich et al. 2013, but effective regarding the resulting modifications of the rock properties. Therefore, the change of porosity within the stepwise artificial alteration was determined for 7 samples (Table 2). The measured porosities $(\varphi)$ range between $0.12 \%$ and $0.41 \%$ for the quarry fresh marble samples, while the varieties Prieborn with $\varphi=0.44 \%$ as well as Carrara Gioia with $\varphi=0.37 \%$ were already weathered at their 'fresh' state. Over the weathering course, the Rosa Estremoz and the Wunsiedel marble 
Fig. 7 Main fabric characteristics of the Wunsiedel marble. Characteristic line drawing of a microscope image, grain size [relative frequency of specific area class has been calculated with respect to the total area (grey bars; $A$ total area) and total number of grains (black bars; $N$ total number of grains)], shape preferred orientation and texture

\begin{tabular}{|c|c|}
\hline $\begin{array}{c}\text { Grainfabric } \\
\text {-seriate-interlobate }\end{array}$ & $\begin{array}{c}\text { Preferred grain shape orientation } \\
\text { - in ZX-and ZY-plane elongation } \\
\text { perpendicular to the foliation }\end{array}$ \\
\hline $\begin{array}{c}\text { Medium grain size } \\
-419 \mu \mathrm{m}\end{array}$ & $\begin{array}{c}\text { Texture } \\
\text { - pronounced c-axis fibre type } \\
\text { with a high intensity }\end{array}$ \\
\hline $\begin{array}{c}\text { Grain boundary geometry } \\
\text {-curved to interlocking }\end{array}$ & \\
\hline
\end{tabular}

Grain fabric
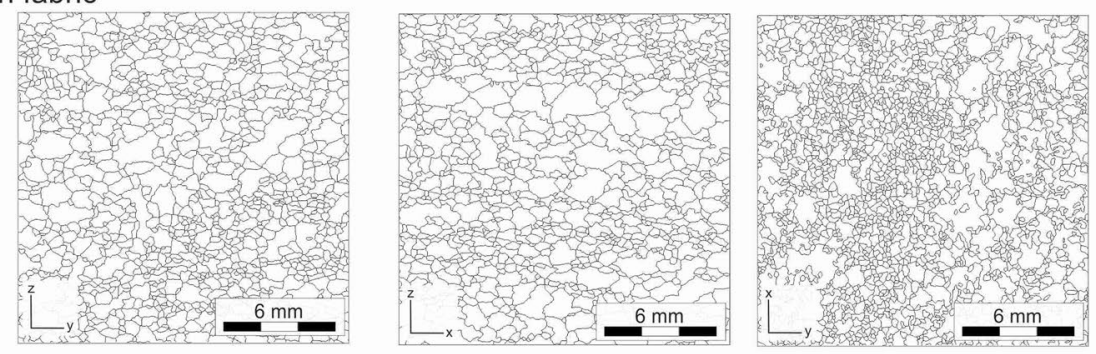

Grain area distribution
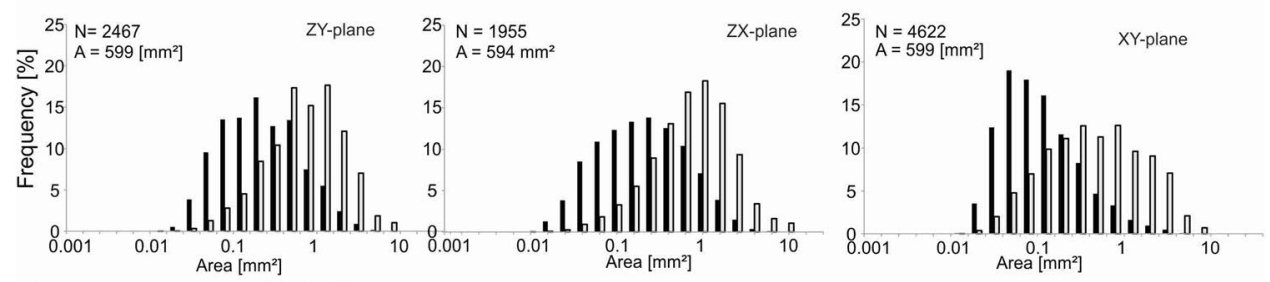

Grain boundary orientation
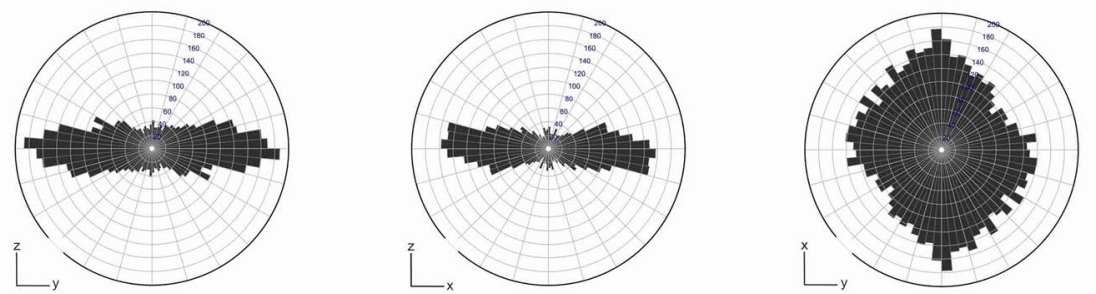

Texture:
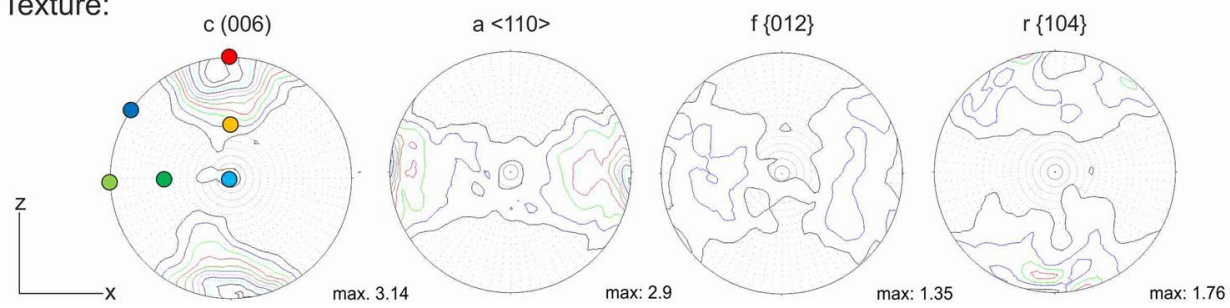

Table 2 Effective porosity $(\varphi)$ in percent for each weathering state (fresh to $200{ }^{\circ} \mathrm{C}$ and an additional freeze - heat cycle) based on the analyses of 10 cubic samples (fresh) down to 5 samples $\left(200{ }^{\circ} \mathrm{C}\right)$

\begin{tabular}{llllllll}
\hline & FRESH $(\%)$ & $60{ }^{\circ} \mathrm{C}(\%)$ & $90{ }^{\circ} \mathrm{C}(\%)$ & $120{ }^{\circ} \mathrm{C}(\%)$ & $150{ }^{\circ} \mathrm{C}(\%)$ & $200{ }^{\circ} \mathrm{C}(\%)$ & $200{ }^{\circ} \mathrm{C}+(\%)$ \\
\hline Blanco Macael & $0.18 \pm 0.02$ & $0.23 \pm 0.03$ & $0.25 \pm 0.02$ & $0.33 \pm 0.03$ & $0.38 \pm 0.01$ & $0.72 \pm 0.13$ & $0.77 \pm 0.08$ \\
Carrara Gioia & $0.37 \pm 0.05$ & $0.44 \pm 0.04$ & $0.43 \pm 0.03$ & $0.50 \pm 0.05$ & $0.50 \pm 0.04$ & $0.54 \pm 0.02$ & $0.80 \pm 0.01$ \\
Lasa & $0.41 \pm 0.01$ & $0.49 \pm 0.02$ & $0.48 \pm 0.02$ & $0.53 \pm 0.03$ & $0.56 \pm 0.02$ & $0.63 \pm 0.05$ & $0.79 \pm 0.02$ \\
Großkunzendorf & $0.12 \pm 0.01$ & $0.16 \pm 0.01$ & $0.23 \pm 0.02$ & $0.26 \pm 0.02$ & $0.36 \pm 0.02$ & $0.41 \pm 0.01$ & $0.75 \pm 0.03$ \\
Prieborn & $0.44 \pm 0.02$ & 0.58 & 0.59 & - & 0.62 & 0.62 & - \\
Wunsiedel & $0.32 \pm 0.14$ & $0.32 \pm 0.15$ & $0.36 \pm 0.16$ & $0.41 \pm 0.16$ & $0.45 \pm 0.17$ & $0.53 \pm 0.18$ & $0.58 \pm 0.19$ \\
Rosa Estremoz & 0.2 & 0.2 & 0.26 & 0.29 & 0.31 & 0.67 \\
\hline
\end{tabular}


show no porosity increase caused by the first heating up to $60{ }^{\circ} \mathrm{C}$, while all the other varieties, even the preweathered samples show an increase of $\varphi$. The next heating step up to $90{ }^{\circ} \mathrm{C}$ shows a furthermore slightly porosity increase. For the next weathering steps, a constant increase can be observed for all samples until $150^{\circ} \mathrm{C}$. While all marbles continue their slightly porosity increase up to $200{ }^{\circ} \mathrm{C}$, the Blanco Macael and the Rosa Estremoz show a significant increase of about $0.35 \%$ up to almost $0.7 \%$ after heating to $200{ }^{\circ} \mathrm{C}$. At this point, they differ strongly from the other samples, which need the additional freeze cycle to increase their porosity up to $0.7 \%$. This last heating-freeze cycle finally increases the porosity to $0.75-0.8 \%$ for all varieties, while the effect is only small for the Blanco Macael. The Wunsiedel marble shows a different behavior within the whole artificial alteration. The porosity increase is low and even the last cycle did not show any significant increasing effect, but this marble shows a comparatively high standard deviation (0.14-0.19), which increases after each weathering step. This reflects the macro- and microscopic visible heterogeneity and shows that the crack growth is not uniform for this marble and depends on specific conditions.

\section{Capillary water uptake}

Almost all weathering processes as freeze-thaw cycles, solution processes, salt-related weathering, and thermohygric processes are determined by the presence of water. The pore space and pore system relates to the amount of water absorption, the nature of water transport, and the size of the surface area available for chemical interactions (Siegesmund and Dürrast 2014). Capillary water uptake is an important parameter for materials with pore diameters within the range of the so-called capillary pores. To determine the transformation within the artificial alteration, the capillary water uptake was analyzed for all marble varieties. The capillary water absorption coefficient $\left[\mathrm{kg} / \mathrm{m}^{2} * \sqrt{\mathrm{h}}\right]$ given in Table 3 was analyzed for one cubic sample in the unweathered

Table $3 w$ value, capillary water uptake, porosity and saturation coefficient for the investigated marble varieties under fresh and weathered conditions

\begin{tabular}{|c|c|c|c|c|c|c|c|c|}
\hline Marble & Weathering state & Direction & $\begin{array}{l}w \text { value } \\
(\mathrm{kg} / \\
\left.\mathrm{m}^{2 *} \sqrt{\mathrm{h}}\right)\end{array}$ & $\mathrm{W}_{\text {(cap) }}$ (weight $\%$ ) & $\mathrm{W}_{(\text {Cap })}(\mathrm{Vol} \%)$ & Porosity [\%] & $\begin{array}{l}\text { Water absorption } \\
\text { [Weight \%] }\end{array}$ & $\begin{array}{l}\text { Saturation } \\
\text { coefficient }\end{array}$ \\
\hline \multirow[t]{2}{*}{$\mathrm{BM}$} & Fresh & $\begin{array}{l}X \\
Y \\
Z\end{array}$ & $\begin{array}{l}0.09 \\
0.07 \\
0.09\end{array}$ & $\begin{array}{l}0.04 \\
0.04 \\
0.04\end{array}$ & $\begin{array}{l}0.12 \\
0.11 \\
0.12\end{array}$ & $\begin{array}{l}0.18 \\
\pm 0.02\end{array}$ & $\begin{array}{l}0.07 \text { (vac) } \\
0.04(\mathrm{~atm})\end{array}$ & 0.57 \\
\hline & $200^{\circ} \mathrm{C}$ & $\begin{array}{l}X \\
Y \\
Z\end{array}$ & $\begin{array}{l}0.32 \\
0.35 \\
0.32\end{array}$ & $\begin{array}{l}- \\
0.20 \\
0.17\end{array}$ & $\begin{array}{l}- \\
0.53 \\
0.47\end{array}$ & $\begin{array}{l}0.72 \\
\pm 0.13\end{array}$ & $\begin{array}{l}0.28 \text { (vac) } \\
0.19 \text { (atm) }\end{array}$ & 0.68 \\
\hline \multirow[t]{2}{*}{ GI } & Fresh & $\begin{array}{l}X \\
Y \\
Z\end{array}$ & $\begin{array}{l}0.09 \\
0.12 \\
0.16\end{array}$ & $\begin{array}{l}0.11 \\
0.12 \\
0.18\end{array}$ & $\begin{array}{l}0.29 \\
0.32 \\
0.49\end{array}$ & $\begin{array}{l}0.37 \\
\pm 0.05\end{array}$ & $\begin{array}{l}0.14 \text { (vac) } \\
0.13 \text { (atm) }\end{array}$ & 0.93 \\
\hline & $200^{\circ} \mathrm{C}$ & $\begin{array}{l}X \\
Y \\
Z\end{array}$ & $\begin{array}{l}0.45 \\
0.42 \\
0.42\end{array}$ & $\begin{array}{l}0.23 \\
0.23 \\
0.23\end{array}$ & $\begin{array}{l}0.62 \\
0.63 \\
0.63\end{array}$ & $\begin{array}{l}0.54 \\
\pm 0.02\end{array}$ & $\begin{array}{l}0.29 \text { (vac) } \\
0.23 \text { (atm) }\end{array}$ & 0.79 \\
\hline \multirow[t]{2}{*}{ LA } & Fresh & $\begin{array}{l}\mathrm{X} \\
\mathrm{Y} \\
\mathrm{Z}\end{array}$ & $\begin{array}{l}0.09 \\
0.07 \\
0.16\end{array}$ & $\begin{array}{l}0.11 \\
0.10 \\
-\end{array}$ & $\begin{array}{l}0.30 \\
0.28 \\
-\end{array}$ & $\begin{array}{l}0.41 \\
\pm 0.01\end{array}$ & $\begin{array}{l}0.15 \text { (vac) } \\
0.11(\mathrm{~atm})\end{array}$ & 0.73 \\
\hline & $200^{\circ} \mathrm{C}$ & $\begin{array}{l}X \\
Y \\
Z\end{array}$ & $\begin{array}{l}0.09 \\
0.40 \\
0.39\end{array}$ & $\begin{array}{l}0.25 \\
0.26 \\
0.26\end{array}$ & $\begin{array}{l}0.68 \\
0.70 \\
0.71\end{array}$ & $\begin{array}{l}0.63 \\
\pm 0.05\end{array}$ & $\begin{array}{l}0.29 \text { (vac) } \\
0.26(\mathrm{~atm})\end{array}$ & 0.90 \\
\hline \multirow[t]{2}{*}{ GK } & Fresh & $\begin{array}{l}X \\
Y \\
Z\end{array}$ & $\begin{array}{l}0.05 \\
0.02 \\
0.04\end{array}$ & $\begin{array}{l}0.02 \\
0.04 \\
0.02\end{array}$ & $\begin{array}{l}0.05 \\
0.12 \\
0.06\end{array}$ & $\begin{array}{l}0.12 \\
\pm 0.01\end{array}$ & $\begin{array}{l}0.04 \text { (vac) } \\
0.03 \text { (atm) }\end{array}$ & 0.75 \\
\hline & $200^{\circ} \mathrm{C}$ & $\begin{array}{l}X \\
Y \\
Z\end{array}$ & $\begin{array}{l}0.55 \\
0.45 \\
0.29\end{array}$ & $\begin{array}{l}0.23 \\
0.24 \\
0.24\end{array}$ & $\begin{array}{l}0.62 \\
0.65 \\
0.66\end{array}$ & $\begin{array}{l}0.41 \\
\pm 0.01\end{array}$ & $\begin{array}{l}0.27 \text { (vac) } \\
0.24 \text { (atm) }\end{array}$ & 0.89 \\
\hline $\mathrm{P}$ & Fresh & $\begin{array}{l}X \\
Y \\
Z\end{array}$ & $\begin{array}{l}0.09 \\
0.17 \\
0.13\end{array}$ & $\begin{array}{l}0.16 \\
0.16 \\
0.16\end{array}$ & $\begin{array}{l}0.43 \\
0.42 \\
0.42\end{array}$ & $\begin{array}{l}0.44 \\
\pm 0.02\end{array}$ & $\begin{array}{l}0.21 \text { (vac) } \\
0.16 \text { (atm) }\end{array}$ & 0.76 \\
\hline $\mathrm{W}$ & Fresh & $\begin{array}{l}X \\
Y \\
Z\end{array}$ & $\begin{array}{l}0.09 \\
0.03 \\
0.14\end{array}$ & $\begin{array}{l}0.11 \\
0.06 \\
0.07\end{array}$ & $\begin{array}{l}0.29 \\
0.17 \\
0.18\end{array}$ & $\begin{array}{l}0.32 \\
\pm 0.14\end{array}$ & $\begin{array}{l}0.12 \text { (vac) } \\
0.09 \text { (atm) }\end{array}$ & 0.75 \\
\hline
\end{tabular}


state and after heating cycles up to $200{ }^{\circ} \mathrm{C}$. The $\mathrm{w}$ value is given for 3 directions, as well as the water absorption (Wcap) in weight and volume percent. The porosity can also be found in Table 2. The given water absorption value in weight percent is given as mean value of all analyzed cubes under the specific conditions (10 samples at the fresh state, 5 samples for the $200{ }^{\circ} \mathrm{C}$ state). The $\mathrm{w}$ value can be used to classify rocks (Snethlage 2008) into three types (1) slightly absorbing $\left[w<0.5\left(\mathrm{~kg} / \mathrm{m}^{2} * \sqrt{\mathrm{h}}\right),(2)\right.$ medium absorbing $\left(w 0.5-3.0 \mathrm{~kg} / \mathrm{m}^{2} * \sqrt{\mathrm{h}}\right.$ ), and (3) highly absorbing [w $>3.0$ $\left.\left(\mathrm{kg} / \mathrm{m}^{2 *} \sqrt{\mathrm{h}}\right)\right]$. According to this classification, all analyzed marble varieties are slightly absorbing regardless if they are quarry fresh [w values between 0.02 and $0.17\left(\mathrm{~kg} / \mathrm{m}^{2 *} \sqrt{ } \mathrm{h}\right.$ ) or artificially weathered $\left(0.09-0.45\left[\mathrm{~kg} / \mathrm{m}^{2} * \sqrt{\mathrm{h}}\right]\right.$, but all of them increase according to the weathering intensity. Only the strongly weathered Großkunzendorf shows a slightly higher w value of $0.55\left[\mathrm{~kg} / \mathrm{m}^{2 *} \sqrt{ } \mathrm{h}\right]$ in $\mathrm{X}$-direction. The thermal-induced deterioration of all marble types shows an increasing capillary water uptake capability, which is connected to the increasing porosity (see Siegesmund and Dürrast, 2014). Regardless of the weathering state, it should be noted that the capillary water uptake occurs relatively fast and is finished within the first $60-180 \mathrm{~min}$. The saturation coefficient $\mathrm{S}$ describes how much of the total pore space is accessible to water absorption and helps to determine the frost resistance. Siegesmund and Dürrast 2014 describe that for metamorphic rocks, the saturation coefficient has limited significance due to the very small water absorption values under atmospheric and under vacuum conditions. They are influenced by the measurement procedure, the standard deviation of different samples, and the resolution limit. According to the classification of Hirschwald 1912, $S$ values below 0.75 stand for a weather and frost resistant rock, while values below 0.9 indicate a rock which is not frost and weather resistant. For any rock type with a saturation coefficient between 0.75 and 0.9 , further investigations are recommended. The analyzed marble varieties represent the entire spectrum of the $S$ value with 0.57 for the Blanco Macael up to 0.93 for the Carrara Gioia, whereby most of the samples are assigned to the group of rocks, where further investigations are recommended.

\section{Ultrasonic measurements}

The correlation of the P-wave velocity determined by ultrasonic measurements and the weathering state of marble was confirmed by many scientific analyses (Ahmad et al. 2009; Babacan and Gelisli 2015; Boudani et al. 2015; Dürrast et al. 1999; Fleischer 2002; Köhler 1991, 2014; Lindner et al. 1999; Menningen et al. 2018a, 2018b, 2019, Rüdrich 2003; Rüdrich et al. 2013; Siegesmund et al. 2000a; Siegesmund et al. 2004b; Weiss et al. 1999; Weiss et al. 2002a). Whereas the P-wave velocity of a quarry fresh marble is relatively high [6-7 $(\mathrm{km} / \mathrm{s})]$, it decreases with increasing weathering state. This velocity decrease is connected to the formation of microcracks throughout the weathering process, which has a huge influence on the velocity reduction (e.g., Weiss et al. 2002a). Köhler 1991, established a velocity-based classification for the weathering state of Carrara marble which helps to define the weathering state of objects made of marble. As those measurements allow a non-destructive evaluation of the material, they are used for quality assurance as well as for preservation purposes in the context of heritage conservation.

\section{Transmission measurements}

The distribution of elastic waves depends on the mineralogical composition, the fabric as well as the type and arrangement of cracks. Furthermore, the crack filling medium, water or air, has a significant impact (e.g., Siegesmund 1996; Weiss et al. 2002a). To assign a specific weathering state to an ultrasonic velocity, the systematic alteration of the marble samples was connected to repeated ultrasonic measurements. All cubic samples were analyzed after each temperature cycle under dry and wet conditions. In Table 4, the mean dry ultrasonic velocities are given in three directions as well as the amount of anisotropy (\%). The variation of the maximum and minimum velocity is used to calculate the anisotropy $\mathrm{A}(\%)=(\mathrm{Vpmax}-\mathrm{Vpmin}) / \mathrm{Vpmax} * 100$ (Siegesmund and Dürrast 2014). The Blanco Macael shows the strongest and most distinct velocity decrease after almost every weathering cycle with a total reduction down to 1.60 $\mathrm{km} / \mathrm{s}$ which is a reduction of $65.58 \%$ in comparison to the unweathered velocity in Z-direction. The strongest impact is caused by the heating cycle up to $200^{\circ} \mathrm{C}$, with an average reduction of $27.4 \%$ in comparison to the $150{ }^{\circ} \mathrm{C}$ cycle. The average velocity reduction per weathering step is $0.51 \mathrm{~km} / \mathrm{s}$ $( \pm 0.23)$ and combined with a steadily increasing anisotropy up to $30.7 \%$. In comparison, the Lasa marble shows an alternating intensity of the velocity reduction. Here, every second weathering step shows a higher reduction and reaches its strongest influence at the combination of $200{ }^{\circ} \mathrm{C}$ heating and freezing. That this combination has the biggest impact on the velocities can also be observed for the Großkunzendorf, Wunsiedel and the Lasa marble (see Fig. 8). The amount of anisotropy increases with each weathering step. While the Carrara Gioia shows almost no changes and the anisotropy ranges between 5.24 and $8.84 \%$, the Wunsiedel marble shows the highest initial anisotropy of $17.36 \%$ and increases successive up to $34.05 \%$. It can be observed that the main velocity reduction for each sample takes place in Z-direction, whereas the Großkunzendorf shows an equalization after the second heating-freeze cycle. This may indicate a foliation parallel preferred crack formation. 
Table 4 Ultrasonic velocity $[\mathrm{km} / \mathrm{s}]$ measured on cubic samples after each weathering step (fresh-200 ${ }^{\circ} \mathrm{C}++$ ) according to the 3 main directions $\mathrm{X}, \mathrm{Y}$ and $\mathrm{Z}$

\begin{tabular}{|c|c|c|c|c|c|c|}
\hline & Direction & Blanco Macael & Gioia & Lasa & Großkunzendorf & Wunsiedel \\
\hline Fresh $(n=10)$ & $\begin{array}{l}\mathrm{X} \\
\mathrm{Y}[\mathrm{km} / \mathrm{s}] \\
\mathrm{Z} \\
\boldsymbol{A}[\%]\end{array}$ & $\begin{array}{l}5.09 \pm 0.12 \\
5.28 \pm 0.15 \\
4.71 \pm 0.12 \\
10.77\end{array}$ & $\begin{array}{l}3.82 \pm 0.21 \\
3.70 \pm 0.23 \\
3.59 \pm 0.20 \\
6.00\end{array}$ & $\begin{array}{l}4.73 \pm 0.12 \\
4.83 \pm 0.09 \\
4.40 \pm 0.08 \\
8.86\end{array}$ & $\begin{array}{l}6.00 \pm 0.06 \\
6.12 \pm 0.16 \\
5.76 \pm 0.11 \\
\mathbf{5 . 9 4}\end{array}$ & $\begin{array}{l}6.08 \pm 0.48 \\
6.09 \pm 0.26 \\
5.04 \pm 1.04 \\
\mathbf{1 7 . 3 6}\end{array}$ \\
\hline $60^{\circ} \mathrm{C}(n=9)$ & $\begin{array}{l}\mathrm{X} \\
\mathrm{Y}[\mathrm{km} / \mathrm{s}] \\
\mathrm{Z} \\
\boldsymbol{A}[\%]\end{array}$ & $\begin{array}{l}4.37 \pm 0.14 \\
4.81 \pm 0.12 \\
3.98 \pm 0.13 \\
\mathbf{1 7 . 3 3}\end{array}$ & $\begin{array}{l}3.37 \pm 0.23 \\
3.37 \pm 0.20 \\
3.19 \pm 0.23 \\
\mathbf{5 . 2 4}\end{array}$ & $\begin{array}{l}4.52 \pm 0.09 \\
4.58 \pm 0.11 \\
4.09 \pm 0.16 \\
10.59\end{array}$ & $\begin{array}{l}6.13 \pm 0.16 \\
6.00 \pm 0.04 \\
5.83 \pm 0.12 \\
4.80\end{array}$ & $\begin{array}{l}5.93 \pm 0.35 \\
5.75 \pm 0.44 \\
4.83 \pm 0.94 \\
\mathbf{1 8 . 5 2}\end{array}$ \\
\hline $90^{\circ} \mathrm{C}(n=8)$ & $\begin{array}{l}\mathrm{X} \\
\mathrm{Y}[\mathrm{km} / \mathrm{s}] \\
\mathrm{Z} \\
\boldsymbol{A}[\%]\end{array}$ & $\begin{array}{l}4.08 \pm 0.23 \\
4.58 \pm 0.20 \\
3.66 \pm 0.26 \\
20.18\end{array}$ & $\begin{array}{l}3.14 \pm 0.18 \\
3.13 \pm 0.15 \\
2.97 \pm 0.18 \\
\mathbf{5 . 4 2}\end{array}$ & $\begin{array}{l}3.96 \pm 0.17 \\
4.03 \pm 0.15 \\
3.52 \pm 0.15 \\
\mathbf{1 2 . 5 4}\end{array}$ & $\begin{array}{l}5.65 \pm 0.12 \\
5.59 \pm 0.12 \\
5.40 \pm 0.07 \\
4.44\end{array}$ & $\begin{array}{l}6.16 \pm 0.54 \\
5.89 \pm 0.64 \\
4.79 \pm 1.16 \\
22.17\end{array}$ \\
\hline $120^{\circ} \mathrm{C}(n=7)$ & $\begin{array}{l}\mathrm{X} \\
\mathrm{Y}[\mathrm{km} / \mathrm{s}] \\
\mathrm{Z} \\
\boldsymbol{A}[\%]\end{array}$ & $\begin{array}{l}3.95 \pm 0.19 \\
4.14 \pm 0.18 \\
3.14 \pm 0.21 \\
\mathbf{2 4 . 1 1}\end{array}$ & $\begin{array}{l}2.76 \pm 0.18 \\
2.77 \pm 0.12 \\
2.62 \pm 0.16 \\
\mathbf{5 . 4 2}\end{array}$ & $\begin{array}{l}3.81 \pm 0.10 \\
3.89 \pm 0.09 \\
3.35 \pm 0.08 \\
\mathbf{1 3 . 7 3}\end{array}$ & $\begin{array}{l}5.30 \pm 0.17 \\
5.16 \pm 0.12 \\
4.89 \pm 0.11 \\
7.71\end{array}$ & $\begin{array}{l}5.68 \pm 0.46 \\
5.41 \pm 0.58 \\
4.61 \pm 0.98 \\
\mathbf{1 8 . 8 4}\end{array}$ \\
\hline $150^{\circ} \mathrm{C}(n=6)$ & $\begin{array}{l}\mathrm{X} \\
\mathrm{Y}[\mathrm{km} / \mathrm{s}] \\
\mathrm{Z} \\
\boldsymbol{A}[\%]\end{array}$ & $\begin{array}{l}3.00 \pm 0.17 \\
3.40 \pm 0.13 \\
2.50 \pm 0.14 \\
\mathbf{2 6 . 6 7}\end{array}$ & $\begin{array}{l}2.43 \pm 0.14 \\
2.45 \pm 0.12 \\
2.29 \pm 0.14 \\
6.63\end{array}$ & $\begin{array}{l}3.27 \pm 0.13 \\
3.24 \pm 0.19 \\
2.83 \pm 0.11 \\
\mathbf{1 3 . 4 0}\end{array}$ & $\begin{array}{l}4.38 \pm 0.11 \\
4.16 \pm 0.08 \\
3.96 \pm 0.15 \\
9.57\end{array}$ & $\begin{array}{l}5.30 \pm 0.46 \\
5.01 \pm 0.47 \\
4.08 \pm 0.76 \\
\mathbf{2 3 . 6 1}\end{array}$ \\
\hline $200^{\circ} \mathrm{C}(n=5)$ & $\begin{array}{l}\mathrm{X} \\
\mathrm{Y}[\mathrm{km} / \mathrm{s}] \\
\mathrm{Z} \\
\boldsymbol{A}[\%]\end{array}$ & $\begin{array}{l}2.12 \pm 0.21 \\
2.56 \pm 0.22 \\
1.80 \pm 0.17 \\
29.51\end{array}$ & $\begin{array}{l}2.31 \pm 0.09 \\
2.28 \pm 0.06 \\
2.11 \pm 0.09 \\
8.84\end{array}$ & $\begin{array}{l}2.89 \pm 0.12 \\
2.93 \pm 0.09 \\
2.54 \pm 0.25 \\
13.30\end{array}$ & $\begin{array}{l}3.84 \pm 0.09 \\
3.63 \pm 0.05 \\
3.42 \pm 0.19 \\
10.98\end{array}$ & $\begin{array}{l}4.92 \pm 0.44 \\
4.54 \pm 0.41 \\
3.53 \pm 0.66 \\
\mathbf{2 8 . 3 2}\end{array}$ \\
\hline $\begin{array}{r}200{ }^{\circ} \mathrm{C}+ \\
(n=4)\end{array}$ & $\begin{array}{l}\mathrm{X} \\
\mathrm{Y}[\mathrm{km} / \mathrm{s}] \\
\mathrm{Z} \\
\boldsymbol{A}[\%]\end{array}$ & $\begin{array}{l}1.98 \pm 0.11 \\
2.34 \pm 0.12 \\
1.62 \pm 0.05 \\
\mathbf{3 0 . 7 1}\end{array}$ & $\begin{array}{l}2.13 \pm 0.05 \\
2.13 \pm 0.04 \\
1.95 \pm 0.04 \\
8.38\end{array}$ & $\begin{array}{l}2.37 \pm 0.10 \\
2.44 \pm 0.07 \\
1.97 \pm 0.03 \\
19.27\end{array}$ & $\begin{array}{l}3.23 \pm 0.05 \\
3.63 \pm 0.04 \\
2.75 \pm 0.08 \\
\mathbf{1 4 . 8 3}\end{array}$ & $\begin{array}{l}4.39 \pm 0.43 \\
3.94 \pm 0.32 \\
2.90 \pm 0.53 \\
\mathbf{3 4 . 0 5}\end{array}$ \\
\hline $\begin{array}{r}200^{\circ}++ \\
(n=4)\end{array}$ & $\begin{array}{l}\mathrm{X} \\
\mathrm{Y}[\mathrm{km} / \mathrm{s}] \\
\mathrm{Z} \\
\boldsymbol{A}[\%]\end{array}$ & - & $\begin{array}{l}1.83 \pm 0.02 \\
1.82 \pm 0.03 \\
1.68 \pm 0.04 \\
8.05\end{array}$ & - & $\begin{array}{l}2.73 \pm 0.08 \\
2.69 \pm 0.07 \\
2.65 \pm 0.06 \\
2.87\end{array}$ & - \\
\hline
\end{tabular}

$N$ number of cubes, each direction was measured on 5 positions

Anisotropy A [\%] is given for each weathering step and refers to the respective mean value

\section{Influence of humidity and water saturation}

The weathering state of marble can be determined by ultrasonic measures, as long as the material is dry. The effect of an increasing porosity caused by cracks is reduced as soon as water penetrates the pore space and increases the velocities. This increase can reach almost intrinsic values for a fully saturated sample. The ultrasonic velocities for the water-saturated samples after each heating cycle are given in Table 5. There, the mean values, out of 4-9 cubes and 5 measurements per direction, are displayed.

Independent of the weathering state, all cubes and varieties show a significant increase of the compressional wave velocity, covering almost the span of velocities for a calcite single crystal $[5.7 \mathrm{~km} / \mathrm{s}$ parallel to the c-axis and $7.7 \mathrm{~km} / \mathrm{s}$ parallel to the $a$-axes according to Dandekar (1968)]. Until a stress of $150{ }^{\circ} \mathrm{C}$, the velocities range between 5.73 and $6.75 \mathrm{~km} / \mathrm{s}$, with a slightly fluctuation trend. After the next heating step up to $200{ }^{\circ} \mathrm{C}$, these velocities are slowly but clearly reduced for all marble varieties, while the Großkunzendorf still keeps higher velocities. After the combination of heat and freezing temperatures, none of the marbles show higher velocities than $6.03 \mathrm{~km} / \mathrm{s}$. Rüdrich 2003 observed the same for strongly weathered Carrara and Großkunzendorf marble and named the lower compressibility of water and/or the incomplete water saturation as the reason. As all samples show the same behavior, the lower water compressibility seems to be more plausible, as the high number of cracks and, therefore, higher water proportion reduce the overall velocity. Regardless of this, the directional dependence of the wave velocity can still be observed for all samples and is consistent with the dry samples.

Besides the water saturation, the ultrasonic velocities have been measured under different air humidities for the different weathering states in a climate chamber. After 3 days in a specific relative air humidity, the weight and the ultrasonic velocities have been determined. In Fig. 9, the velocity evolution for the Blanco Macael is shown as an 
Fig. 8 Velocity reduction (\%) for each weathering step with regard to the former velocity

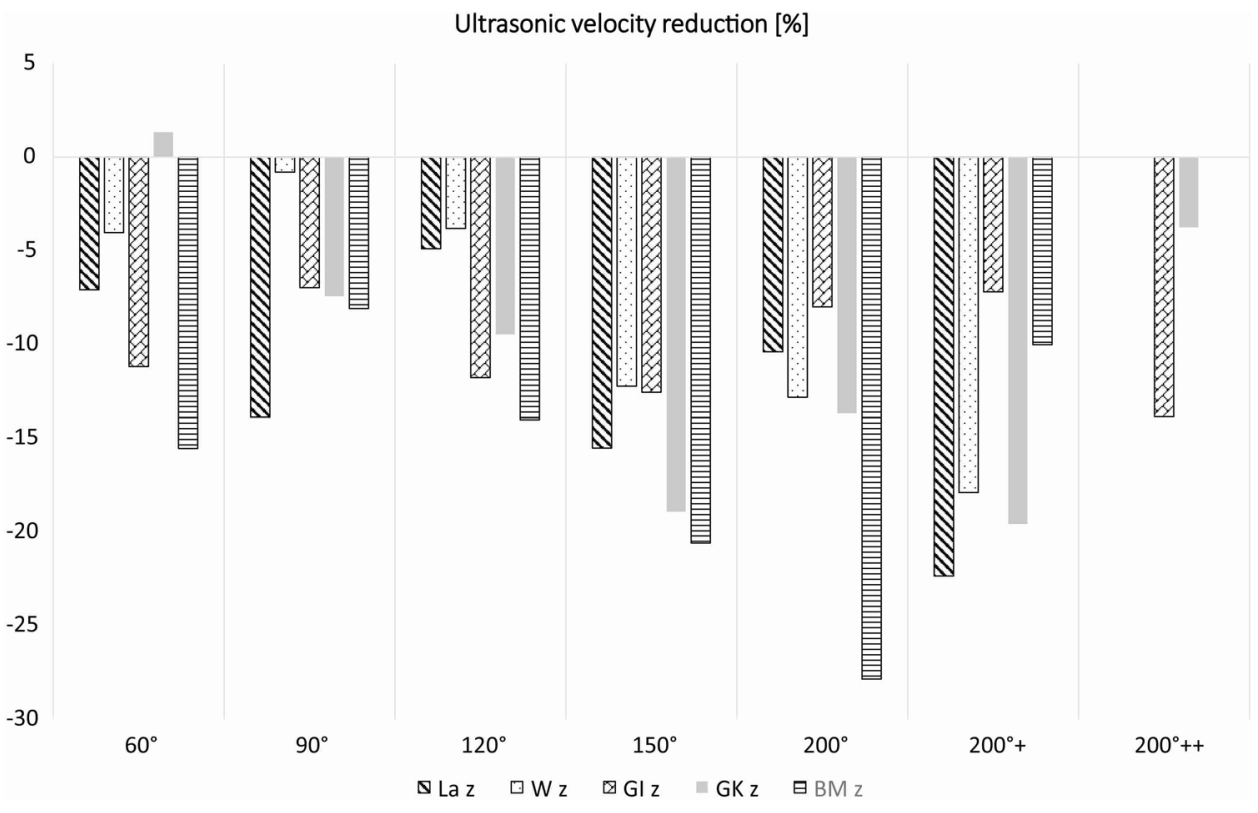

example. In dependence on the relative air humidity, the velocities increase slightly, while the highest impact can be observed for the unweathered sample. With increasing weathering state, the influence of the humidity decreases. A comparable evolution can be observed for all marble varieties, while the Großkunzendorf shows a less clear trend.
Generally, the influence of the air humidity seems to be low, while as higher the weathering state of the marble as lower the influence, which can be observed in Fig. 9. In Fig. 10, the maximum velocity increase is given for all five marble types in Z-direction (the Z-direction is perpendicular to the metamorphic layering), according to the specific
Table 5 Ultrasonic velocity $(\mathrm{km} / \mathrm{s})$ measured on cubic samples under wet conditions after each weathering step $\left(60-200{ }^{\circ} \mathrm{C}\right.$ ) according to the 3 main directions $\mathrm{X}, \mathrm{Y}$ and $\mathrm{Z}$

\begin{tabular}{cllllll}
\hline & Direction & Blanco Macael & Gioia & Lasa & Großkunzendorf & Wunsiedel \\
\hline $60^{\circ} \mathrm{C}$ & $\mathrm{X}$ & $6.65 \pm 0.08$ & $6.07 \pm 0.07$ & $6.12 \pm 0.05$ & $6.46 \pm 0.13$ & $6.62 \pm 0.11$ \\
$(n=9)$ & $\mathrm{Y}[\mathrm{km} / \mathrm{s}]$ & $6.74 \pm 0.11$ & $6.04 \pm 0.12$ & $6.26 \pm 0.12$ & $6.38 \pm 0.09$ & $6.30 \pm 0.78$ \\
& $\mathrm{Z}$ & $6.35 \pm 0.06$ & $5.91 \pm 0.08$ & $6.07 \pm 0.10$ & $6.30 \pm 0.10$ & $5.88 \pm 0.20$ \\
& $\mathrm{~A}[\%]$ & $\mathbf{5 . 7 9}$ & $\mathbf{2 . 6 4}$ & $\mathbf{3 . 0 4}$ & $\mathbf{2 . 9 4}$ & $\mathbf{1 1 . 1 8}$ \\
$90^{\circ} \mathrm{C}$ & $\mathrm{X}$ & $6.25 \pm 0.07$ & $5.97 \pm 0.10$ & $6.26 \pm 0.08$ & $6.41 \pm 0.15$ & $6.80 \pm 0.11$ \\
$(n=8)$ & $\mathrm{Y}[\mathrm{km} / \mathrm{s}]$ & $6.27 \pm 0.11$ & $5.82 \pm 0.26$ & $6.33 \pm 0.08$ & $6.29 \pm 0.09$ & $6.56 \pm 0.11$ \\
& $\mathrm{Z}$ & $5.91 \pm 0.11$ & $5.73 \pm 0.12$ & $6.07 \pm 0.06$ & $6.21 \pm 0.17$ & $6.21 \pm 0.16$ \\
& $\mathrm{~A}[\%]$ & $\mathbf{5 . 7 4}$ & $\mathbf{3 . 1 8}$ & $\mathbf{4 . 1 1}$ & $\mathbf{3 . 1 2}$ & $\mathbf{8 . 6 8}$ \\
$120^{\circ} \mathrm{C}$ & $\mathrm{X}$ & $6.39 \pm 0.03$ & $6.03 \pm 0.12$ & $6.11 \pm 0.07$ & $6.62 \pm 0.16$ & $6.67 \pm 0.41$ \\
$(n=7)$ & $\mathrm{Y}[\mathrm{km} / \mathrm{s}]$ & $6.59 \pm 0.03$ & $5.92 \pm 0.14$ & $6.06 \pm 0.10$ & $6.54 \pm 0.07$ & $6.62 \pm 0.17$ \\
& $\mathrm{Z}$ & $6.17 \pm 0.02$ & $5.78 \pm 0.13$ & $5.81 \pm 0.09$ & $6.47 \pm 0.10$ & $6.31 \pm 0.17$ \\
& $\mathrm{~A}[\%]$ & $\mathbf{6 . 3 7}$ & $\mathbf{4 . 1 5}$ & $\mathbf{4 . 9 1}$ & $\mathbf{2 . 2 7}$ & $\mathbf{5 . 4 0}$ \\
$150{ }^{\circ} \mathrm{C}$ & $\mathrm{X}$ & $6.23 \pm 0.08$ & $6.13 \pm 0.05$ & $6.10 \pm 0.09$ & $6.43 \pm 0.12$ & $6.75 \pm 0.15$ \\
$(n=6)$ & $\mathrm{Y}[\mathrm{km} / \mathrm{s}]$ & $6.30 \pm 0.09$ & $5.99 \pm 0.10$ & $6.22 \pm 0.11$ & $6.33 \pm 0.09$ & $6.56 \pm 0.12$ \\
& $\mathrm{Z}$ & $5.97 \pm 0.11$ & $5.97 \pm 0.13$ & $5.92 \pm 0.16$ & $6.17 \pm 0.14$ & $6.21 \pm 0.20$ \\
& $\mathrm{~A}[\%]$ & $\mathbf{5 . 2 4}$ & $\mathbf{6 . 6 3}$ & $\mathbf{6 . 5 9}$ & $\mathbf{4 . 0 4}$ & $\mathbf{8 . 0 0}$ \\
$200{ }^{\circ} \mathrm{C}$ & $\mathrm{X}$ & $5.87 \pm 0.13$ & $6.07 \pm 0.05$ & $6.00 \pm 0.06$ & $6.37 \pm 0.18$ & $5.38 \pm 0.77$ \\
$(n=5)$ & $\mathrm{Y}[\mathrm{km} / \mathrm{s}]$ & $5.95 \pm 0.13$ & $6.04 \pm 0.05$ & $6.07 \pm 0.07$ & $6.23 \pm 0.03$ & $5.07 \pm 0.94$ \\
& $\mathrm{Z}$ & $5.62 \pm 0.12$ & $5.67 \pm 0.44$ & $5.81 \pm 0.11$ & $6.21 \pm 0.12$ & $4.23 \pm 1.14$ \\
& $\mathrm{~A}[\%]$ & $\mathbf{5 . 5 5}$ & $\mathbf{6 . 5 9}$ & $\mathbf{4 . 2 8}$ & $\mathbf{2 . 5 1}$ & $\mathbf{2 1 . 5 6}$ \\
$200^{\circ} \mathrm{C}+$ & $\mathrm{X}$ & $5.74 \pm 0.08$ & $5.76 \pm 0.14$ & $5.79 \pm 0.09$ & $6.03 \pm 0.12$ & \\
$(n=4)$ & $\mathrm{Y}[\mathrm{km} / \mathrm{s}]$ & $5.41 \pm 0.60$ & $5.66 \pm 0.14$ & $5.80 \pm 0.16$ & $5.78 \pm 0.14$ & \\
& $\mathrm{Z}$ & $5.32 \pm 0.29$ & $5.49 \pm 0.07$ & $5.62 \pm 0.10$ & $5.71 \pm 0.15$ & \\
& $\mathrm{~A}[\%]$ & $\mathbf{7 . 3 2}$ & $\mathbf{4 . 6 9}$ & $\mathbf{3 . 1 0}$ & $\mathbf{5 . 3 1}$ & \\
\hline & & & &
\end{tabular}

Anisotropy A [\%] is given for each weathering step and refers to the respective mean value $N$ number of cubes, each direction was measured on 5 different positions 
Fig. 9 Velocity evolution in dependency of the relative humidity according to the different weathering states for the Blanco Macael. Given are the analyzed three main directions $\mathrm{X}, \mathrm{Y}$, and $\mathrm{Z}$

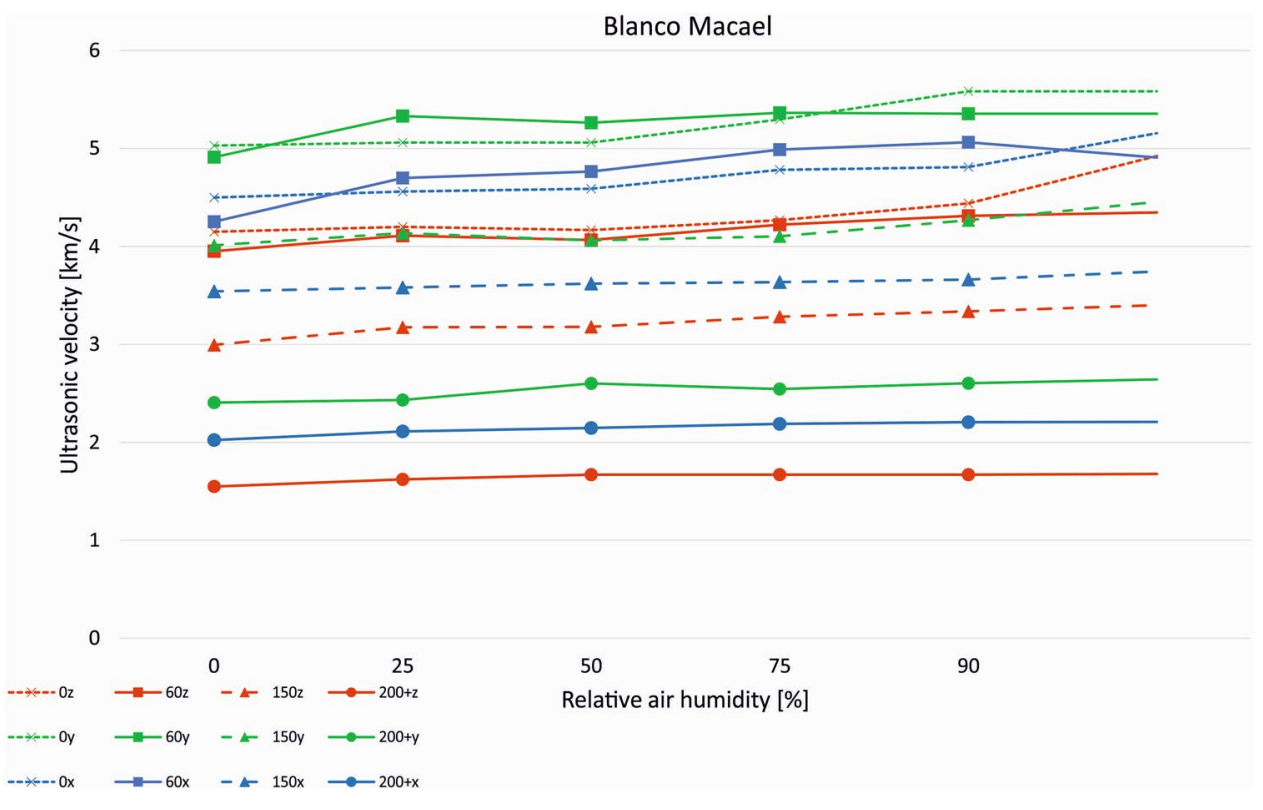

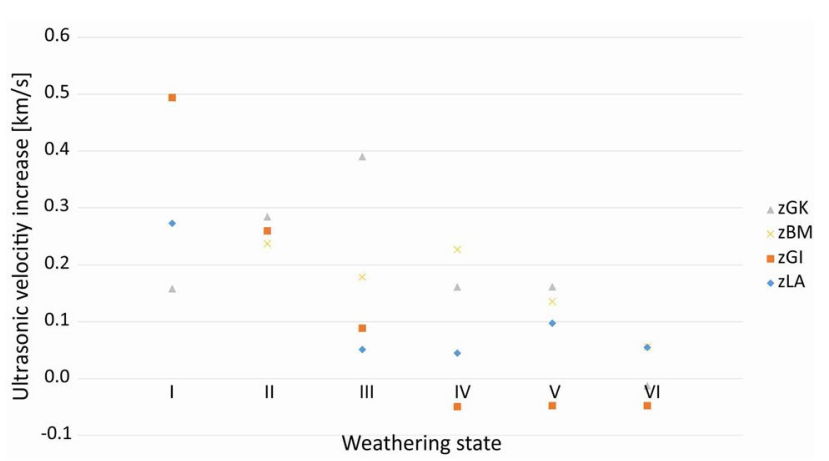

Fig. 10 Maximum velocity increase $(\mathrm{km} / \mathrm{s})$ for the Großkunzendorf, Lasa, Blanco Macael, and Carrara Gioia marble in Z-direction, according to the weathering state $\left(I\right.$ unweathered to $\mathrm{VI}=200{ }^{\circ} \mathrm{C}$ )

weathering state. This behavior can be determined for all marble types. The Großkunzendorf shows no clear trend. Due to the long drying times of the Wunsiedel marble, the samples were not conclusively alterated and could not be considered for this examination.

\section{Intrinsic velocity distribution}

As already described above, the water saturation of deteriorated marble can cause almost intrinsic velocity distributions. The intrinsic velocity distribution represents the crackfree compressive wave velocity, exclusively caused by the rock-forming minerals and their spatial arrangement. The P-wave velocities determined for a calcite single crystal are strongly anisotropic and differ with regard to the measured direction. A pronounced texture caused by the arrangement of those single crystals leads to an overprint of the anisotropic properties of calcite on the whole rock properties.

Based on the textural data, it was possible to calculate the polycrystal compressional wave velocity for each sample and to quantify their directional dependence, known as intrinsic anisotropy (Table 6). The calculated velocities range between 6.96 and $6.32 \mathrm{~km} / \mathrm{s}$, while the anisotropy varies between 2.94 and 9.2\%. As shown, the intrinsic anisotropy depends on the intensity of the texture (Fig. 11). The Großkunzendorf, with a low texture of $1.57 \mathrm{mrd}$, shows only a low intrinsic anisotropy. On the other hand, the Prieborner with a strong texture of $3.3 \mathrm{mrd}$ has a high intrinsic anisotropy of $9.2 \%$.

Table 6 Intrinsic ultrasonic velocity $(\mathrm{km} / \mathrm{s})$ and the anisotropy (\%) calculated on basis of the Texture

\begin{tabular}{llllllcc}
\hline & Blanco Macael & Gioia & Lasa & Großkunzendorf & Wunsiedel & Rosa Estremoz & Prieborn \\
\hline $\mathrm{V} \mathrm{p}_{\min }[\mathrm{km} / \mathrm{s}]$ & 6.8 & 6.8 & 6.8 & 6.8 & 6.9 & 6.8 & 6.96 \\
$\mathrm{~V} \mathrm{p}_{\max }[\mathrm{km} / \mathrm{s}]$ & 6.4 & 6.5 & 6.5 & 6.6 & 6.4 & 6.4 & 6.32 \\
$\mathrm{~A}[\%]$ & $\mathbf{5 . 8 8}$ & $\mathbf{4 . 4 1}$ & $\mathbf{4 . 4 1}$ & $\mathbf{2 . 9 4}$ & $\mathbf{7 . 2 5}$ & $\mathbf{5 . 8 8}$ & $\mathbf{9 . 2}$ \\
\hline
\end{tabular}




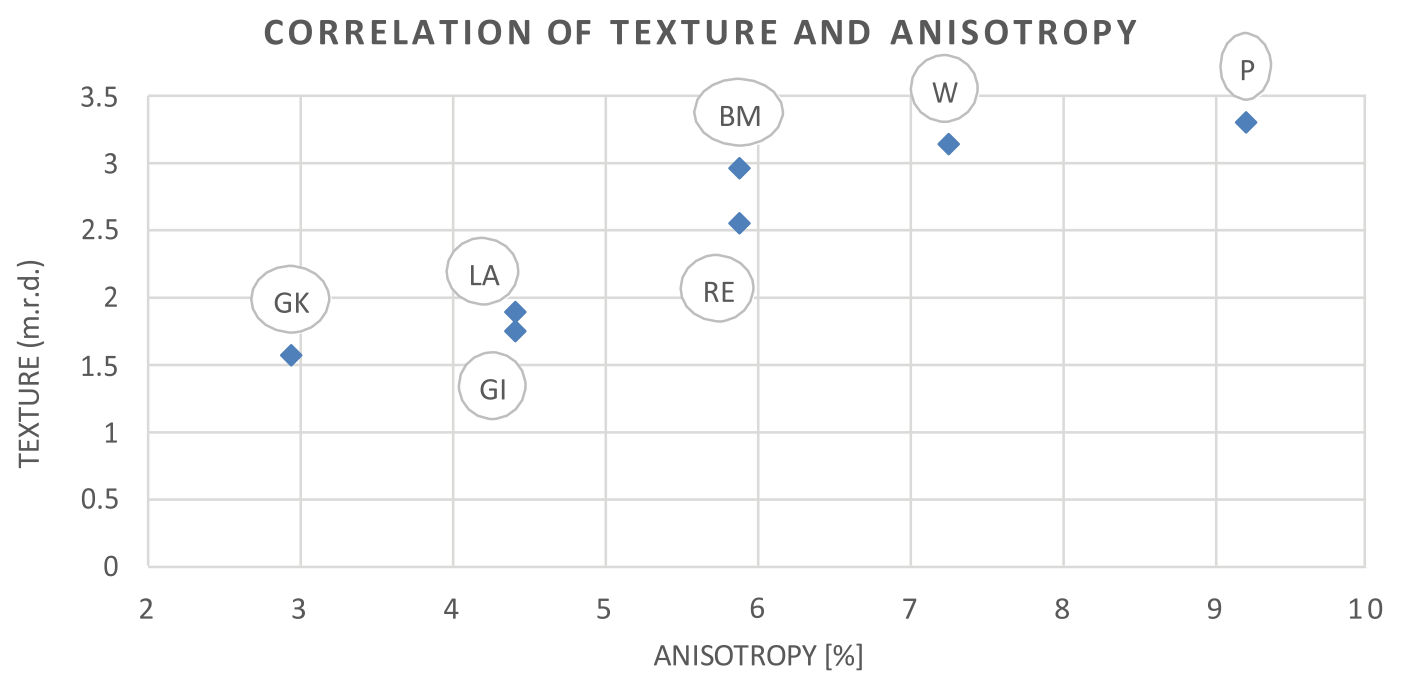

Fig. 11 Correlation of texture (mrd) and anisotropy (\%) determined for seven analyzed marble varieties

\section{Ultrasonic wave velocities measured on spherical samples}

To determine the spatial distribution of the velocity decrease, spherical samples were used to perform measurements in more than 100 directions. Those measurements were repeatedly executed for the same sample under dry and fully water-saturated conditions after each weathering step.

\section{Crack-related velocity reduction}

While the intrinsic velocity distribution is only influenced by rock-forming minerals, the measured velocity will always be lower. This velocity reduction is caused by cracks forming throughout the exhumation, exploitation process, and the further processing of the marble, and finally, it is affected by weathering processes.

As shown, the alteration of marble significantly reduces the ultrasonic velocities due to the formation of cracks. To determine the specific crack evolution within the weathering process, spherical samples were analyzed after each weathering step. The knowledge about an existing preferential orientation of microcracks and their influence on the intrinsic velocity distribution is of particular importance with regard to ultrasonic tomography (Rüdrich 2003).

Therefore, the spherical samples were analyzed under dry conditions and compared to the almost intrinsic, watersaturated sample. The calculated $\Delta-\mathrm{Vp}$-Plot is the difference between the water saturated and dry sample and allows an approximately determination of the preferred orientation. In Figs. 12 and 13, the results for all varieties after their alteration up to $200^{\circ} \mathrm{C}$ are given.

The comparison of the water saturated, weathered, and calculated $\Delta$-Vp-Plot shows that the main crack pattern caused by artificial weathering increases the intrinsic anisotropy (Fig. 14). The comparable distribution pattern of the water-saturated and the calculated pole figure points on this conclusion. It can be observed that former high ultrasonic velocities show the lowest velocity reduction, and on the other hand, the former low velocities show the highest reduction. While this general observation can be made, there are also several modifications between the different varieties. The samples Carrara Gioia and Wunsiedel show a crack pattern that is more comparable to the weathered distribution than to the water saturated. The pole figures of the varieties Blanco Macael, Lasa, and Großkunzendorf show more or less the same distribution pattern, independent if they are water saturated or weathered. Therefore, the calculated distribution pattern is comparable to them. In contrast, the results for the Rosa Estremoz differ. Here, we have a strong increase of the reduction parallel to the Z-direction, while the lowest increase can be observed in Y-direction. All anisotropies increase due to the weathering process, while the anisotropy of the $\Delta$-Vp-Plot distinguishes between comparable anisotropies, as were found for the water-saturated sample (Blanco Macael), medium intensities, ranging between the intrinsic, water saturated, low anisotropy, and the high anisotropy of the weathered sample. The calculated Wunsiedel pole figure shows an anisotropy which is higher (54\%) than the weathered anisotropy of $50 \%$. This marble shows a strong foliation parallel preferred grain shape orientation, influencing the crack distribution pattern.

The fresh, unweathered sample shows velocities between 4.9 and $4.1 \mathrm{~km} / \mathrm{s}$, while the velocity distribution is primarily dominated by the texture, with a velocity minimum in Z-direction, slightly elongated in Y-direction and a maximum velocity in $\mathrm{X}$-direction, slightly dipping into the Y-direction. Compared to the unweathered cubic samples, 


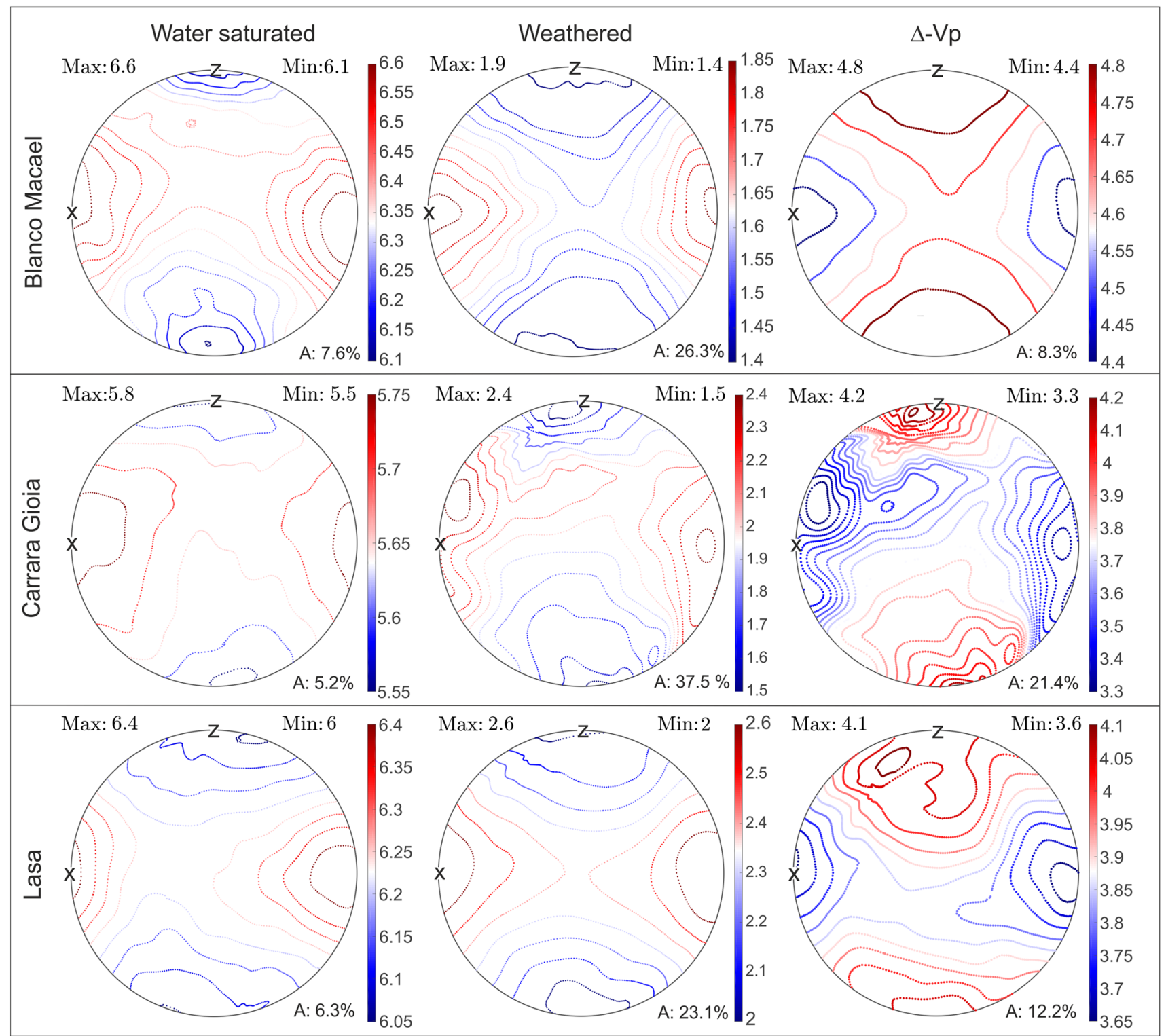

Fig. 12 Velocity distribution $\mathrm{Vp}$ in $\mathrm{km} / \mathrm{s}$ for the marble varieties Blanco Macael, Carrara Gioia, and Lasa. The plots show the distributions for the water-saturated state (left side) the weathered, dry sample $\left(200{ }^{\circ} \mathrm{C}\right)$ in the middle and $\Delta \mathrm{Vp}$, the calculated difference between saturated and weathered

show sub maxima in this area. Even if the temperature was only increased up to $60^{\circ} \mathrm{C}$, the velocities decrease down to $4.5-3.6 \mathrm{~km} / \mathrm{s}$. The temperature step up to $90{ }^{\circ} \mathrm{C}$ decreases the maximum velocity down to $4.0 \mathrm{~km} / \mathrm{s}$ and the minimum velocity down to $3.3 \mathrm{~km} / \mathrm{s}$, while the calculated difference between the maximum and minimum reduction decreases and lies between 2.8 and $2.3 \mathrm{~km} / \mathrm{s}$. The velocity maximum of $4.0 \mathrm{~km} / \mathrm{s}$ has now almost the same position oriented in $\mathrm{X}$-direction, while the lower velocities are rearranged in Z-direction. The crack pattern shows that a small channel in Y-Z-direction appears, decorated with spots of reductions between 2.8 and $2.6 \mathrm{~km} / \mathrm{s}$. Within the next heating cycle 


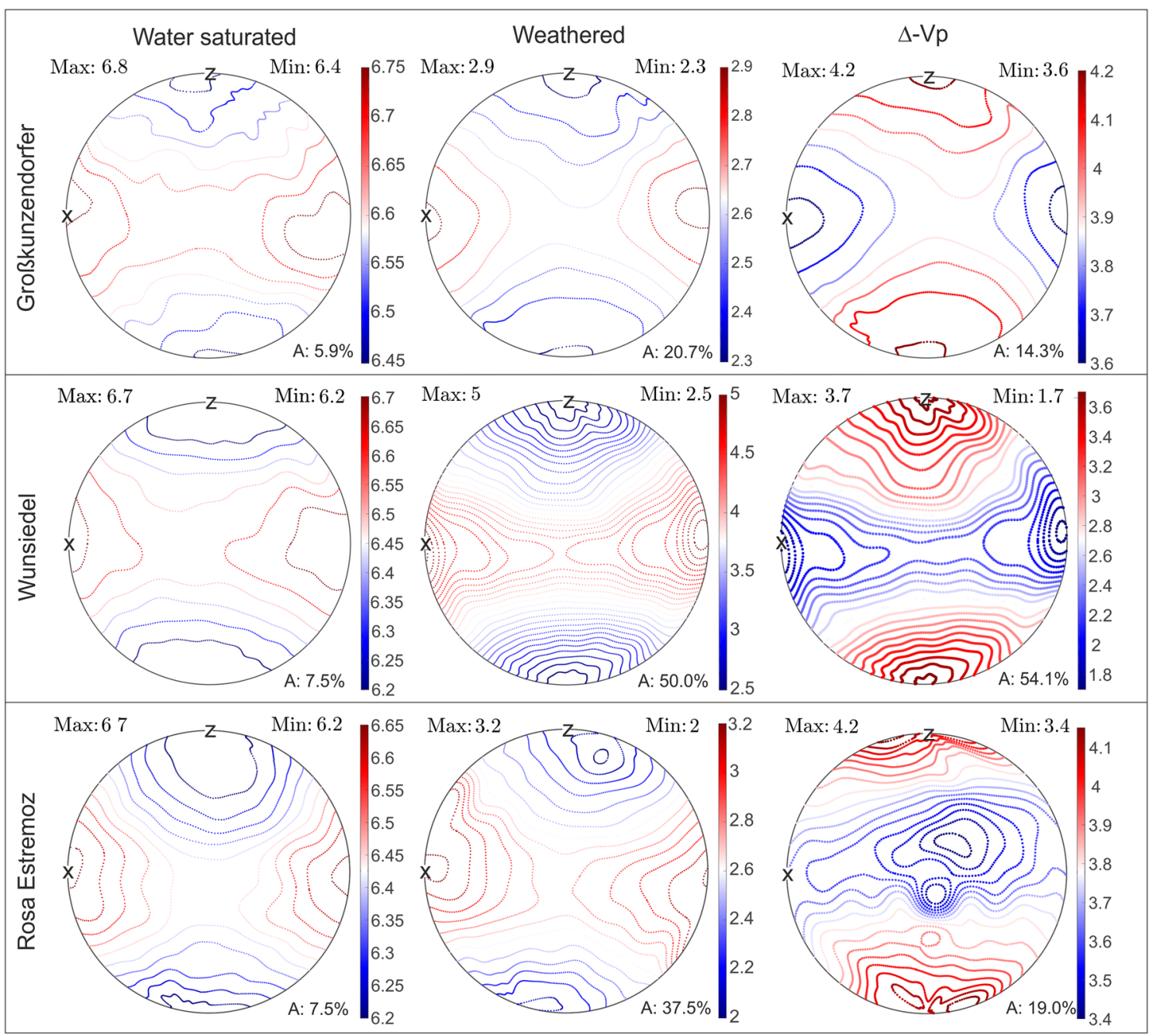

Fig. 13 Velocity distribution $\mathrm{Vp}$ in $\mathrm{km} / \mathrm{s}$ for the varieties Großkunzendorf, Wunsiedel and Rosa Estremoz. The plots show the distributions for the water-saturated state (left side) the weathered, dry sample $\left(200^{\circ} \mathrm{C}\right)$ in the middle and $\Delta \mathrm{Vp}$, the calculated difference between saturated and weathered

evolution could be observed for almost all analyzed samples. With increasing weathering state, the velocity distribution adapts to the intrinsic distribution and amplifies it.

\section{Relationship of velocity and porosity}

That a decreasing compressive wave velocities correlates with a porosity increase is known and was described by different authors (Mahmutoğlu 2017; Rüdrich 2003; Rüdrich et al. 2013; Siegesmund et al. 2010; Weiss et al. 2002a). The analyzed marble varieties were examined with regard to this relationship. In Fig. 15, the mean value for the different weathering states are given for the Blanco Macael (BM), Lasa (LA), Carrara Gioia (GI), and the Großkunzendorf (GK). The results for the Wunsiedel are not inserted, as they show a huge standard deviation and complicate the readability of the graph. Each weathering state is labeled with tern increases the intrinsic anisotropy. This exemplaric crack 


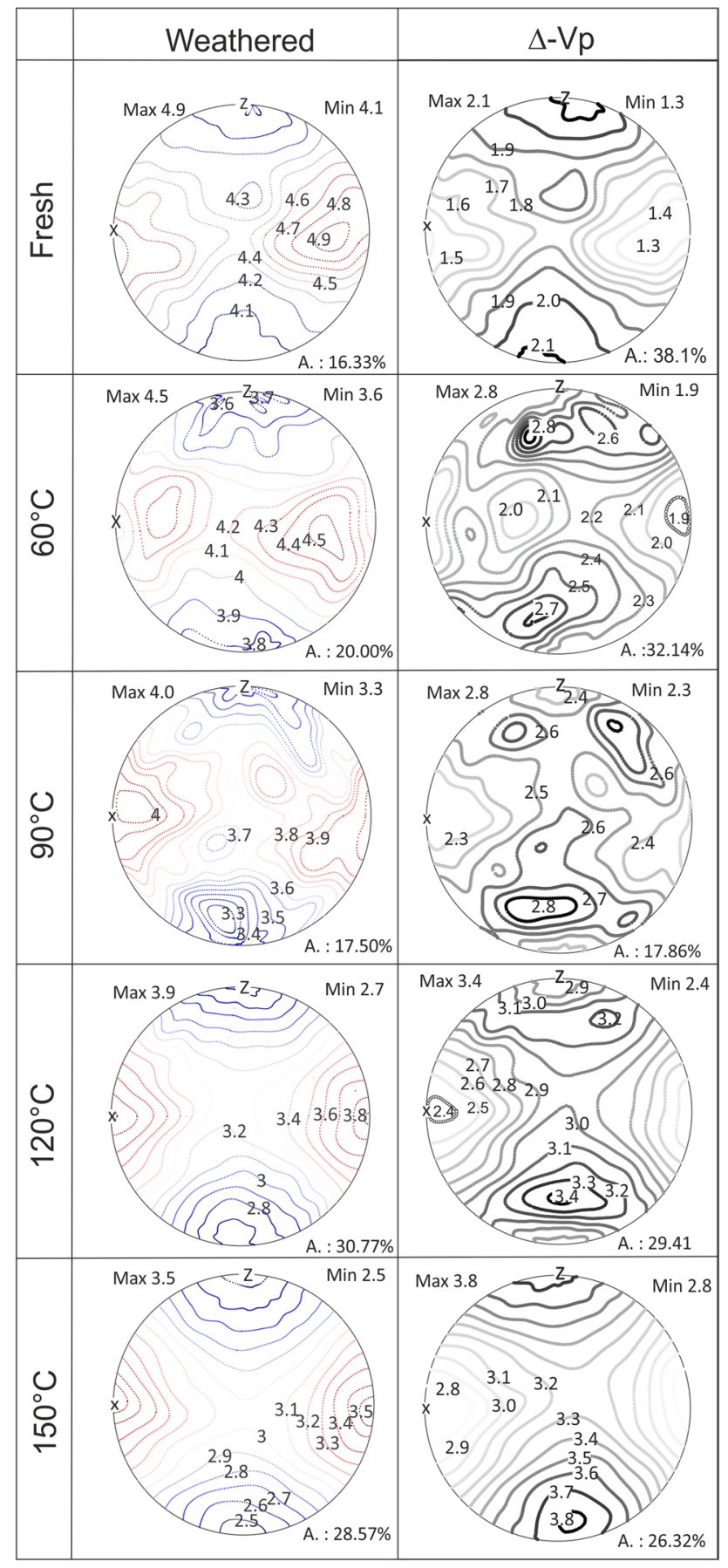

Fig. 14 Development of the velocity distribution $\mathrm{Vp}(\mathrm{km} / \mathrm{s})$ for each weathering step under dry conditions (left side) and the evolution of the $\Delta$ - $\mathrm{Vp}$-Plot in proportion to the water-saturated state (right side) for the Blanco Macael

a roman number $(0-\mathrm{VI})$, while $(0)$ indicates the unweathered state, (I) the heating cycle up to $60^{\circ} \mathrm{C}$, (II) $90^{\circ} \mathrm{C}$, (III) $120{ }^{\circ} \mathrm{C}$, (IV) $150{ }^{\circ} \mathrm{C}$, (V) $200{ }^{\circ} \mathrm{C}$, and (VI), the heating up to $200{ }^{\circ} \mathrm{C}$, and an additional freeze cycle. To improve the readability, each weathering cluster is labeled by a circle.
It can be observed that each weathering cycle causes a low porosity increase, starting around $0.1-0.2 \%$ and $4-6 \mathrm{~km} / \mathrm{s}$ and increases to almost $0.9 \%$ and velocities between 1 and $3 \mathrm{~km} / \mathrm{s}$. The Blanco Macael shows the biggest porosity increase by heating up to $200{ }^{\circ} \mathrm{C}(\mathrm{V})$, while the following cycle (VI) causes a low further porosity increase. The combination of heating and freezing (VI) has the biggest influence on the porosity of the GI and GK, while this effect is less distinct for the Lasa. The strongest impact can be stated for the Großkunzendorf marble; here, every weathering step causes an increase of porosity, much higher than the one before, with a low range within each weathering group. Whereas the Carrara Gioia shows a clear influence of the combination heating and freeze (VI), the antecedent cycles cause relatively small changes between 4.1 and $2.1 \mathrm{~km} / \mathrm{s}$ and a porosity between 0.32 and $0.59 \%$. The relationship of the compressive wave velocity and the porosity was analyzed by different authors. Köhler 1991 developed a correlation function between velocity and porosity which was based on experimental data, determined by numerous measurements on Carrara marble in different weathering states. Weiss et al., 2001 presented a model hypothesis based on the mathematical approach of O'Connell and Budiansky 1974 and include the principle that an existing porosity is formed by different ellipsoidal cracks. His approach considers possible crack geometries as pore aspect ratio defined by a length relationship. Rüdrich et al. 2013 used both approaches to test a data set of 123 marble samples. Their data ranged between 7.0 and $2.0 \mathrm{~km} / \mathrm{s}$ with very low porosities based on very flat cracks with an aspect ratio of 0.005 , which could be correlated to the approach of O'Connell and Budiansky 1974. Two strongly weathered samples showed a modification of the crack geometry based on corrosion, what leads to a porosity increase, but has no distinct effect on the ultrasonic velocities. In those cases, Rüdrich et al. 2013 received a correlation to the empirical correlation function of Köhler 1991. They concluded that purely mechanical crack formation follows the model approach of O'Connell and Budiansky 1974 and thereby requires a very small porosity increase with a strong velocity decrease. As soon as the fabric is affected by disintegration, solution processes can become active and modify the microcracks. They assume that in those cases, a strong porosity increase correlates to a relatively small velocity reduction. To see how the determined data should be interpreted within this context, Fig. 16 shows the average compressional wave velocities for all analyzed marble varieties within the artificial alteration under dry conditions. The correlation of velocity and porosity after Köhler 1991 is given in red, the theoretical predictions according to the models of O'Connell and Budiansky 1974 are given as black hatched lines. According to the results of Rüdrich 2003, Rüdrich et al. 2013, and Weiss et al. 2001, all samples follow the model approach of O'Connell and Budiansky 1974 
Fig. 15 Correlation of the ultrasonic velocities and porosity in the course of the velocity reduction caused by artificial alteration

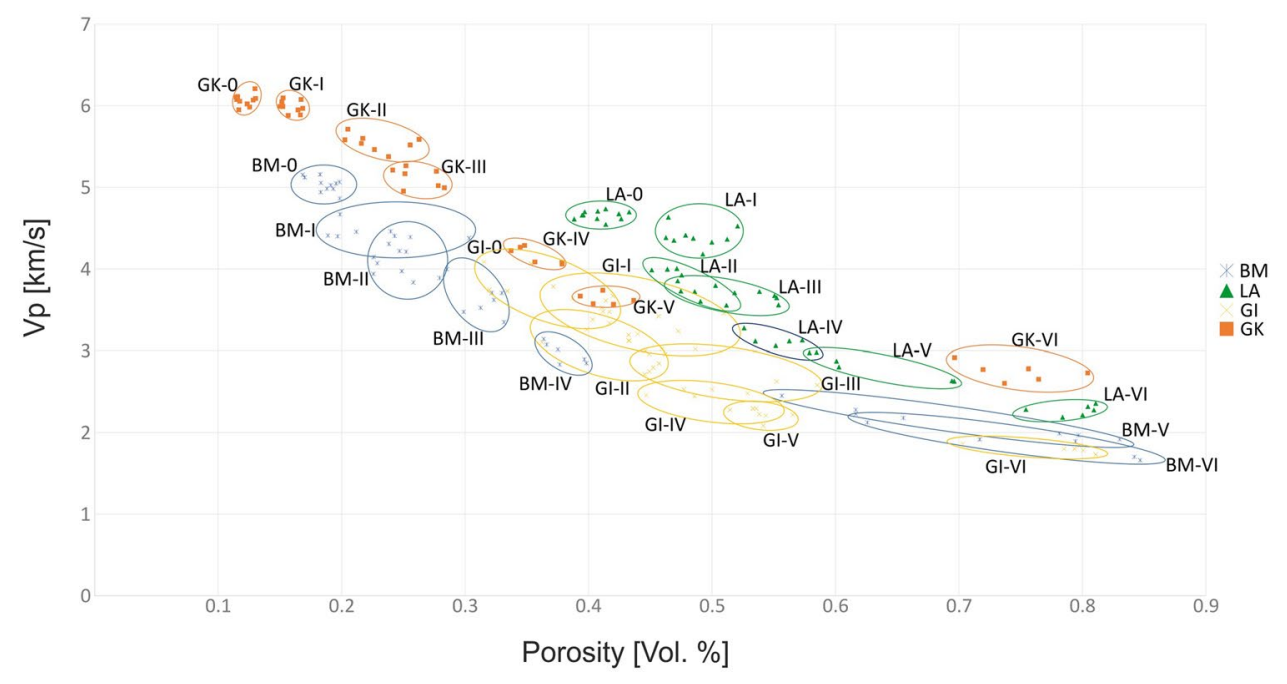

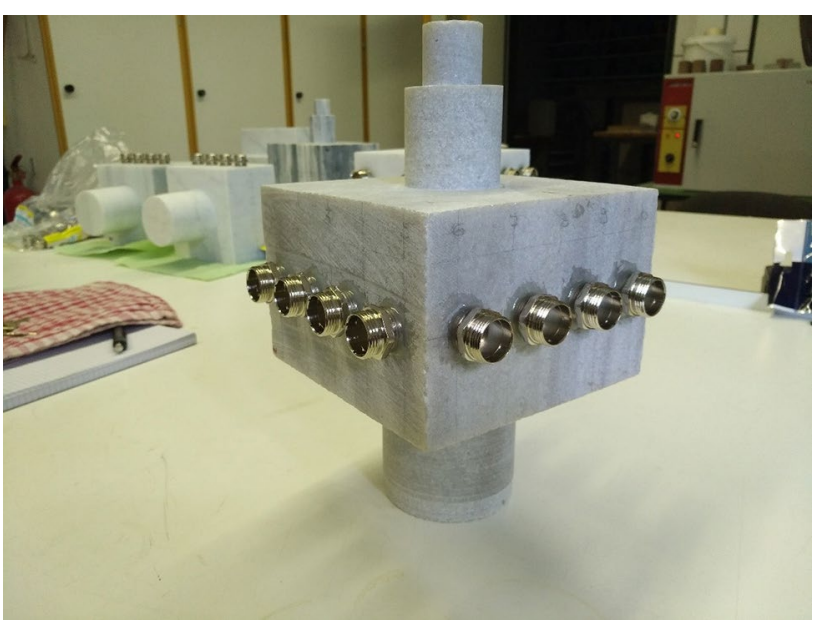

Fig. 17 Phantom made of Großkunzendorf marble

example, strongly deteriorated Blanco Macael shows clear signs of total granular disintegration.

\section{Experimental tomography}

For an in-depth knowledge with regard to the development of a tomogram throughout an alteration, phantoms made of Blanco Macael, Carrara Gioia, Lasa, Großkunzendorf, and Wunsiedel marble were manufactured. Those five samples were prepared according to the known spatial orientation of the fabric elements and transferred to the reference coordinate system. The phantoms were made out of the same block as all the other specimens to ensure comparable conditions, to determine the weathering behavior by ultrasonic tomography with well-known material properties during the course of artificial weathering (Fig. 17). A methodical recording of the weathering behavior needs constant test conditions. To ensure these conditions, the ultrasonic transducer was fixed 


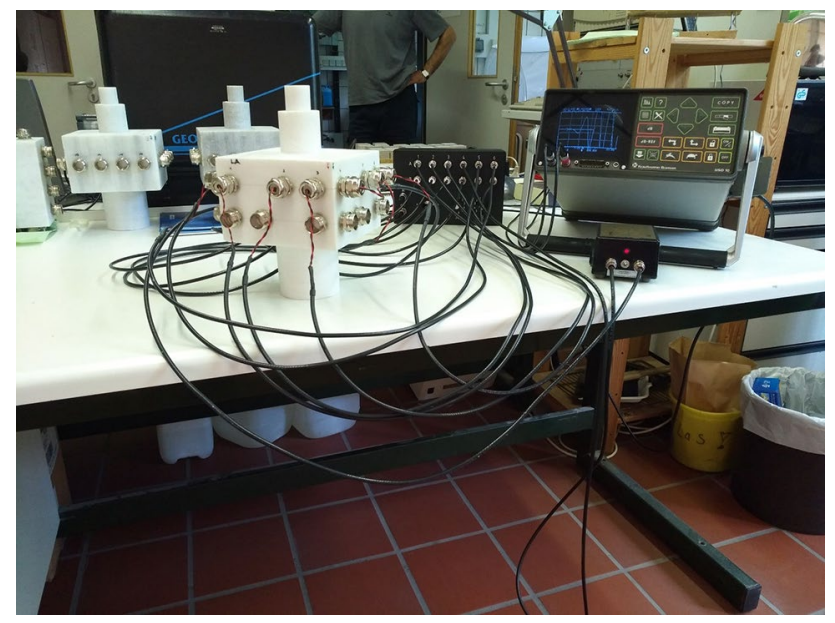

Fig. 18 Marble phantom with the fixed different probe positions connected to the ultrasound generator

on the surface. This required the use of numerous ultrasonic transducers, which have been developed with a frequency of $1 \mathrm{MHz}$. The transducers were connected to a multiplex which allowed the switching through the different probe positions (Fig. 18). With this equipment, a repeatability under stable conditions was ensured.

Figure 19 shows the modeled tomograms of the marble phantoms in their previous state without consideration of the anisotropy and on the right considering the final percentage of anisotropy. It can be observed that for all samples, a certain degree of anisotropy already has to be considered under unweathered conditions. This correlates very well with the data obtained from the systematic measurements of the cubes and spherical samples (see Tables 4 and 5). Only the unweathered sample of Großkunzendorf (Fig. 19), needs no consideration of anisotropy. This decision was made on basis of the distribution patterns for the root-mean-square (RMS) residuals, which are provided by the software GeoTomCG.

The velocities range between $3.8 \mathrm{~km} / \mathrm{s}$ for the Carrara Gioia and $6.5 \mathrm{~km} / \mathrm{s}$ for the Wunsiedel marble. The orientation of all tomograms is the same, while the direction of the lowest velocities correlates with the Z-direction. The anisotropy ranges between 0\% (Großkunzendorf) and 20\% (Wunsiedel), causing relatively homogeneous tomograms. The irregularities that occur at the edges of the tomograms are triggered by the receiver positions and an increased number of rays and are not caused by the marble itself.

While all tomograms show elongated zones of higher velocities tending to the $\mathrm{Z}$-direction, there is one area with lower velocities tending to the $\mathrm{X}$-direction, which can be observed for the Wunsiedel marble. In this area, macroscopically visible healed cracks can be observed, influencing the velocity.
After the marble phantoms were recorded tomographically in their previous state, they were artificially alterated by thermal stress and then measured again. For all marble varieties, a higher degree of anisotropy results from an increasing weathering state, which corresponds with the systematic observations of the other samples. In Figs. 20 and 21, the tomogram evolution is given for the Blanco Macael and the Carrara Gioia. Exemplaric for the other samples, the Blanco Macael is depicted as a case where a high anisotropy (50\%) needs to be considered for the tomographic inversion. The Carrara Gioia still has a high anisotropy of $20 \%$, but was depicted to show the effect of the application of higher anisotropies than necessary. Furthermore, it is shown that by taking the anisotropy into account, previously occurring zoning is put into perspective. This is an important aspect that leads to misinterpretations if not considered. In particular, Fig. 20 shows the large transformation for the velocity distribution of the Blanco Macael after recalculation of the weathered tomogram with 50\% anisotropy (Fig. 20). The previously occurring low-velocity channels are relativized and bond to a considerably more homogeneous distribution, which also shows higher velocities than in the isotropic representation. A comparable evolution can be observed for the Carrara Gioia with an increasing homogeneity until the necessary amount of anisotropy was chosen with $20 \%$. As soon as this percentage becomes exceeded, a new channel of higher velocities appears (Fig. 21). The shown tomograms demonstrate that the anisotropy has a large influence and definitely needs to be determined and well chosen as otherwise misinterpretations are possible.

\section{Dynamic Young's modulus}

The dynamic Young's modulus (Edyn) was determined based on the ultrasonic velocities for the cubes (Table 4) with a frequency of $350 \mathrm{kHz}$. The Poisson's ratio was calculated and ranged between 0.296 and 0.303 , while the shear wave data were determined on basis of the modeled textural velocities. The Edyn varies between $25.2 \pm 2.9 \mathrm{kN} / \mathrm{mm}^{2}$ for the Carrara Gioia and $71 \pm 1.6 \mathrm{kN} / \mathrm{mm}^{2}$ for the Großkunzendorf in the unweathered state (Fig. 22). Each weathering step causes a clear reduction of the Young's modulus and decreases to values between $6 \pm 0.3 \mathrm{kN} / \mathrm{mm}^{2}$ for the Carrara Gioia and $25 \pm 4.6 \mathrm{kN} / \mathrm{mm}^{2}$ for the Wunsiedel. The highest reduction can be observed for the Blanco Macael with $85.91 \%$ and the lowest for the Wunsiedel marble with $62.3 \%$ and is for all samples almost linear. As the dynamic Young's modulus describes the elasticity of a material and its resistance to deformation, all marble types show a strong decrease within this property. 
Fig. 19 Tomograms investigated for the dummies in the unweathered state. The isotropic tomograms are given in the left column, while the anisotropic tomograms are shown in the right column by using the GeoTom code (GeoTomLLC 2020). The amount of anisotropy is given below the tomograms. Velocities are given in $\mathrm{km} / \mathrm{s}$
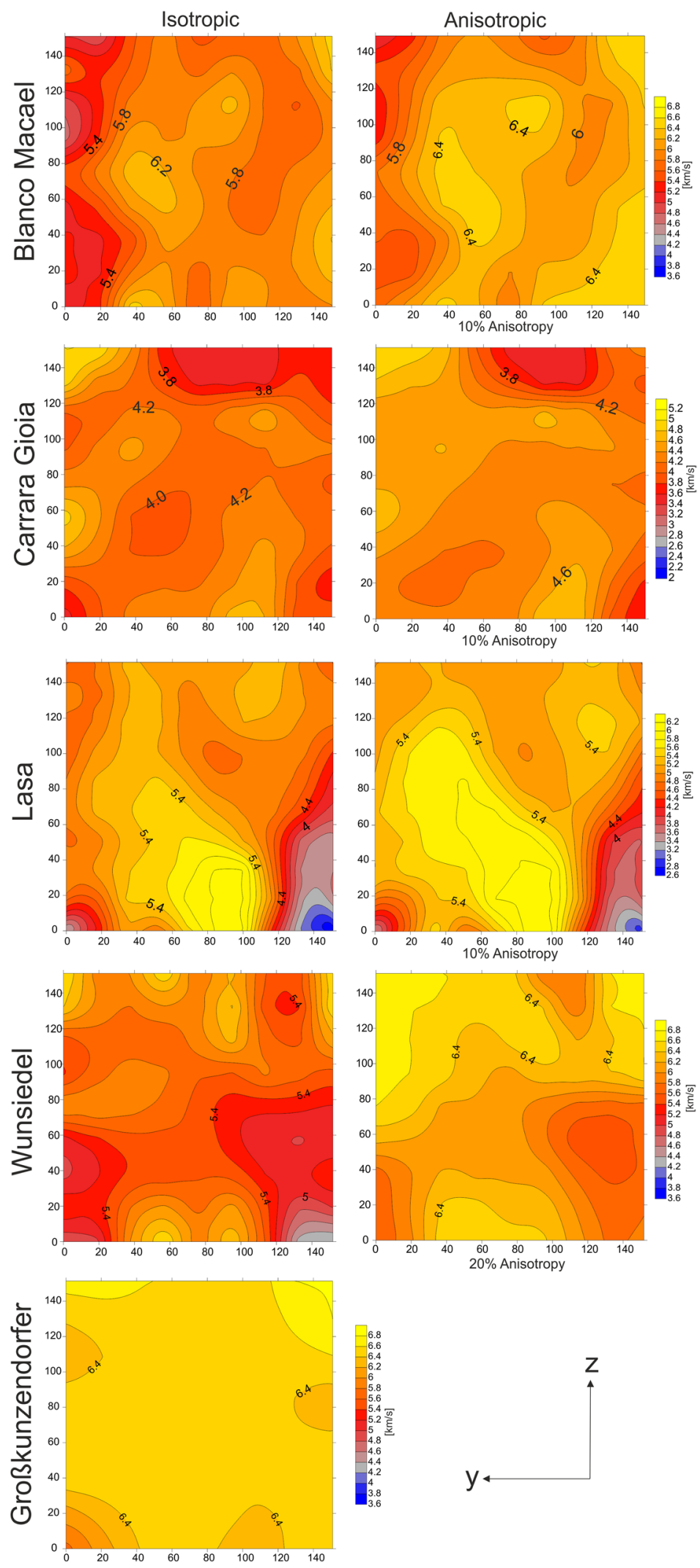


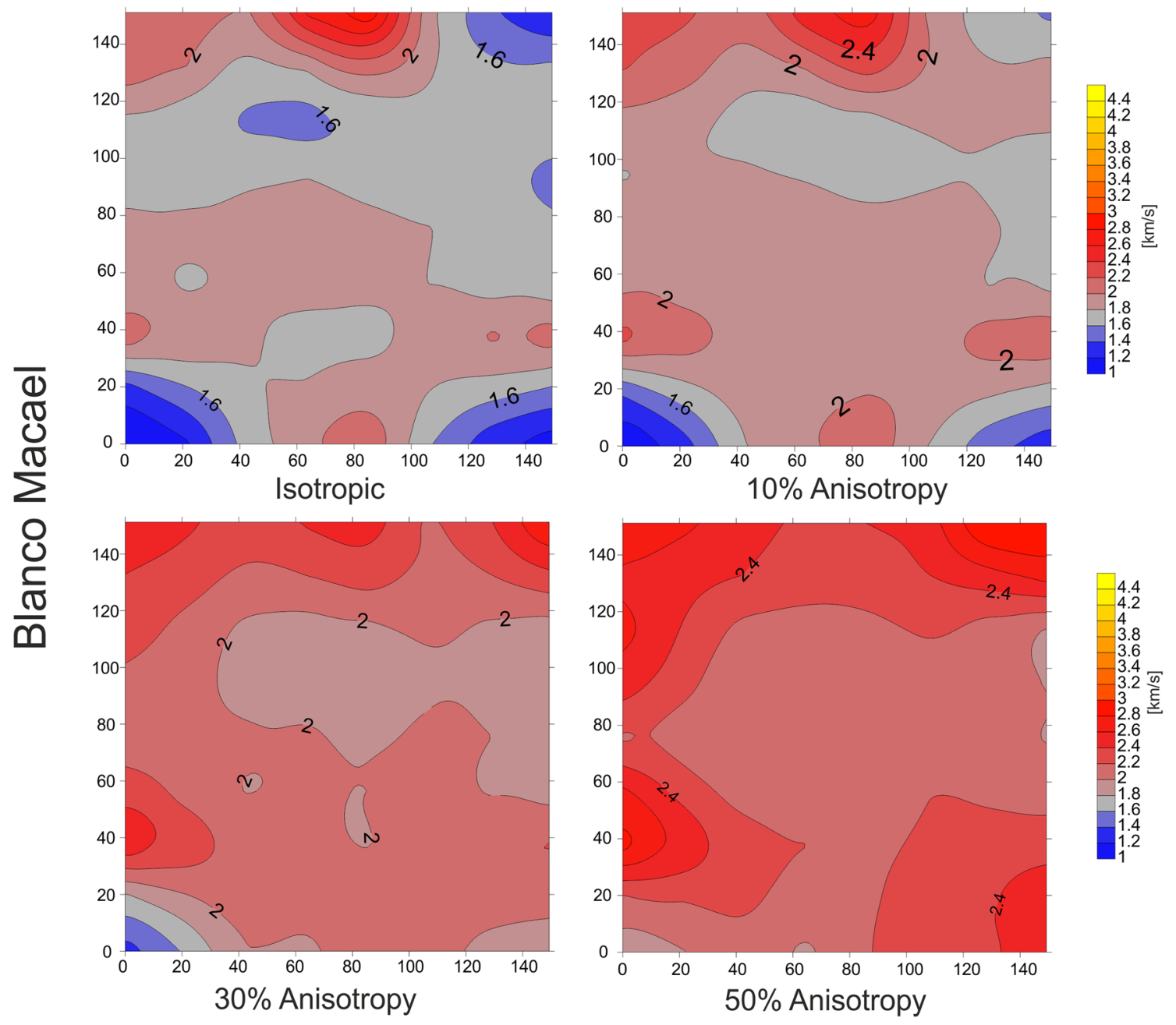

Fig. 20 Tomograms for the weathered Blanco Macael with different amounts of anisotropy (\%)

\section{Thermal dilatation}

The specific weathering behavior of marble is based on the thermal properties of calcite and dolomite. Main influencing parameter is the lattice preferred orientation where, according to a pronounced texture, the single crystal properties influence the properties of the whole rock. The calcite single crystal properties are not only anisotropic regarding their ultrasonic wave velocities, but also for the thermal dilatation coefficient $\alpha$. While heating leads to an expansion parallel to the c-axis, it causes contraction parallel to the a-axes. A strong texture leads to an expansion of the marble sample according to the preferred orientation of the c-axis and a less intense expansion or contraction according to the preferred orientation of the a-axes. As the expansion and contraction affect the grain-to-grain contacts even within a small temperature range (Battaglia et al. 1993) and may cause an irreversible length change (Luque et al. 2010; Rüdrich et al. 2002; Rüdrich 2003; Shushakova et al. 2013; Siegesmund et al. 2000; Tschegg et al. 1999; Zeisig et al. 2002), the application of thermal cycles is a good instrument to determine the weathering vulnerability of marble. The thermal dilatation, $\varepsilon(\mathrm{mm} / \mathrm{m})$, as a function of temperature describes the expansion behavior during thermal exposure and was analyzed simultaneously for six specimens using a pushrod dilatometer. For these investigations, six specimens in $\mathrm{X}$-, Y- and Z-direction as well as in XY-, XZ-, and YZdirection, according to the reference system, were measured for each marble type. The samples were heated from 20 to $90{ }^{\circ} \mathrm{C}$ and subsequently cooled down to $20{ }^{\circ} \mathrm{C}$. To ensure the equilibration of the samples, heating and cooling was performed with a velocity of $1{ }^{\circ} \mathrm{C} / \mathrm{min}$, while the maximum and minimum temperature was hold for $6 \mathrm{~h}$. This cycle was performed for four times and used to calculate the thermal dilatation coefficient $\alpha$. The results are plotted in Fig. 23 and shown for all investigated marble samples in context with their texture. It can be stated that the thermal expansion for all marble varieties shows a clear directional dependency 


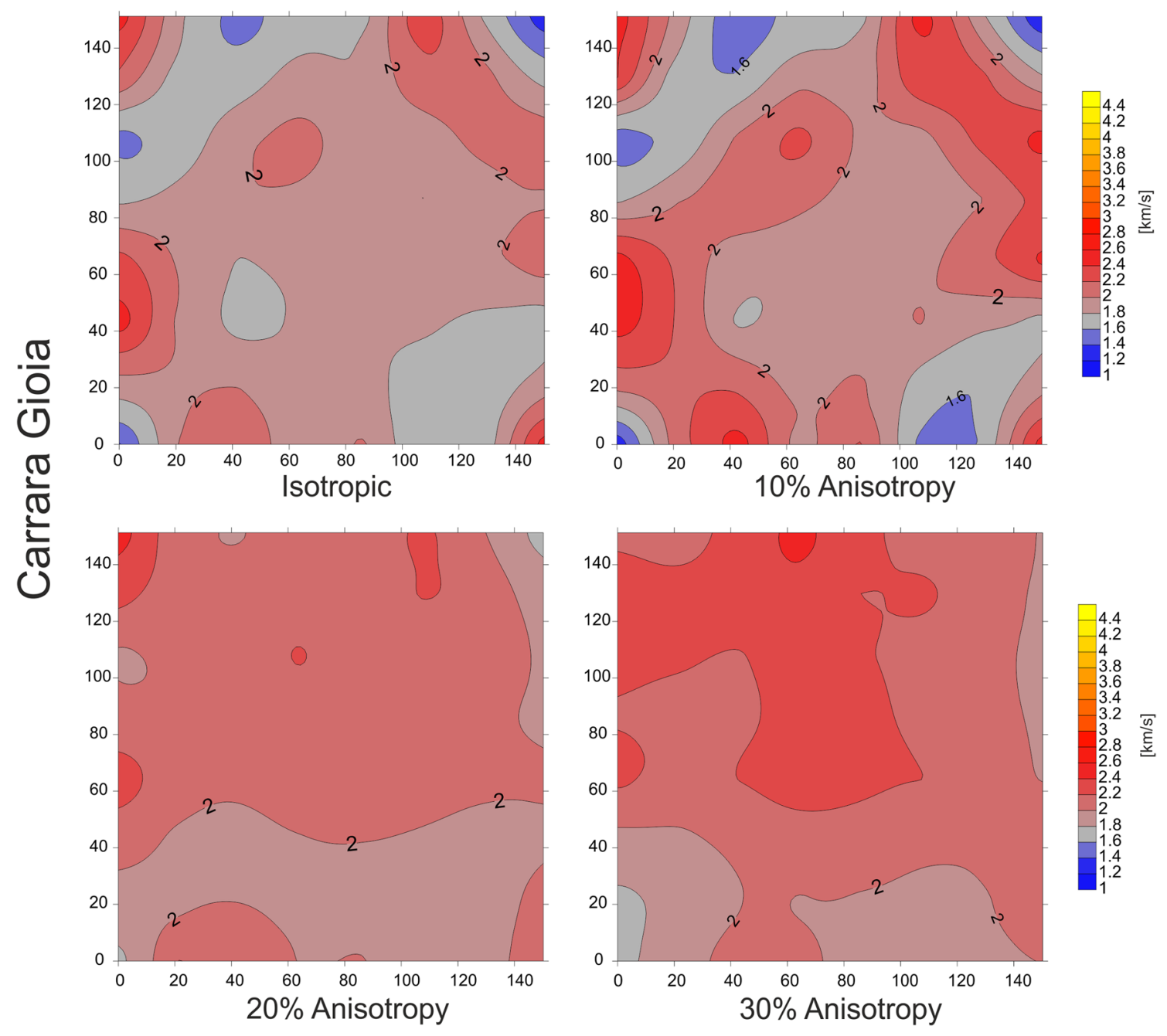

Fig. 21 Tomograms for the weathered Carrara Gioia with different amounts of anisotropy (\%)

Fig. 22 Evolution of the dynamic Young's modulus within the artificial alteration

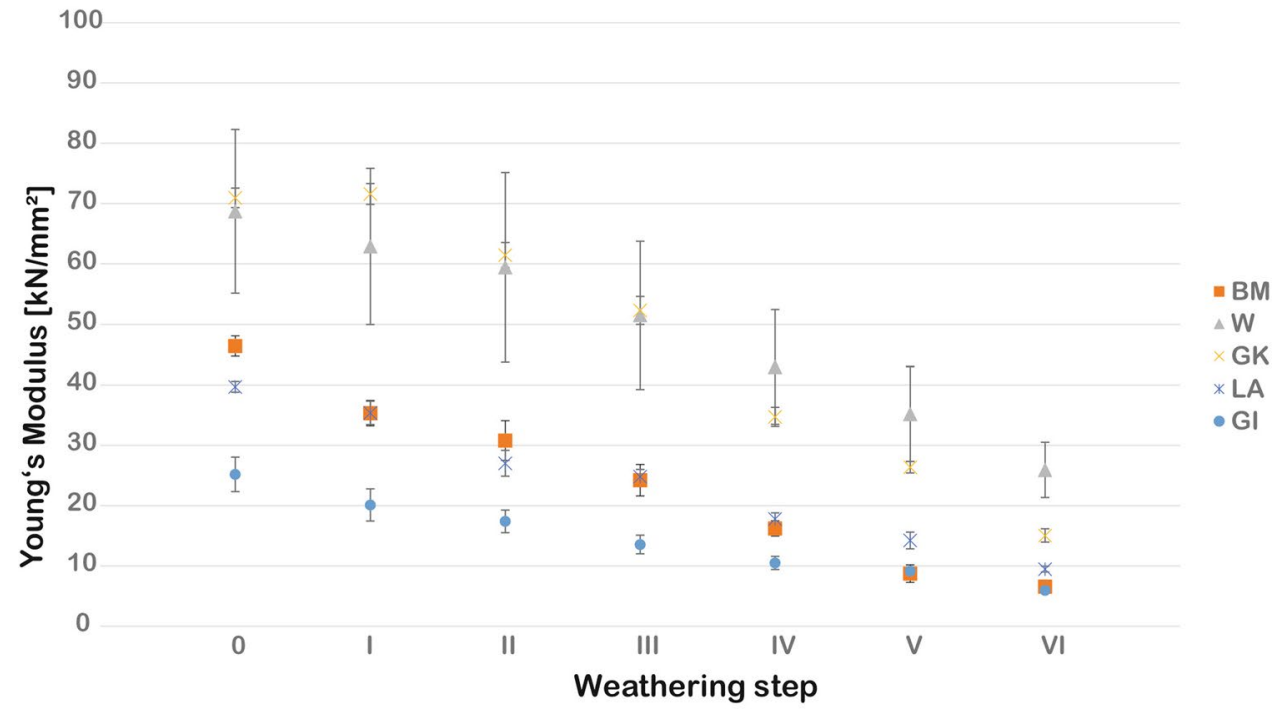


Fig. 23 Thermal dilatation $\varepsilon$ $(\mathrm{mm} / \mathrm{m})$ shown as a loop of hysteresis with directional dependence (left graphs and middle) and pole figures of the lattice preferred orientation for c- and a-axis (right plots), for the specimens

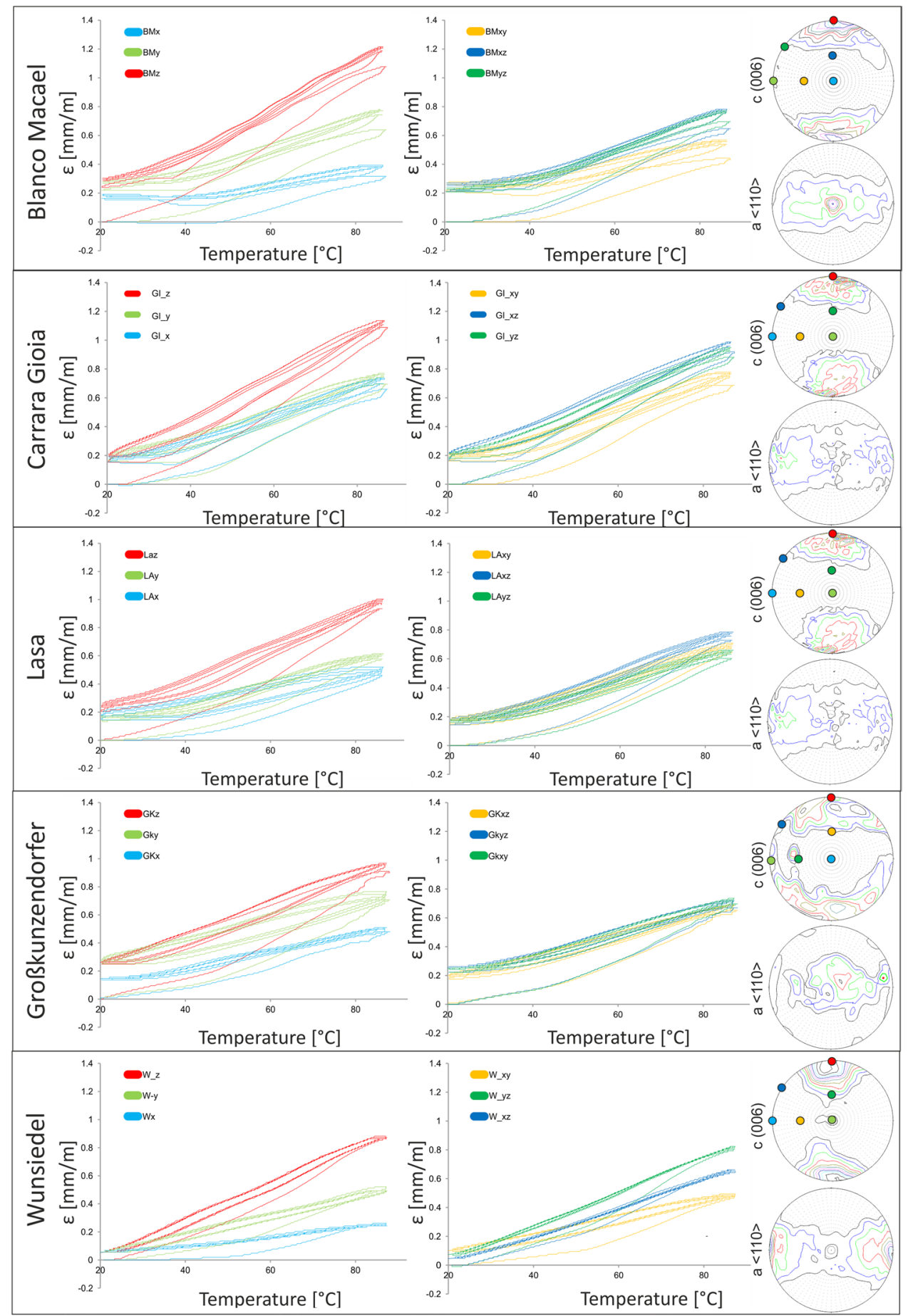

according to the crystallographic preferred orientation, represented by the pole figures of the $\mathrm{c}$ - and a-axis distribution. Each sample shows the highest expansion in Z-direction, perpendicular to the foliation plane, which correlates with the direction of the highest intensity of the c-axis maxima, while the lowest expansions can be found along the a-axes in X-direction. All marbles show a more or less pronounced anisotropy of expansion in relation to the spatial position of the test specimens taken, which is primarily reflected in the main directions ( $\mathrm{X}, \mathrm{Y}$, and $\mathrm{Z}$ ). The minor directions show a significantly less pronounced anisotropy, depending on how close the specimen location is to the respective aand c- axis maxima. The Wunsiedel marble shows the most obvious variation, with different expansion rates in all six sample directions. Basically, in the first cycle, a successive increase of the slope until the maximum heating temperature can be observed for all samples and directions. Within this cycle, the slope of the hysteresis curve is flatter until a 
Table 7 Thermal dilatation coefficient $\alpha\left[10^{-6} \mathrm{~K}^{-1}\right]$ under dry conditions

\begin{tabular}{|c|c|c|c|c|c|c|c|c|}
\hline Marble & Cycle & $\begin{array}{l}x \\
\alpha\left[10^{-6} \mathrm{~K}^{-1}\right]\end{array}$ & $y$ & $z$ & $\mathrm{xz}$ & $\mathrm{yz}$ & xy & $\begin{array}{l}\text { Anisotropy } \\
\mathrm{A}_{\alpha} \%\end{array}$ \\
\hline \multirow[t]{2}{*}{ Blanco Macael } & 1 st. cycle & 4.77 & 9.62 & 16.23 & 9.75 & 10.47 & 6.52 & 70.61 \\
\hline & $2-4$ th cycle & $3.15 \pm 0.09$ & $7.82 \pm 0.23$ & $14.20 \pm 0.09$ & $8.12 \pm 0.18$ & $8.38 \pm 0.01$ & $4.64 \pm 0.09$ & 77.81 \\
\hline \multirow[t]{2}{*}{ Gioia } & 1st.cycle & 9.75 & 10.42 & 16.19 & 10.31 & 13.08 & 13.65 & 39.78 \\
\hline & $2-4$ th cycle & $8.42 \pm 0.07$ & $8.65 \pm 0.10$ & $14.20 \pm 0.16$ & $11.67 \pm 0.08$ & $11.14 \pm 0.11$ & $8.67 \pm 0.02$ & 40.93 \\
\hline \multirow[t]{2}{*}{ Lasa } & 1 st. cycle & 6.83 & 8.73 & 14.15 & 11.04 & 9.13 & 9.70 & 54.91 \\
\hline & 2-4th cycle & $4.77 \pm 0.11$ & $6.58 \pm 0.11$ & $11.42 \pm 0.22$ & $9.30 \pm 0.11$ & $7.23 \pm 0.10$ & $7.86 \pm 0.01$ & 58.23 \\
\hline \multirow[t]{2}{*}{ Großkunzendorf } & 1st. cycle & 6.95 & 10.25 & 13.17 & 9.41 & 9.68 & 10.09 & 47.23 \\
\hline & 2-4th cycle & $5.61 \pm 0.27$ & $6.47 \pm 0.21$ & $10.45 \pm 0.10$ & $7.27 \pm 0.07$ & $7.19 \pm 0.03$ & $7.50 \pm 0.04$ & 46.32 \\
\hline \multirow[t]{2}{*}{ Wunsiedel } & 1st. cycle & 3.82 & 7.60 & 13.05 & 10.01 & 12.16 & 7.04 & 70.73 \\
\hline & 2-4th cycle & $2.87 \pm 0.09$ & $6.47 \pm 0.10$ & $12.32 \pm 0.02$ & $9.18 \pm 0.16$ & $11.29 \pm 0.07$ & $5.70 \pm 0.08$ & 76.70 \\
\hline
\end{tabular}

Displayed are the coefficient for the first cycle and the average values for the 2nd-4th cycle under dry conditions for every direction, calculated from the increasing part of every $20^{\circ}-90^{\circ}-20^{\circ} \mathrm{C}$ cycle

temperature of $40-60^{\circ}$. After this part, the curve starts to become steeper. As soon as the cooling phase is started, the curve declines almost linear until lower temperatures of about $40{ }^{\circ} \mathrm{C}$ have been achieved. In this temperature range, the temperature continues to decrease, while the contraction does not progress. This phenomenon can be clearly observed for the Blanco Macael and the Carrara Gioia and is less pronounced for the Großkunzendorf and the Lasa marble. The Wunsiedel shows the same phenomenon, while it is only weakly pronounced. The latter explain the flatter increase in a lower temperature range with a buffering effect due to already existing microcracks. With increasing temperature, this effect declines, and the coefficient increases. The result of this cycle is an irreversible length change; therefore, this phase seems to be the crack initializing. For the second-tofourth cycle, the slope of the hysteresis curve is more linear, and the expansion and contraction shows almost the same temperature-dilatation rate. According to this, the first cycle shows the highest $\alpha$-coefficients (Table 7), defined by the gradient of the slope, whereas they are lower for the second cycle and remain approximately constant for the following cycle. The smallest value in the first cycle was determined for the Wunsiedel $\left(3.82 \times 10^{-6} \mathrm{~K}^{-1}\right.$ in X-direction) and the highest for Blanco Macael $\left(16.23 \times 10^{-6} \mathrm{~K}^{-1}\right.$ in Z-direction). Cycles $2-4$ show a range between $2.87 \times 10^{-6} \mathrm{~K}^{-1}$ (X-direction Wunsiedel) and $14.2 \times 10^{-6} \mathrm{~K}^{-1}$ (Z-direction) determined for the Blanco Macael and Carrara Gioia. The $\alpha$-coefficients of the other directions are somewhere between the values of the $\mathrm{Z}$ - and $\mathrm{X}$-directions, which can also be observed by the expansion intensity. The variation intensity in every direction for one sample represents an anisotropic rock property and shows with $\mathrm{A} \alpha 77.81 \%$ [A $\alpha=$ $\alpha \max -\alpha \min ) / \alpha \max * 100(\%)]$ the highest anisotropy for the Blanco Macael, whereas the lowest anisotropy was measured for the Carrara Gioia with A $\alpha 40.93 \%$ (Table 7).

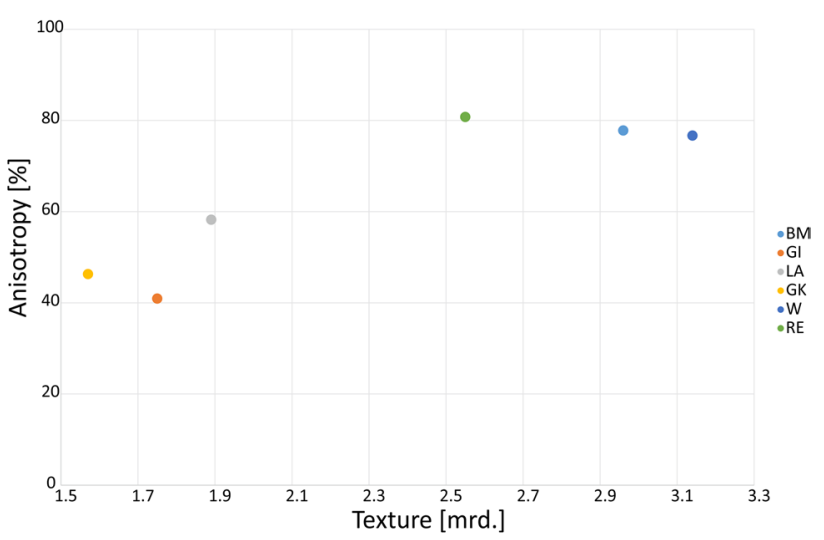

Fig. 24 Correlation of the anisotropy for the thermal expansion and the texture

The directional dependence of the thermal dilatation is strongly influenced by the texture and the resulting amount of anisotropy can be correlated with the texture (see Fig. 24). As stronger the intensity of the c-axis maximum, as higher the anisotropy. These findings agree with the results by Koch 2006, who analyzed an almost linear trend of the function anisotropy/texture. While there is a correlation between the amount of anisotropy and the texture, the amount of maximum expansion is independent from the texture intensity.

A particularly weathering relevant aspect of the graphics in Fig. 23 is the measure of the residual strain, the irreversible length change after the heating cycle. Here, all samples show a certain measure of the residual strain ( $(\varepsilon R S)$, whereby the Wunsiedel marble shows the lowest residual strain and the Großkunzendorf the highest. As described before, the first cycle leads to an irreversible length change, which hardly increases under dry conditions. Comparable data were obtained by Koch and Siegesmund 2004, who 
Fig. 25 Residual strain $\varepsilon R S(\mathrm{~mm} / \mathrm{m})$, curves indicate X- (blue), Y(green), and Z- (red) direction. Progressive increase of residual strain of the Blanco Macael, Carrara Gioia, Lasa, Großkunzendorfer, and Wunsiedel marble, investigated as a function of the number of heating cycles under dry (4 cycles, red background) and wet (5 cycles, blue background) conditions

also described that the same cycles under hygrothermal conditions can, however, reactivate and increase this irreversible expansion. Therefore, the samples were subsequently thermohygrically weathered for five further cycles. For this purpose, the samples were again cyclically heated from 20 to $90{ }^{\circ} \mathrm{C}$ and cooled down under implementation of water into the system at $20^{\circ} \mathrm{C}$ (Fig. 25) shows the results of the irreversible residual strain $(\varepsilon R S)$ under thermal (red highlighted) and thermohygric (blue highlighted) load for all marbles in the six directions.

The graphs show that under dry conditions (highlighted in red), the greatest increase of $\varepsilon$ RS occurs in the first heating cycle and is then significantly lower or does not further increase. An exception is the Großkunzendorf, whose curve progression potentially indicates a further increase of $\varepsilon R S$. In contrast, the Wunsiedel shows a very low degree of residual strain and also exclusively after the first heating cycle. Afterwards, no further increase can be observed. All varieties show an anisotropy of residual strain under dry conditions, which is most clearly developed for the Großkunzendorf and Blanco Macael. The thermohygric load (highlighted in blue) leads for all varieties to a further increase of the residual strain. It reaches a maximum value of $0.56 \mathrm{~mm} / \mathrm{m}$ for the Blanco Macael in the Z-direction and at $0.1 \mathrm{~mm} / \mathrm{m}$ in the X-direction of the Wunsiedel marble. The increase in residual strain also seems to have not yet been completed for the varieties Großkunzendorf, Blanco Macael, and Lasa, and therefore, higher values of $\varepsilon$ RS can probably be reached. Apart from the varieties Gioia and Wunsiedel, all marbles show the highest residual strain in Z-direction and a more (Großkunzendorf, Blanco Macael) or less pronounced directional dependence (Gioia, Lasa). Since the residual strain is also influenced by other parameters, such as grain shape and grain boundaries, a simple correlation of the values with the results of the texture analysis is not possible. According to the four types of thermal dilatation (Siegesmund and Dürrast 2014), all tested samples belong to Type IV with an anisotropic $\alpha$ value and residual strain $\varepsilon$ RS.

Thermal degradation in the form of microcracking results in a volumetric expansion of a stone sample. Indeed, bowing of a stone façade panel most likely results from asymmetric microcracking on one side of the panel. Accordingly, microcracking of a stone sample upon heating or cooling will result in a permanent volumetric expansion of a stone sample when it returns to its ambient temperature. This
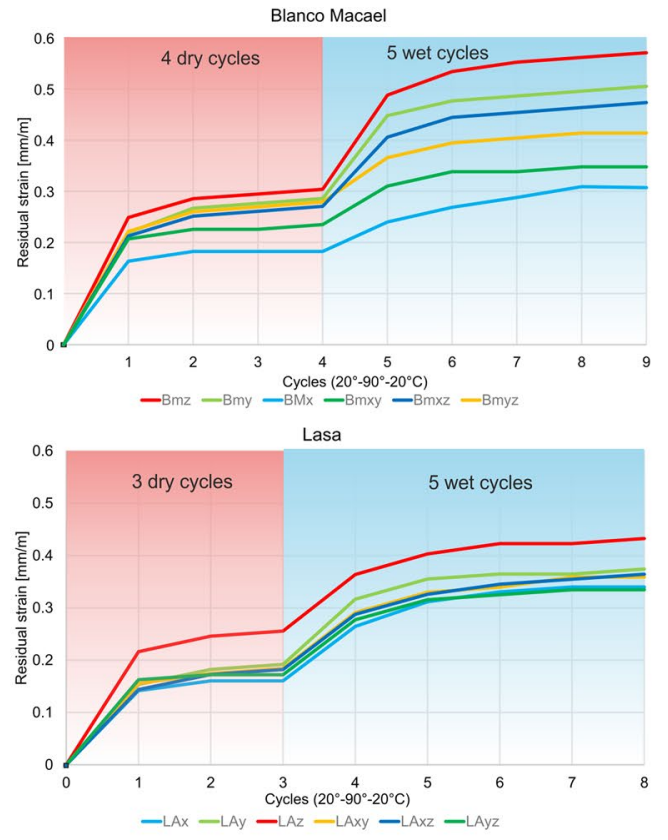

Gioia
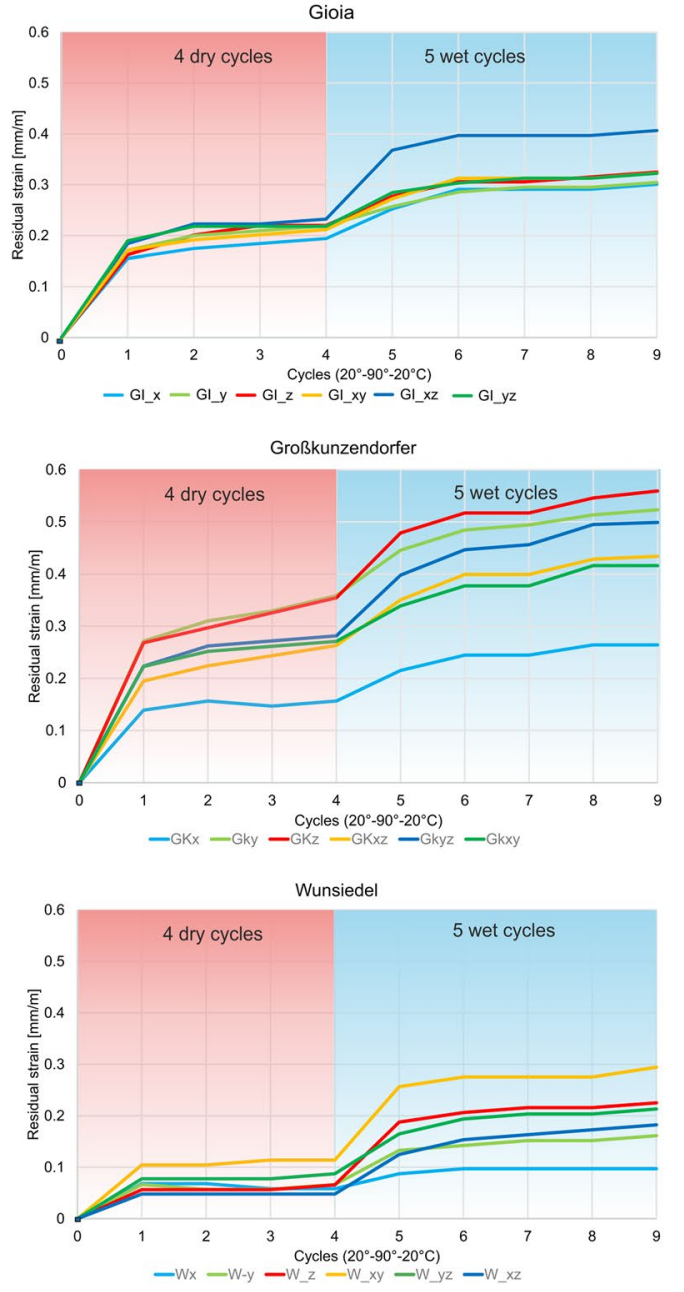
relative volume change as measured by thermal dilation is thus a measure or index of stone degradation. Thus, the overall objective of this approach is to develop a volumetric extension index (a deterioration index) for the characterization of the degradation potential. The index will reflect the relative volume change on the basis of the knowledge of thermal dilatation.

\section{Determination of volume expansion index}

Quantitatively, a continuous surface can be described by the following series of Shushakova (2014):

$$
F\left(x_{1}, x_{2}, x_{3}\right)=a_{0}^{(0)}+a_{\mathrm{i}}^{(1)} x_{\mathrm{i}}+a_{\mathrm{ij}}^{(2)} x_{\mathrm{i}} x_{\mathrm{j}}+a_{\mathrm{ijk}}^{(3)} x_{\mathrm{i}} x_{\mathrm{j}} x_{\mathrm{k}}+\ldots,
$$

where summation over repeated indexes is implied (the Einstein summation convention). The central symmetry implies that only even term will be present. Accordingly, up to fourth-order terms, the continuous surface is described by

$F\left(x_{1}, x_{2}, x_{3}\right)=a_{0}^{(0)}+a_{\mathrm{ij}}^{(2)} x_{\mathrm{i}} x_{\mathrm{j}}+\ldots$

The matrix $a_{\mathrm{ij}}^{(2)}$ has to be symmetric and therefore, given by six independent elements, which can be found if at least six values of $F\left(x_{1}, x_{2}, x_{3}\right)$ are known from the dilatation experiments. In general, the second-order surface describing the shape change is complex surface, but as seen below, is well approximated as an ellipsoid.

In most practical instances, the deformation surface for marble is an ellipsoid to very high accuracy due to the axial symmetry of the deformation with respect to the crystallographic c-axis. Accordingly, the dilatation experiment data are analyzed by the ellipsoidal approximation. The symmetrical second rank tensor $a_{\mathrm{ij}}^{(2)}$ is given by the following matrix:

$a_{i j}^{(2)}=\left(\begin{array}{lll}a_{11}^{(2)} & a_{12}^{(2)} & a_{13}^{(2)} \\ a_{21}^{(2)} & a_{22}^{(2)} & a_{23}^{(2)} \\ a_{31}^{(2)} & a_{32}^{(2)} & a_{33}^{(2)}\end{array}\right)$ and $\begin{array}{r}\mathrm{a}_{13}^{(2)}=\mathrm{a}_{31}^{(2)}, \\ \mathrm{a}_{23}^{(2)}=\mathrm{a}_{32}^{(2)},\end{array}$

Its values can be found from the following set of equations:

$F^{\mathrm{k}}\left(x_{1}^{\mathrm{k}}, x_{2}^{\mathrm{k}}, x_{3}^{\mathrm{k}}\right)=a_{\mathrm{ij}}^{(2)} x_{\mathrm{i}}^{\mathrm{k}} x_{\mathrm{j}}^{\mathrm{k}}, k=1, . ., 6$

Thus, the matrix $a_{i j}^{(2)}$ is defined as

$a_{\mathrm{ij}}^{(2)}=\left(\begin{array}{lll}\varepsilon_{\mathrm{x}} & \varepsilon_{\mathrm{xy}}-\left(\varepsilon_{\mathrm{x}}+\varepsilon_{\mathrm{y}}\right) / 2 & \varepsilon_{\mathrm{xz}}-\left(\varepsilon_{\mathrm{x}}+\varepsilon_{\mathrm{z}}\right) / 2 \\ \varepsilon_{\mathrm{xy}}-\left(\varepsilon_{\mathrm{x}}+\varepsilon_{\mathrm{y}}\right) / 2 & \varepsilon_{\mathrm{y}} & \varepsilon_{\mathrm{yz}}-\left(\varepsilon_{\mathrm{y}}+\varepsilon_{\mathrm{z}}\right) / 2 \\ \varepsilon_{\mathrm{xz}}-\left(\varepsilon_{\mathrm{x}}+\varepsilon_{\mathrm{z}}\right) / 2 & \varepsilon_{\mathrm{yz}}-\left(\varepsilon_{\mathrm{y}}+\varepsilon_{\mathrm{z}}\right) / 2 & \varepsilon_{\mathrm{z}}\end{array}\right)$,

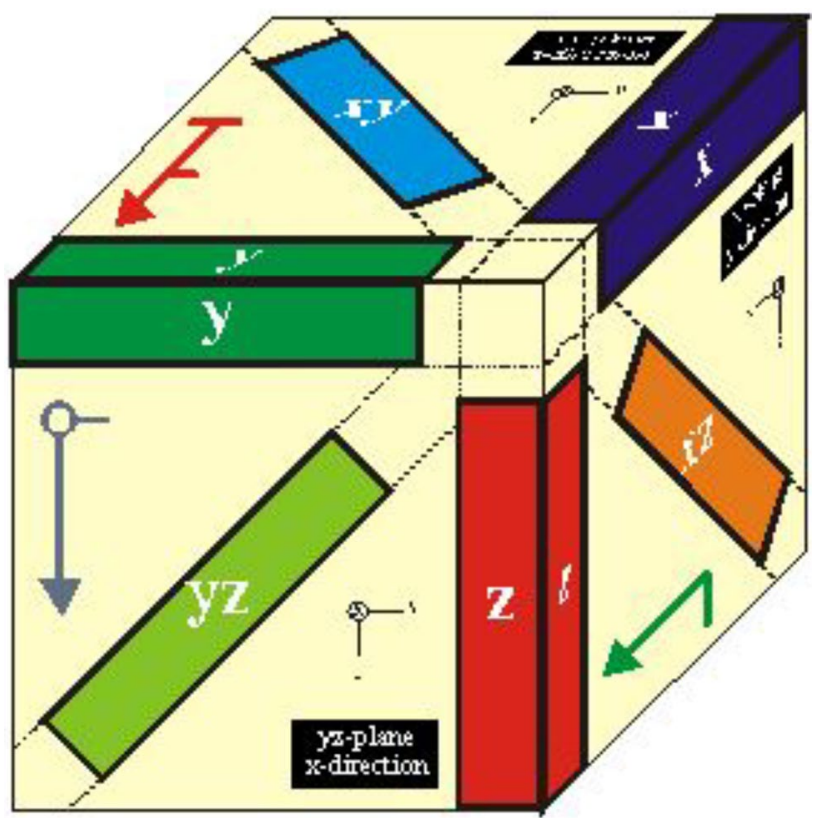

Fig. 26 The choice of cut directions for thermal expansion measurements. X-direction corresponds to lineation and Z-direction is perpendicular to a foliation of sample

where $\varepsilon_{\mathrm{x}}, \varepsilon_{\mathrm{y}}, \varepsilon_{\mathrm{z}}, \varepsilon_{\mathrm{xy}}, \varepsilon_{\mathrm{xz}}, \varepsilon_{\mathrm{yz}}$ are values of residual strain measured in these directions (see Fig. 26).

When the matrix elements are found, it is possible to determine matrix eigenvalues and eigenvectors, by solving the equation:

$a_{\mathrm{ij}}^{(2)} y_{\mathrm{i}}=\lambda_{\mathrm{j}} y_{\mathrm{j}}$.

Each $3 \times 3$ matrix has 3 eigenvectors and 3 corresponding eigenvalues. The relative volume change of the finite deformation is given by the three eigenvalues according to

$\frac{\Delta V}{V}=\left(1+\lambda_{1}\right)\left(1+\lambda_{2}\right)\left(1+\lambda_{3}\right)-1$.

For infinitesimal deformations, the volume change can be approximated by

$\frac{\Delta V}{V} \approx \lambda_{1}+\lambda_{2}+\lambda_{3}$

This value of the relative volume change represents a decay index. A larger value of this index corresponds to greater instability of the material and to its consequent failure upon heating or cooling.

The eigenvalues are also useful in another very important sense, and notably, the smallest eigenvalue is equal to the smallest dilatational strain and the largest eigenvalue is equal to the largest dilatational strain. Additionally, the directions 


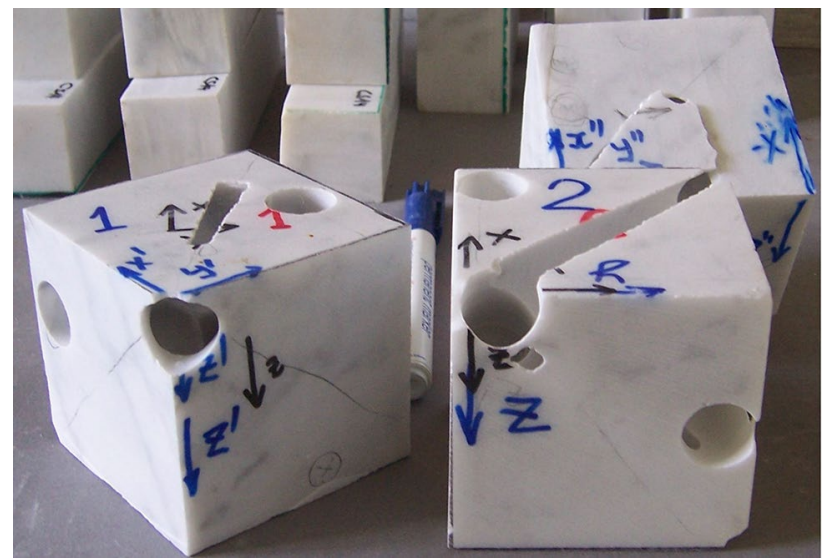

Fig. 27 Samples for thermal expansion experiments, showing the local coordinate system in the blue color and the global coordinate system in the black color. Also seen are holes from where the thermal dilatometry samples were cut
Table 8 Calculated decay index for three cubes after dry and wet conditions

\begin{tabular}{lll}
\hline Cube & \multicolumn{2}{l}{ Decay index } \\
\cline { 2 - 3 } & $\begin{array}{l}\text { After five } \\
\text { dry cycles }\end{array}$ & $\begin{array}{l}\text { After } \\
\text { ten wet } \\
\text { cycles }\end{array}$ \\
\hline Cube 1 & 0.38 & 3.61 \\
Cube 2 & 0.21 & 2.59 \\
Cube 3 & 0.29 & 3.90 \\
\hline
\end{tabular}

Values are multiplied by $10^{-3}$ of corresponding eigenvectors correspond to the directions of minimal and maximal dilatation, respectively. As will be seen below, the samples directions do not necessarily coincide with the directions of minimal and maximal dilatation. The sample choices for the thermal expansion experiments are illustrated in Fig. 26.

To verify the approach of decay, three marble cubes were cut from the same piece of Carrara marble (See Fig 27, Table 8). From each cube, six samples (X-, Y-, Z-, XZ-, $\mathrm{XY}$-, and YZ-direction) were cut for the thermal dilatation measurements.

\section{Results and discussion: verification of the approach}

Five repetitive heating-cooling cycles under dry conditions and afterwards ten cycles under water-saturated conditions were carried out (see Koch and Siegesmund 2004). The thermal dilatation is plotted for each of three cubes in Fig. 28. The directional dependence under dry conditions is not pronounced, i.e., they show more or less an isotropic thermal behavior. The largest residual strain of $0.17 \mathrm{~mm} / \mathrm{m}$ is observed in YZ-direction for cube 1, XZ-direction for cube 2 exhibits $0.14 \mathrm{~mm} / \mathrm{m}$ expansion, and the thermal dilatation of $0.11 \mathrm{~mm} / \mathrm{m}$ is observed in XZ-direction for cube 3. Under wet conditions, the thermal behavior has totally changed (see Fig. 28).

From Fig 28, the effect of the heterogeneity is evident. Accordingly, the total relative volume change is proposed. The results under dry and wet conditions are presented in Table 8. The decay index is comparable for the three cubes after the five dry cycles, while a difference in values is observed after wet cycles. Such a difference could be caused by the heterogeneity, i.e. influence preferred orientation and pre-existing microcracks on thermal response of marble. The presence of water has significant impact, as well (Sage et al. 1988, Siegesmund et al. 2000 or Koch and Siegesmund 2004).

To compare the direction of the maximum and minimum thermal dilatation and its coincidence after the thermal treatment under wet conditions for the three cubes, the pole figure projections of the second rank tensors were plotted and are shown in Fig. 29. All three samples show large values for the relative volume change (Table 8 ) and the quite same direction of maximum and minimum dilatation (Fig. 29). In sum, this marble type (Carrara) has a high risk associated with failure while exposed under higher temperature and moisture. The studies of Weiss et al. 2002, 2003, 2004; Koch and Siegesmund 2004; Siegesmund et al. 2008; Shushakova et al. 2011; 2012; Weiss et a. 2004; Siegesmund \& Dahms 2014 clearly demonstrated that this Carrara marble exhibits rapidly deterioration phenomena. Thus, the decay index is a good quantification tool to predict the thermal behavior of marble, and such an approach was applied for the characterization of the investigated marbles.

\section{Decay indexes for the investigated marbles}

Six independent directions for each sample (Fig. 26) were cut for the thermal expansion measurements. Four cycles under dry conditions and seven cycles under wet conditions were carried out. The resulted residual strains in X-, Y-, and $\mathrm{Z}$ - directions after the dry and wet cycles for the 12 marbles are listed in Tables 9 and 10, respectively. Decay indexes were calculated for each of the 12 marble samples on the basis of thermal expansion measurements after the dry and wet cycles. The results are given in Table 11 .

Decay indexes are quite different under dry and watersaturated conditions. After the dry cycles, marbles such as Arabescato Altissimo, Sölk, Thassos, and Wachau show small deterioration indexes (less than $0.01 \%$ volume expansion). A larger value of the decay index is observed for a majority of the samples after the wet cycles. A significant increase is evidenced for the Carrara (Arabescato Altissimo) marble (from 0.05 to 3.46). Only the Wachau marble does not exhibit any significant change between dry and wet conditions (from 0.06 to 0.09 ). 
Cube 1

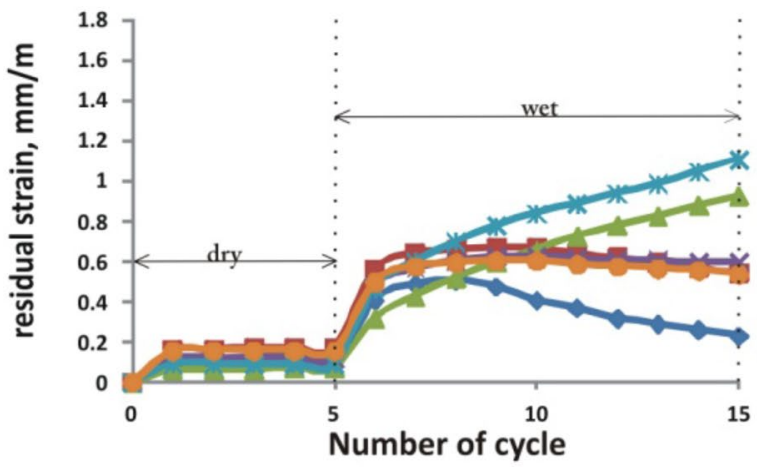

Cube 3

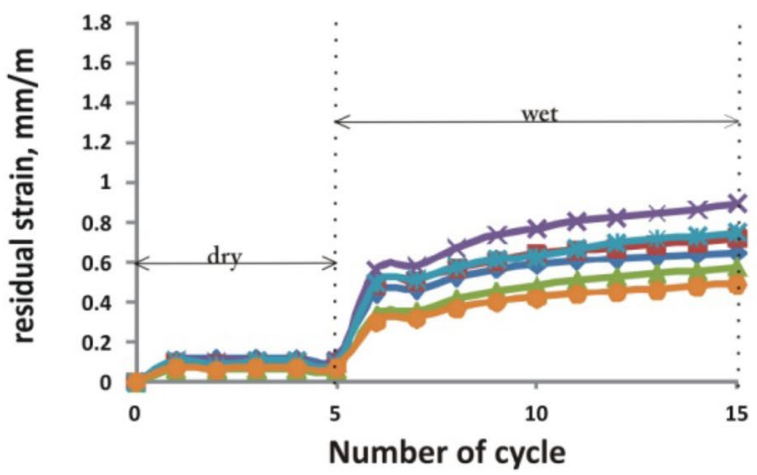

Cube 2
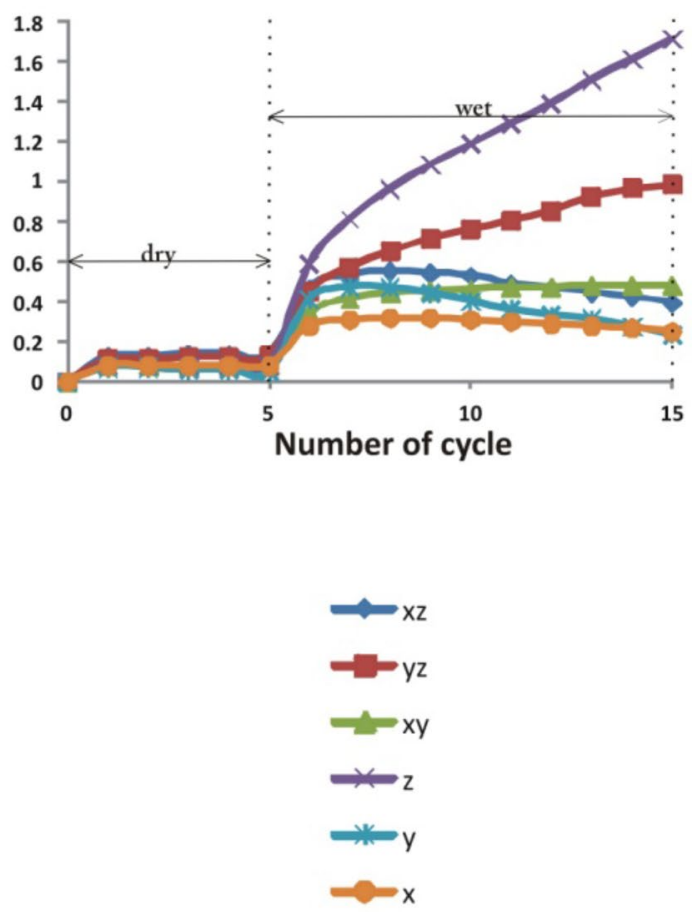

Fig. 28 The residual strain as a function of the numbers of heating-cooling cycles $\left(20-90-20{ }^{\circ} \mathrm{C}\right)$ under dry (from 1 to 5 cycles) and water-saturated (from 6 to 15 cycle) conditions for the three cubes in X-,Y-, Z-, XY- YZ-, and XZ-directions

To elucidate maximum and minimum thermal dilatation, plots of residual strain tensor after dry and wet conditions were created for each marble sample. Two examples, the Arabescato Altissimo (AA) marble and the Sölk (SK) marble, are illustrated in Fig. 30. The direction of maximum and minimum thermal expansion changes with the presence of moisture. The AA marble with the weak texture exhibits a significant directional change, while the SK marble with strong texture shows only a slight difference. Some of the marbles with a strong texture exhibit a directional change, as well. Eigenvectors corresponding to the largest and the smallest dilatation could be found and defined in the reference frame of the marble.

\section{Summary and conclusions}

Although marble has a very simple mineralogical composition, i.e., calcite or dolomite as rock-forming minerals, the weathering features appear in a large variety of forms. In the case of the physical weathering of marbles, the phenomena may range from superficial disintegration to complete loss of cohesion along grain boundaries due to dilatancy, i.e., the total decay of the material. The decay of marbles is sometimes the most spectacular deterioration feature, although the loss in cohesion and the loss in strength are already evident without the well-known bowing of marble panels. Some of the mechanisms that have been suggested to explain the decay of marble include marble type and its fabrics, stress relief, thermal expansion, and expansion due to moisture and temperature (thermohygric properties) or the building physics and the chemical and or biological action. Some following conclusions can be drawn:

1. The investigations have shown that marble decay causes a significant decrease in the strength properties (Young's modulus, etc.), while the porosity as well as the pore radii distribution change. The decrease of the mechanical properties with the increase in deterioration is significant but non-linear. Strength loss versus the increase in porosity relationship is representative for the investigated marbles.

2. A conclusive result was obtained by combining the effect of strength loss and its relationship to the porosity and the compressional wave velocities. Several samples representing a broad variation in decay phe- 
Fig. 29 Plots of residual strain tensors after ten wet cycles: a cube $1, \mathbf{b}$ cube 2 , and $\mathbf{c}$ cube 3 in the reference frame of sample 2
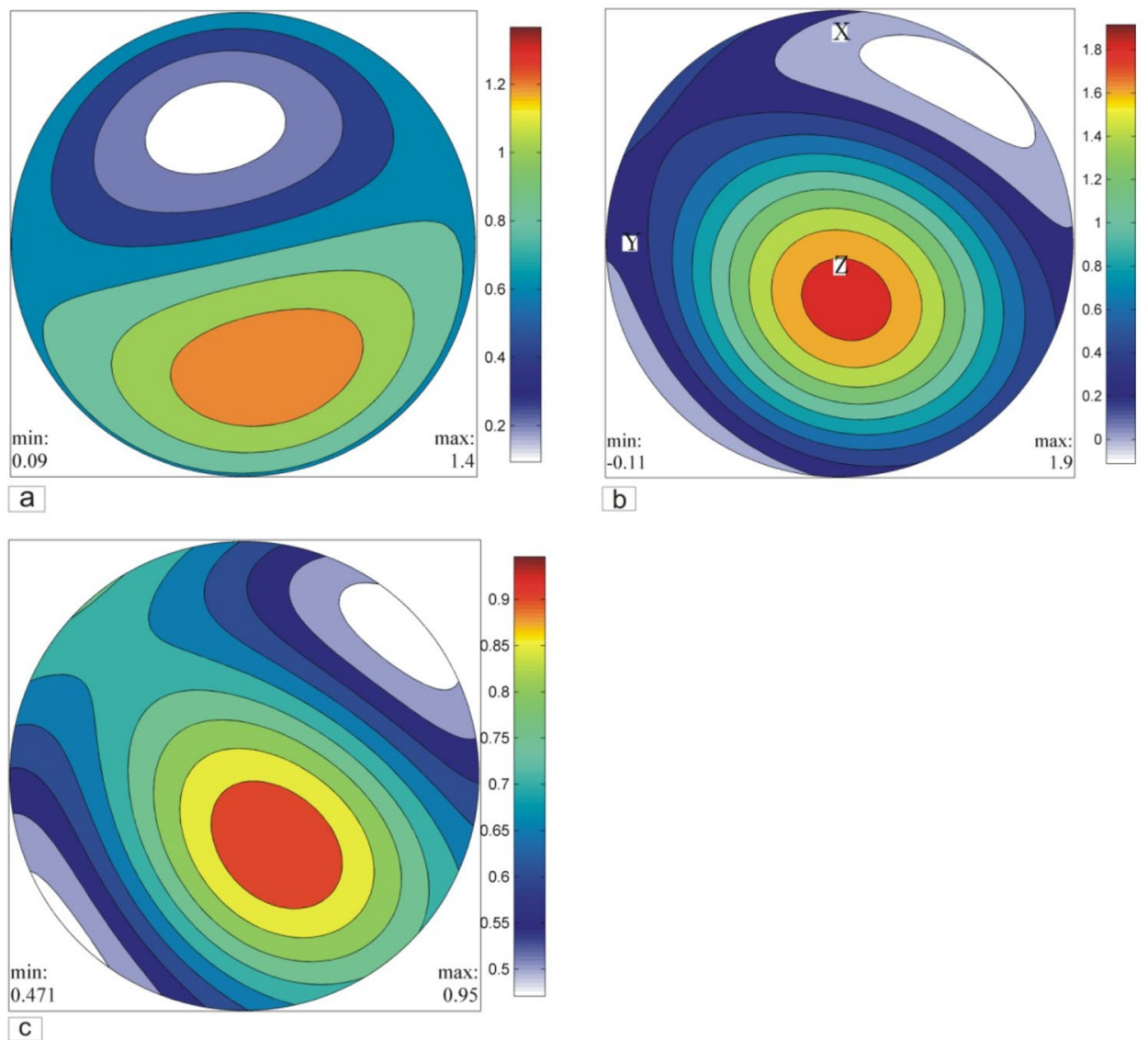

Table 9 Residual strains for investigated marbles in X-, Y-, Z-directions after four repeated heating-cooling cycles

\begin{tabular}{lccc}
\hline Marble sample & \multicolumn{3}{c}{ Residual strain $\mathrm{mm} / \mathrm{m}$} \\
\cline { 2 - 4 } & X-direction & Y-direction & Z-direction \\
\hline $\begin{array}{l}\text { Arabescato Altissimo (Car- } \\
\text { rara) }\end{array}$ & -0.03 & 0 & -0.02 \\
Bianco Carrara & 0.05 & 0.08 & 0.10 \\
Grechisches Volakas & 0.08 & 0.08 & 0.06 \\
High-temperature Carrara & 0.20 & 0.08 & 0.40 \\
$\quad$ marble & & & \\
Lasa & 0.11 & 0.06 & 0.12 \\
Sölk & 0.03 & 0 & 0.01 \\
Thassos & -0.03 & -0.02 & -0.04 \\
Wachau & 0.01 & 0.02 & 0.03 \\
Carrara Gioia & 0.19 & 0.22 & 0.22 \\
Wunsiedel & 0.06 & 0.07 & 0.07 \\
Großkunzendorfer & 0.16 & 0.36 & 0.35 \\
Blanco Macael & 0.29 & 0.18 & 0.30 \\
\hline
\end{tabular}

Values are given in $\mathrm{mm} / \mathrm{m}$

nomena were used to constrain the loss in cohesion of this sample because the $\mathrm{Vp}$ velocities can be applied to characterize the Young's modulus of the marble, and
Table 10 Residual strains for 12 investigated marbles in $\mathrm{X}-$, Y-, $\mathrm{Z}$-directions after repeated heating-cooling cycles under water-saturated conditions

\begin{tabular}{lccc}
\hline Marble sample & \multicolumn{3}{l}{$\begin{array}{l}\text { Residual strain after wet cycles, } \\
\mathrm{mm} / \mathrm{m}\end{array}$} \\
\cline { 2 - 4 } & X-direction & Y-direction & Z-direction \\
\hline $\begin{array}{l}\text { Arabescato Altissimo (Car- } \\
\text { rara) }\end{array}$ & 1.00 & 0.63 & 0.46 \\
Bianco Carrara & 0.39 & 1.06 & 0.79 \\
Grechisches Volakas & 0.78 & 0.60 & 0.77 \\
High-temperature Carrara & 0.58 & 0.29 & 0.33 \\
$\quad$ marble & & & \\
Lasa & 0.19 & 0.18 & -0.04 \\
Sölk & -0.16 & -0.20 & 0.22 \\
Thassos & -0.26 & -0.16 & -0.10 \\
Wachau & -0.07 & 0.04 & 0.28 \\
Carrara Gioia & 0.30 & 0.32 & 0.30 \\
Wunsiedel & 0.10 & 0.16 & 0.23 \\
Großkunzendorfer & 0.26 & 0.52 & 0.56 \\
Blanco Macael & 0.51 & 0.31 & 0.57 \\
\hline
\end{tabular}

Values are given in $\mathrm{mm} / \mathrm{m}$

thus, the derivation of the materials quality or their heterogeneities, respectively. 
Table 11 Defined decay indexes of investigated marble samples after dry and wet cycles

\begin{tabular}{llc}
\hline Sample & \multicolumn{2}{l}{ Decay index } \\
\cline { 2 - 3 } & After dry cycles & After wet cycles \\
\hline Arabescato Altissimo (Carrara) & 0.05 & 3.46 \\
Bianco Carrara & 0.23 & 3.49 \\
Grechisches Volakas & 0.22 & 3.65 \\
High-temperature Carrara & 0.82 & 1.63 \\
$\quad$ marble & & \\
Lasa & 0.31 & 0.23 \\
Sölk & 0.04 & -0.52 \\
Thassos & 0.09 & -0.60 \\
Wachau & 0.06 & 0.09 \\
Carrara Gioia & 0.77 & 1.24 \\
Wunsiedel & 0.20 & 0.53 \\
Großkunzendorfer & 1.12 & 1.97 \\
Blanco Macael & 0.98 & 2.07 \\
\hline
\end{tabular}

Values are multiplied by $10^{-3}$

3. Ultrasonic wave velocities $(\mathrm{Vp})$ is also a measure for the decrease in strength. The reduction of the velocities with increasing state of weathering is correlated with an increasing microcrack density and microcrack width. In addition, the crack type and their distribution in the marble have a significant control on the velocity reduction. The microcrack formation is also crystallographically controlled, i.e., parallel to the cleavage planes or twins. The loading direction for example may control the initiation of intragranular cracks, while in other cases, the shape fabric controls the opening of grain boundaries. Therefore, coarse-grained marbles with interlocking grain boundaries may show completely different microcrack patterns compared to finegrained marbles with polygonal grain boundaries. Consequently, the $\mathrm{Vp}$ velocities may differ significantly. If any lattice preferred orientation of the calcite and dolomite crystals exists, the directional dependence of the $\mathrm{Vp}$ velocities must be considered when discussing the state of weathering.

4. Ultrasonic wave velocity measurements are a powerful and sensitive tool for the damage assessment of marble. Experimental data reveal that the state of preservation of a marble is clearly documented by compressional wave velocities. For the maximum porosity of around $2.5 \%$, velocities determined on dry samples range on the order of $1.5 \mathrm{~km} / \mathrm{s}$. Model calculations
Fig. 30 Plots of residual strain tensors after four dry cycles (left) and after seven wet cycles (right)in the sample reference frame, respectively (a), (b) for the AA marble; (c), (d) for the SK marble

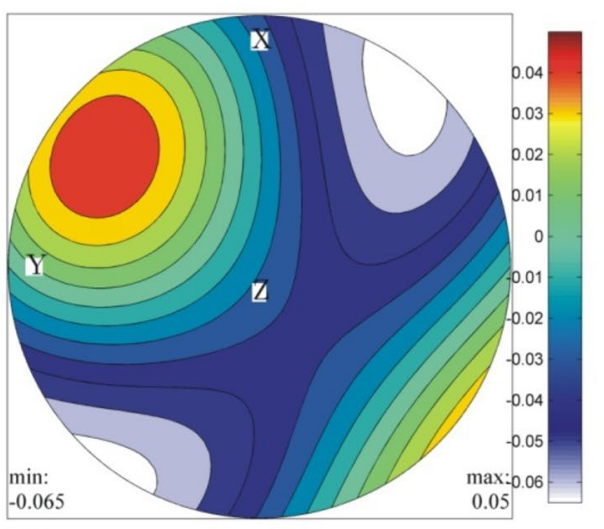

a

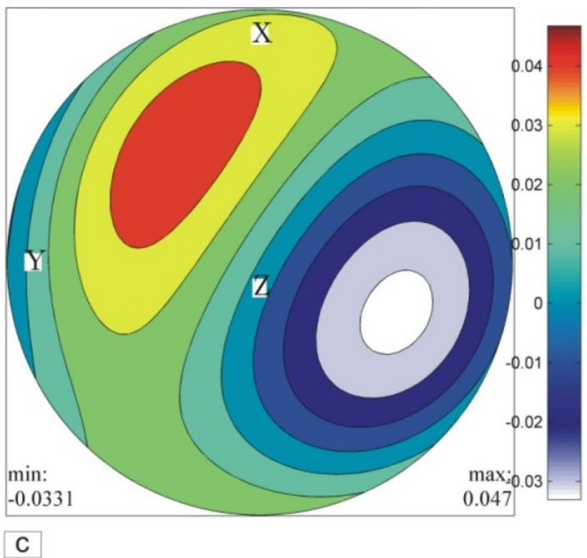

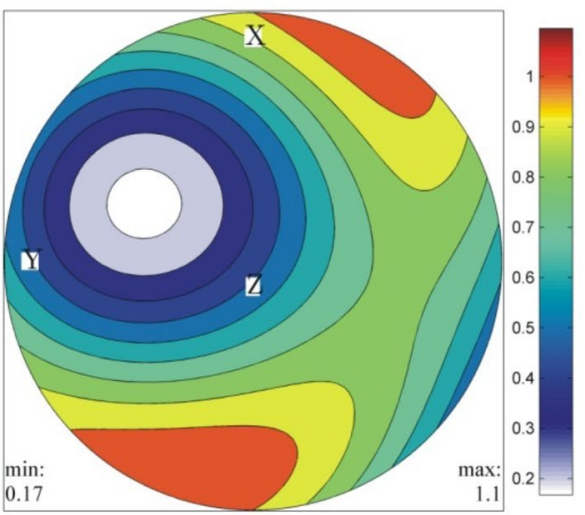

b

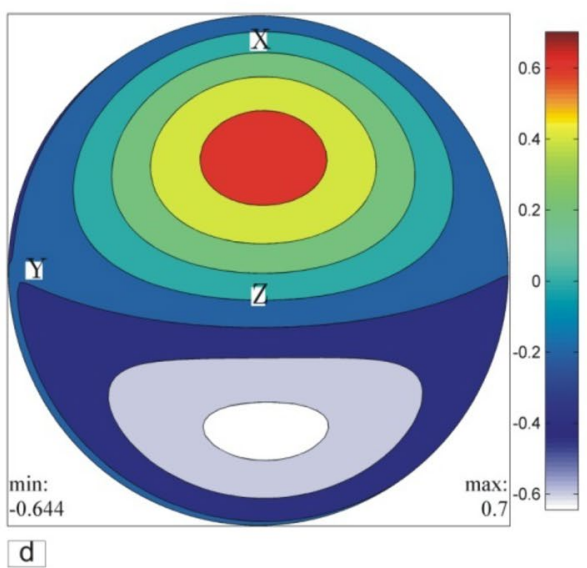


reveal that the velocity reduction is caused by cracks with an extreme aspect ratio of about 0.005 or even less.

5. Water saturation has an important influence on the magnitude and directional dependence of ultrasonic velocities. Hence, it is essential to gather sufficient information on the state of water saturation of an object made from marble to quantify the state of deterioration, since water as a pore fluid significantly increases the velocities. This observation is a key constrain when on-site inspections are performed.

6. For the marble, a close relationship between quantified rock fabrics and the mechanical properties was also demonstrated as a function of an increasing state of weathering. In summary, the mechanical and physical properties decrease with weathering, while the porosity and the pore radii distribution increase.

7. The modal composition is an important constrain for the thermal properties of a marble. Freeze-Thaw cycles as well as heating cycles clearly control the weathering of marbles documented by a drastic change in the Youngs' modulus.

8. Based on a systematic study, a quantitative measure as a deterioration index was constrained and introduced on the basis of thermal expansion measurements. This index will reflect the relative volume change.

9. On the basis of six independent measured thermal expansion directions, it was possible to find the values of the smallest and largest possible dilatations. This is also of practical importance if a special cutting direction can help to overcome or hamper the bowing behavior of marbles.

10. Deterioration index was investigated respective to grain size, texture, and other fabric parameters. The tendency how deterioration index varies with changing properties of marble was found.

11. Assess the approach of describing marble's stability using deterioration index on the basis of studies of durability of the investigated marbles, while the loss in cohesion along microcracks and grain boundaries will reduce the mechanical and elastic properties of the rocks.

12. The quantified deterioration index seems to be a very important tool to define risk numbers when for example the overall situation of outdoor sculptures should be forecasted. In this case, the question of the application of winter shelters can be helpful to overcome the missing basic data by modeling approaches in terms of the decay index.

13. Observations of climate change over the past hundred years have induced the research sector to invest greater resources in forecasting its future evolution and impacts. Efforts to focus on improving knowledge of future climate effects on the risk assessment of highranking cultural heritage by quantifying damage processes are of great importance.

Acknowledgements The study is a result of a long standing research project and the authors want to express immense thanks to J. Ruedrich, T.Weiss, D.Strohmeyer, A. Koch, Ed Fuller, D.Nikolayev, A. Zeisig, A. Hoffmann, S. Mosch for all the discussion and help over the years. The study was supported by the BMBF (Marmorbild FKZ: 03VP00292).

Funding Open Access funding enabled and organized by Projekt DEAL.

Open Access This article is licensed under a Creative Commons Attribution 4.0 International License, which permits use, sharing, adaptation, distribution and reproduction in any medium or format, as long as you give appropriate credit to the original author(s) and the source, provide a link to the Creative Commons licence, and indicate if changes were made. The images or other third party material in this article are included in the article's Creative Commons licence, unless indicated otherwise in a credit line to the material. If material is not included in the article's Creative Commons licence and your intended use is not permitted by statutory regulation or exceeds the permitted use, you will need to obtain permission directly from the copyright holder. To view a copy of this licence, visit http://creativecommons.org/licenses/by/4.0/.

\section{References}

Ahmad A, Pamplona M, Simon S (2009) Ultrasonic testing for the investigation and characterization of stone-a non-destructive and transportable tool. Stud Conserv 54(supp1):43-53

Babacan AE, Gelisli K (2015) Ultrasonic investigations of marble columns of historical structures built in two different periods. Carbonates Evaporites 30(3):357-363

Battaglia S, Franzini M, Mango F (1993) High sensitivity apparatus for measuring linear thermal expansion: preliminary results on the response of marbles. II Nuovo Cimento 16:453-461

Bonazza A, Sabbioni C, Messina P, Guaraldi C, De Nuntiis P (2009) Climate change impact: mapping thermal stress on Carrara marble in Europe. Sci Total Environ 407(15):4506-4512

Boudani ME, Wilkie-Chancellier N, Martinez L, Hébert R, Rolland O, Forst S, Vergès-Belmin V, Serfaty S (2015) Marble characterization by ultrasonic methods. Procedia Earth Planet Sci 15:249-256

Brimblecombe, P. (2003). The effects of air pollution on the built environment (Vol. 2). World Scientific

Dandekar DP (1968) Variation in the elastic constants of Calcite with temperature. J Appl Geophys 39(8):3694-3699

Dürrast H, Siegesmund S, Prasad M (1999) Die Schadensanalyse von Naturwerkstei- nen mittels Ultraschalldiagnostik: Möglichkeiten und Grenzen. Zeitschrift der Deutschen Geologischen Gesellschaft 150(2):359-374

Fleischer, G., 2002. Beurteilung von Ultraschalluntersuchungen an Natursteinobjekten in der Denkmalpflege. na

GeoTomLLC, 2. GeoTomCG software is described on the website and can be purchased from GeoTom through contact information on the website.: The user's manual and a demo program are available free from GeoTom. dev.geotom.net. Accessed 7 Feb 2020

Gottstein G. and Mecking, H. 1985. Recrystallization. In: WENK, H.-R. (eds) Preferred orientation in deformed metals and rocks, an 
introduction to modern texture analysis. Academic Press, Orlando, pp 183-214

Hirschwald J (1912) Die Prüfung der natürlichen Bausteine auf ihre Verwitterungsbeständigkeit. Verlag W. Ernst \& Sohn, Berlin.

Jelinek V (1981) Characterization of the magnetic fabric of rocks. Tectonophysics 79:63-67

Kessler DW (1919) Physical and chemical tests on the commercial marbles of the United States. Technologic Papers Bureau of Standards, No. 123, Government Printing Office, Washington, DC

Koch A (2006) Deformation von Fassadenplatten aus Marmor: Schadenskartierungen und gesteinstechnische Untersuchungen zur Verwitterungsdynamik von Marmorfassaden. Universitätsverlag Göttingen

Koch A, Siegesmund S (2004) The combined effect of moisture and temperature on the anomalous behaviour of marbles. Environ Geol 46:350-363

Köhler, W., 1991. Untersuchungen zu Verwitterungsvorgängen an Carrara-Marmor in Potsdam-Sanssouci. Berichte zu Forschung und Praxis der Denkmalpflege in Deutschland, SteinschädenSteinkonservierung 2, 50-53

Köhler, W., 2014. Leitfaden für Ultraschallmessungen an Marmorskulpturen, in: Bellen- dorf, P. (Ed.), Erhaltung von Marmorskulpturen unter mitteleuropäischen Umwelt- bedingungen. Beiträge des 8. Konservierungswissenschaftlichen Kolloquiums in Berlin, Brandenburg am 17. Oktober 2014 in Potsdam, vol. 32. Arbeitshefte des Brandenburgischen Landesamtes für Denkmalpflege und Archäologischen Landes- museums 32. Wernersche Verl.Ges, Worms, pp. 37-44

Klopfer H, Homann M (1985) Lehrbuch der Bauphysik. Stuttgart, G. Teubner

Leiss B, Ullemeyer K (1999) Texture characterization of carbonate rocks and some implications for the modeling of physical anisotropies, derived from idealized tex- ture types. Zeitschrift der Deutschen Geologischen Gesellschaft 150(2):259-274

Lindner, H., Pretzschner, C., Rost, L., 1999. Ultraschalluntersuchungen an Bauwerken

Luque A, Cultrone G, Mosch S, Siegesmund S, Sebastian E, Leiss B (2010) Aniso- tropic behaviour of White Macael marble used in the Alhambra of Granada (Spain). Eng Geol 115(3-4):209-216

Mahmutoğlu Y (2017) Prediction of weathering by thermal degradation of a coarse- grained marble using ultrasonic pulse velocity. Environ Earth Sci 76(12):785

Menningen, J. 2020. Ultrasonic tomography for the characterization of the weathering state of marble. A systematic study about influencing parameters. Unpub. PhD thesis Univ Goettingen (Germany)

Menningen J, Siegesmund S, Lopes L, Martins R, Sousa L (2018a) The Estremoz marbles: an updated summary on the geological, mineralogical and rock physical characteristics. Environ Earth Sci 77(5):53

Menningen J, Siegesmund S, Tweeton D, Träupmann M (2018b) Ultrasonic tomog- raphy: non-destructive evaluation of the weathering state on a marble obelisk, con- sidering the effects of structural properties. Environ Earth Sci 77(17):1338

Moore AC (1970) Descriptive terminology for the textures of rocks in granulite facies terrains. Lithos 3(2):123-127

O'Connell RJ, Budiansky B (1974) Seismic velocities in dry and saturated cracked sol- ids. J Geophys Res 79(35):5412-5426

Poschlod K (1990) Das Wasser im Porenraum kristalliner Naturwerksteine und sein Einfluss auf die Verwitterung. Münchner geowissenschaftliche Abhandlungen: Reihe B, Allgemeine und angewandte Geologie 7:1-62

Rüdrich, J., 2003. Gefügekontrollierte Verwitterung natürlicher und konservierter Marmore. Diss Univ Göttingen

Rüdrich J, Weiss T, Siegesmund S (2002) Thermal behaviour of weathered and con- solidated marbles. Geological Society, London, Special Publications 205:255-271
Rüdrich J, Knell C, Enseleit J, Rieffel Y, Siegesmund S (2013) Stability assessment of marble statuaries of the Schlossbrücke (Berlin, Germany) based on rock strength measurements and ultrasonic wave velocities. Environ Earth Sci 69(4):1451-1469

Sage JD (1988) Thermal microfracturing of marble. In: Marinos PG, Koukis GC (eds) Engineering geology of ancient works, monuments and historical sites. Balkema, Rotterdam, pp 1013-1018

Scheffzük C, Siegesmund S, Koch A (2004) Strain investigations on calcite marbles using neutron time-of-flight diffraction. Environ Geol 46(3-4):468-476

Scheffzük C, Siegesmund S, Nikolayev DI, Hoffmann A (2007) Texture, spatial and orientation dependence of internal strains in marble: a key to understanding the bowing of marble panels. Geological Society, London, Special Publications 271(1):237-249

Shushakova, V., 2014. Marble decay caused by thermal expansion: microstructure-based mathematical and physical modeling. PhD thesis University Göttingen. 114p

Shushakova V, Fuller ER, Siegesmund S (2011) Influence of shape fabric and crystal texture on marble degradation phenomena: simulations. Environ Earth Sci 63:1587-1601

Shushakova V, Fuller ER, Siegesmund Jr., S (2013) Microcracking in calcite and dolomite marble: microstructural influences and effects on properties. Environ Earth Sci 69:1263-1279

Shushakova V, Fuller ER, Heidelbach F, Mainprice D, Siegesmund S (2013) Mar- ble decay induced by thermal strains: simulations and experiments. Environ Earth Sci 69(4):1281-1297

Siegesmund S (1996) The significance of rock fabrics for the geological interpretation of geophysical anisotropies: Geotektonische Forschungen 85. Schweizerbart, Stuttgart, p 163

Siegesmund S, Kracke T, Ruedrich J, Schwarzburg R (2010) Jewish cemetery in Hamburg Altona (Germany): state of marble deterioration and provenance. Eng Geol 115(3-4):200-208

Siegesmund, S.Dahms, M. 1994. Fabric-controlled anisotropy of elastic, magnetic and thermal properties of rocks. In: BUNGE, H. J., SKROTZKI, W., SIEGESMUND, S. \& WEBER, K. (eds) Textures of Geological Materials, Oberursel (DGM Informationsgesellschaft), 353-379

Siegesmund S, Dürrast H (2014) Physical and mechanical properties of rocks. In: Siegesmund S, Snethlage R (eds) Stone in Architecture. Springer-Verlag, Berlin

Siegesmund S, Ullemeyer K, Weiss T, Tschegg EK (2000) Physical weathering of marbles caused by anisotropic thermal expansion. Int J Earth Sci 89:170-182

Siegesmund S, Rüdrich J, Koch A (2008) Marble bowing: comparative studies of different public building facades. In: Siegesmund S, Snethlage R, Rüdrich J (eds) Monumental future: climate change, air pollution, stone decay and conservation. Environmental geology, vol 56, pp 473-494

Snethlage R (2008) Leitfaden Steinkonservierung.: Planung von Untersuchungen und Maßnahmen zur Erhaltung von Denkmälern aus Naturstein, 3rd edn. Fraunhofer IRB, Stuttgart

Timoshenko SP, Goodier JN (1970) Theory of elasticity, 3rd edn. McGraw-Hill, New York

Tschegg EK, Widhalm C, Eppensteiner W (1999) Ursachen mangelnder Formbe- ständigkeit von Marmorplatten. Zeitschrift der Deutschen Geologischen Gesellschaft 150(2):283-297

Weiss T, Rasolofosaon PN, Siegesmund S (2001) Thermal microcracking in Carrara marble. Zeitschrift der Deutschen Geologischen Gesellschaft, pp 621-636

Weiss T, Siegesmund S, Fuller ER (2002) Thermal stresses and microcracking in calcite and dolomite marbles via finite element modelling. In: Siegesmund S, Weiss T, Vollbrecht A (eds) Natural Stone, Weathering Phenomena, Conservation Strategies and Case Studies. Geological Society Special Publication No. 205, The Geological Society of London, London, pp 89-102 
Weiss T, Siegesmund S, Fuller ER (2003) Thermal degradation of marble: indications from finite-element modelling. Build Environ 38(9-10):1251-1260

Weiss T, Saylor DM, Fuller ER, Siegesmund S (2004) Prediction of the degradation behaviour of calcareous rocks via finite-element modelling. 10th Int. Congress on Deterioration and Conservation of Stone, Stockholm, pp. 163-170

Winkler EM (1994) Stone in Architecture: Properties, Durability, 3rd edn. Springer-Verlag, Berlin

Zeisig A, Siegesmund S, Weiss T (2002) Thermal expansion and its control on the durability of marbles. In: Siegesmund S, Weiss
T, Vollbrecht A (eds) Natural Stone, Weathering Phenomena, Conservation Strategies and Case Studies. Geological Society Special Publication No. 205, The Geological Society of London, London, pp 65-80

Publisher's Note Springer Nature remains neutral with regard to jurisdictional claims in published maps and institutional affiliations. 